\title{
BIAXIAL FATIGUE LOADING OF NOTCHED COMPOSITES
}

\author{
By \\ P. H. Francis \\ D. E. Walrath \\ D. F. Sims \\ D. N. Weed
}

June 24, 1977

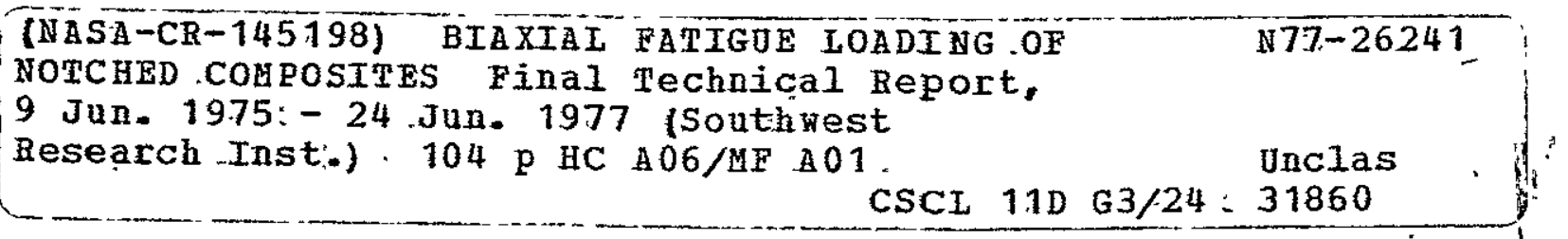

Prepared under Contract No. NASI-13956

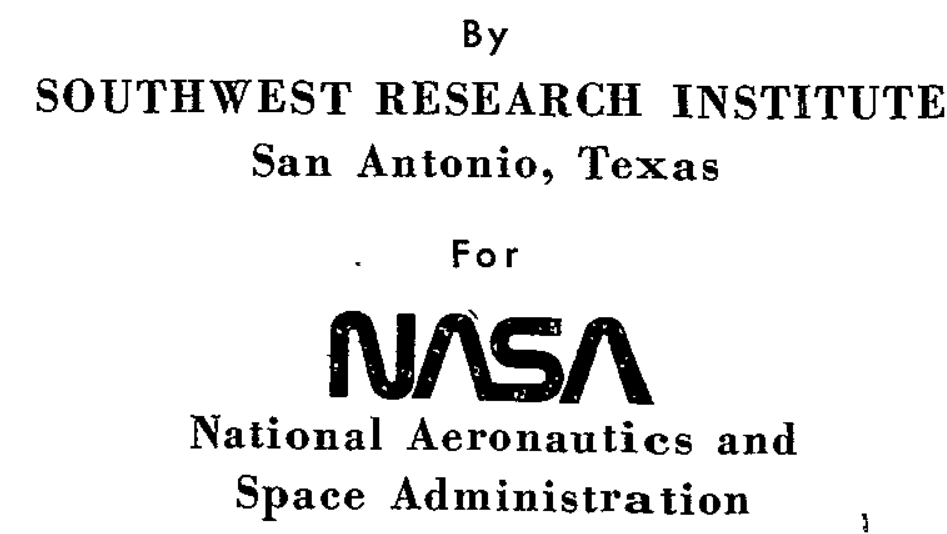

REPRODUCED BY

NATIONAL TECHNICAL

INFORMATION SERVICE

U. S. DEPARTMENT OF COMMERCE 
I. INTRODUCTION AND BACKGROUND 2

A. Research Objectives. 2

B. Survey of Previous Efforts 2

II. EXPERIMENTAL PROCEDURES 4

A. Specimen Fabrication 4

B. Material Specifications and Characterization 6

C. Fatigue Testing of Tubes 8

$\begin{array}{ll}\text { III. EXPERIMENTAL RESULTS } & 10\end{array}$

A. Test Matrix 10

B. Fatigue Test Results: Uniaxial Loading 10

C. Fatigue Test Results: Biaxial Loading 14

IV. DATA ANALYSIS AND CORRELATION 16

A. Data Analysis Approach 16

B. Prediction of Biaxial Fatigue Life from Uniaxial
Data

$\begin{array}{ll}\text { C. Discussion } & 18\end{array}$

V. CONCLUSIONS AND RECOMMENDATIONS 20

$\begin{array}{ll}\text { REFERENCES } & 21\end{array}$

TABLES $\quad .23$

$\begin{array}{ll}\text { FIGURES } & 36\end{array}$

APPENDIX A: Photographs of Failed Specimens 63

Broken Specimens $[+45]_{S}$ Axial Fatigue 64

Broken Specimens $[+45]_{S}$ Internal Pressure Fatigue 68

Broken Specimens $[+45]_{S}$ Torsion Fatigue $\quad 72$

Broken Specimens $[+45]_{s}$ Axial:Torsion Fatigue 1:0.5 77

Broken Specimens $[+45]_{S}$ Axial:Torsion Fatigue 1:1 81

Broken Specimens $[ \pm 45]_{S}$ Axial:Torsion Fatigue 1:2 85 
TABLE OF CONTENTS (Cont'd)

$\underline{\text { Page }}$

Broken Specimens $[0 / 90]_{s}$ Axial Fatigue 89

Broken Specimens $[0 / 90]_{S}$ Torsion Fatigue $\quad 92$

APPENDIX B: List of Symbols $\quad 95$ 


\section{Figure}

1 Tab Mold Mount Assembly

Tab Mold Insert

SwRI Composite Specimens Notching Fixture

4 Graphite/Epoxy Tubular Specimens Notched with

12 Torsion Fatigue [t45],

14 Torsion Fatigue [0/90] $\mathrm{S}$

21 Composite Tube Subjected to Torsional Stress, $\tau_{\mathrm{xy}}=1$

22 Tangential Stress Around a Hole, [+45] saminate 


\section{LIST OF FIGURES (Cont'd)}

Figure

$\underline{\text { Page }}$

23

Tangential Stress Around a Hole, [+45] Saminate

59

24

Tangential Stress Around a Hole, [t45]s Laminate

60

25

Tangential Stress Around a Hole, [+45], Laminate

61

26

Tangential Stress Around a Hole, [+45] Laminate

62 
Table

1 Tests Conducted for Each Loading Mode

Page

Uniaxial Fatigue of $[ \pm 45]_{s}$ Tubes. Axial Loading

24

2

Regression Analysis Constants for $[+45]_{S}$ Fatigue

25

3 Tests

Uniaxial Fatigue of $[ \pm 45]_{s}$ Tubes. Internal Pressure Loading

Uniaxial Fatigue of $[ \pm 45]_{\mathrm{s}}$ Tubes. Torsional Loading

Uniaxial Fatigue of $[0 / 90]_{S}$ Tubes. Axial Loading

Uniaxial Fatigue of $[0 / 90]$ s Tubes. Torsion Loading

Regression Analysis Constants for $[0 / 90]_{S}$ Fatigue Tests

Biaxial Fatigue of $[+45]_{\text {s }}$ Tubes. Axial: Torsion Loading $1: 0.5$

10 Biaxial Fatigue of $[\underline{45}]_{s}$ Tubes. Axial: Torsion Loading 1:1

11. Biaxial Fatigue of $[+45]_{S}$ Tubes. Axial: Torsion Loading 1:2 


\section{SUMMARY}

Thin-walled, 2.54-cm (1-in.) diameter tubular specimens of T300/934 graphite/epoxy were fabricated and fatigue cycled in combinations of axial, torsional, and internal pressure loading. Two different four-ply layup configurations were tested: $[0 / 90]_{S}$ and $[+45]_{\mathrm{S}} ;$ all tubes contained a $0.48-\mathrm{cm}$ (3/16-in.) diameter circular hole penetrating one wall midway along the tube length. S-N curves were developed to characterize fatigue behavior under pure axial, torsional, or internal pressure loading, as well as combined loading fatigue. A theory was developed based on the Hill plane stress model which enabled the $\mathrm{S}-\mathrm{N}$ curve for combined stress states to be predicted from the S-N data for the uniaxial loading modes. Correlation of the theory with the experimental data proved to be remarkably good. 


\section{INTRODUCTION AND BACKGROTND}

\section{A. Research Objectives}

The basic objective of this work was to develop a quantitative procedure to predict fatigue life in notched composites under biaxial loading. The development of this procedure involves the cyclic loading of notched laminated graphite/epoxy tubes with various combinations of tension, torsion, and internal pressure. A correlation was then made between damage development, residual strength, stress level, and cycles.

\section{B. Survey of Previous Efforts}

In many cases composite materials offer a substantial improvement over metals in application to structures under cyclic loading. However, the response of composites to fatigue is different from that of metals. Metals usually exhibit one failure mode (cracking), while composites may exhibit a combination of complex failure modes. Some of these failure modes are fiber breakage, delamination, matxix cracking, and fiber-matrix debonding. This combination of failure modes has contributed to the complexity of predicting the fatigue characteristics of fiber-reinforced composites and has inspired a large number of fatigue investigations on composites. Recent review papers by Boller(1) and Salkind(2) 1ist many of these investigations. In this report, no attempt will be made to survey the large number of publications on composite fatigue. However, several general conclusions can be made regarding composite fatigue results.

1. The S-N curves for composites, particularly graphite/epoxy, are usually very flat (1ittle or no wearout) for all fiber orientations, but especially so in the fiber-dominated cases.

2. In many cases, the residual strength of a specimen having experienced fatigue cycling (but not failed) is equal to or somewhat greater than the static strength of an untested specimen.

3. The fatigue behavior in the case of matrix dominated orientations, for example $+45^{\circ}$ laminate in axial tension, is dependent on the tèst frequency.

Several investigations have recently been conducted on fatigue of composites which are related to the present research objectives, and will be mentioned only briefly here. These include the work on notched fatigue strength by Halpin, et al., (3) on glass/epoxy, Stinchcomb, et al., (4) on boron/epoxy and boron/aluminum, and Pipes, et al., $(5,6)$ on boron/epoxy. A11 of the above cited investigations were conducted on flat coupon-type specimens.

The amount of fatigue data on tubular specimens is quite limited. Lucas and Sainsbury-Carter (7), Nevadunsky, et al., (8) and Salkind (9) have conducted fatigue tests on tubulax specimens under axial tension only. The 
only known biaxial fatigue testing on tubular specimens has been conducted at SwRI. (10) otherwise, biaxial fatigue data on notched tubular specimens are virtually non-existent, and hence this is the primaxy thrust of the present work. 


\section{EXPERTMENTAL RROCEDURES}

\section{A. Specimen Fabrication}

Four-ply laminated graphite/epoxy tubes were the principal test specimens used during this program. Processing detailis have been given elsewhere, (11) but basically the procedure involves fitting a hollow, perforated mandrel with an elastomeric bladder, then wrapping the prepreg tape, together with appropriate vent and bleeder materials, around the mandrel. This assembly is placed inside a split female mold, and the mandrel pressurized from within during the cure cycle. Details of this procedure are described by the following steps:

1. Prepare template for layup.

2. Layup prepreg to desired orientation.

3. Prepare mandrel by applying a release coat of MS-136.

4. Spiral wrap vent cloth over mandrel.

a. Wrap a teflon film perforated on 5.1-cm (2-in.) center over vent cloth.

b. Spiral wrap one ply of Mochburg paper bleeder over vent film.

c. Wrap one ply of Tx1040 separator cloth over bleeder.

5. Ro11 layup onto mandrel.

6. Tape both ends of layup to prevent resin loss, allowing approximately $5 \mathrm{~cm}$ (2 in.) of vent to extend beyond layup.

7. Place layup in female mold. Place mold in oven and proceed with cure cycle according to Fiberite specification: $177^{\circ} \mathrm{C}$ $\left(350^{\circ} \mathrm{F}\right)$ specimen temperature for 2 hours at a gage pressure of $620 \mathrm{kPa}(90 \mathrm{psi})$; then cool to $65^{\circ} \mathrm{C}\left(150^{\circ} \mathrm{F}\right)$ under above pressure.

After tubes are fabricated and trimmed to size, they were tabbed inside and outside at either end for insertion into the hydraulic grip system. The tubes have a finished length of $25.4 \mathrm{~cm}(10.0 \mathrm{in.}) ; 6.4-\mathrm{cm}(2.5-\mathrm{in}$.$) long$ tabs are placed at either end, leaving about $12.7 \mathrm{~cm}(5.0 \mathrm{in}$.$) of gage. Iength.$ Initial efforts at tabbing involved placing a vet layup of glass or Mochburg paper $^{*}$ in the tab areas, curing, and machining to tolerance. This procedure

${ }^{*}$ Three tab systems were tried using this approach: 7781 dry glass, impregnated with Epon 815 resin; three plies of $1009-36$ Scotch ply with [0/90/0] orientation; and three plies of Mochburg paper bIeeder, impregnated with Epon 815 resin.. 
proved time-consuming and expensive. Therefore, efforts were made to develop an improved tabbing technique.

The procedure currently being used results in a cast tab of neat resin Epon 815, using curing agent U. Figures 1 and 2 show diagrams of the tab molding apparatus. Basically, the tube is guided downward through a split, close-fitting outer sleeve, until the tube seats and is accurately aligned concentrically between the outer sleeve and a nandrel insert; these concentric cylinders form a mold for the neat resin. Resin is introduced, cured, and the tube removed with both inner and outer tabs on one end of the specimen in place, requiring no further work to bring them in tolerance. The specific tab processing details are sumarized as follows:

1. Specimen is sanded and wiped clean with MEK in tab area.

2. Mold is preheated to $49^{\circ} \mathrm{C}\left(120^{\circ} \mathrm{F}\right)$.

3. Resin is mixed (Epon 815 and $20 \%$ of curing agent v).

4. Mixture is placed in vacuum and degassed until all air is removed.

5. Mixture is poured into mold, and tube is placed into mold where it remains until cure is complete.

6. Same steps repeated for opposite end of tube.

To complete specimen fabrication, all of the tubular fatigue specimens were notched in the certer by drilling a $0.48-\mathrm{cm}$ (3/16-in.) hole through one wall of the tube. This was accomplished in a specially built precision drill fixture, capable of machining small [0.13-m (0.005-in.)] width notches as well as holes in composite tubes or flat laminates. As shown in Figure $3, a$ sma11 diamond pointed bit is driven at approximately $20,000 \mathrm{rpm}$ by an air powered motor. This motor is mounted on a precision clockmotor driven feed to drill into a tube or flat laminate at $0.13 \mathrm{~mm} / \mathrm{min}(0.005 \mathrm{in} / \mathrm{min})$. The tray on which the tube is mounted can also be driven in either direction parallel to the tube axis at $0.13 \mathrm{~mm} / \mathrm{min}(0.005 \mathrm{in} / \mathrm{min})$ to machine longitudinal notches in a tube. One other clock drive is used to rotate the specimen to machine transverse notches. All tubes tested in fatigue during this program contained a single $0.48-\mathrm{cm}$ (3/16-in.) hole through one wall in the center of the gage section. Two typical [+45]s notched tubular specimens are show in Figure 4.

Four flat laminated graphite/epoxy panels, each measuring $28 \mathrm{~cm} \times 10 \mathrm{~cm}$ (11 in. $x 4$ in.), were fabricated for purposes of making coupon-type specimens. These panels were processed in a blanket press using the same cure cycle as was used in tube processing. One ply of vent cloth perforated on 5 -cm (2-in.) centers and one bleeder ply were used on either side of the layup during cure. The four layups prepared were $[0]_{6},[90]_{8},\left[0 / 90_{2} / 0\right]_{2}$, and $[ \pm(+45)]_{\mathrm{S}}$. After fabrication, the laminated plates were trimmed and squared, and areas to be tabbed were sanded with 120-grit sandpaper and wiped clean with MEK or acetone. A liquid adhesive* was applied to bond the tabs onto the panel. The

\footnotetext{
Epoxi-Patch, manufactured by the Hysol Division of the Dexter Corporation.
} 
panel was cut into 1.9-cm (3/4-in.) wide tensile specimens using a diamond slitting blade.*

The tabs, which are bonded to the laminated panel before cutting the specimens from the panel, were fabricated of unidirectional glass tape. $t$ The tape was laminated into a $7-p 1 y$ stxip $\left[(0 / \overline{90)} \mathrm{s} / \overline{90}]_{\mathrm{s}} 1.4 \mathrm{~mm}(0.055 \mathrm{in.})\right.$ thick. After cure, the strip was machined into a 3.8-cm (1.5-in.) wide tab strip with a $35^{\circ}$ chamfer atong one side.

\section{B. Material Specifications and Characterization}

A11 test specimens fabricated during this research program were made using Fiberite hy-E $1034 \mathrm{C}$ high temperature graphite/epoxy prepreg tape. This material uses the Union Carbide $T-300$ graphite fiber, and is certified to meet the following Fiberite property specifications:**

Fiberite Specifications for hy-E 1034C (T300/934)

Graphite/Epoxy Materials System

\section{Prepreg Specifications}

Resin Content

Volatile Content

Ply Thickness (cured)

Ge1 Time at $171^{\circ} \mathrm{C}\left(340^{\circ} \mathrm{F}\right)$

Composite Properties

Tensile Strength

Tensile Modulus

Flexural Strength

Flexural Modulus

Short Beam Shear Strength

Specific Gravity

Fiber Volume
Nominal Values

$40 \%$
$0.5 \%$
$0.13 \mathrm{~mm}(0.005 \mathrm{in.})$
11 minutes

$24^{\circ} \mathrm{C}\left(75^{\circ} \mathrm{F}\right)$

$177^{\circ} \mathrm{C}\left(350^{\circ} \mathrm{F}\right)$

$1620(235.0)$

$1379(200.0)$

$162(23.5)$

$162(23.5)$

$1861(270.0)$

$1517(220.0)$

$158(23.0)$

$158(23.0)$

$65(9.5)$

Early in the program, this material system was characterized for its elastic and strength properties by testing $\left[0^{\circ}\right]_{4}$ tubes, loaded by axial tension, internal pressure, or torsion. These results were compared to data developed from the coupon specimens, results of which are as follows:

\footnotetext{
* 15.2 cm $(6-i n$.$) diametex, 0.6-mm (0.025-in.) thick, manufactured by Elgin$ Diamond Products of 366 Bluff City Blvd., Elgin, Illinois.

tScotch PIy 1009-36 E Glass, 3M Company. $x:$

Theis dald wert whined by Fibrite from composites which were fabri-

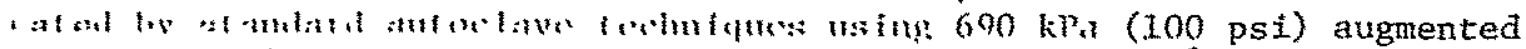
pressire. All sichength. valtues are reporced in $x$ Mpa (103 psi) units, all moduli are $x$ GPa ( $10^{6}$ psi).
} 


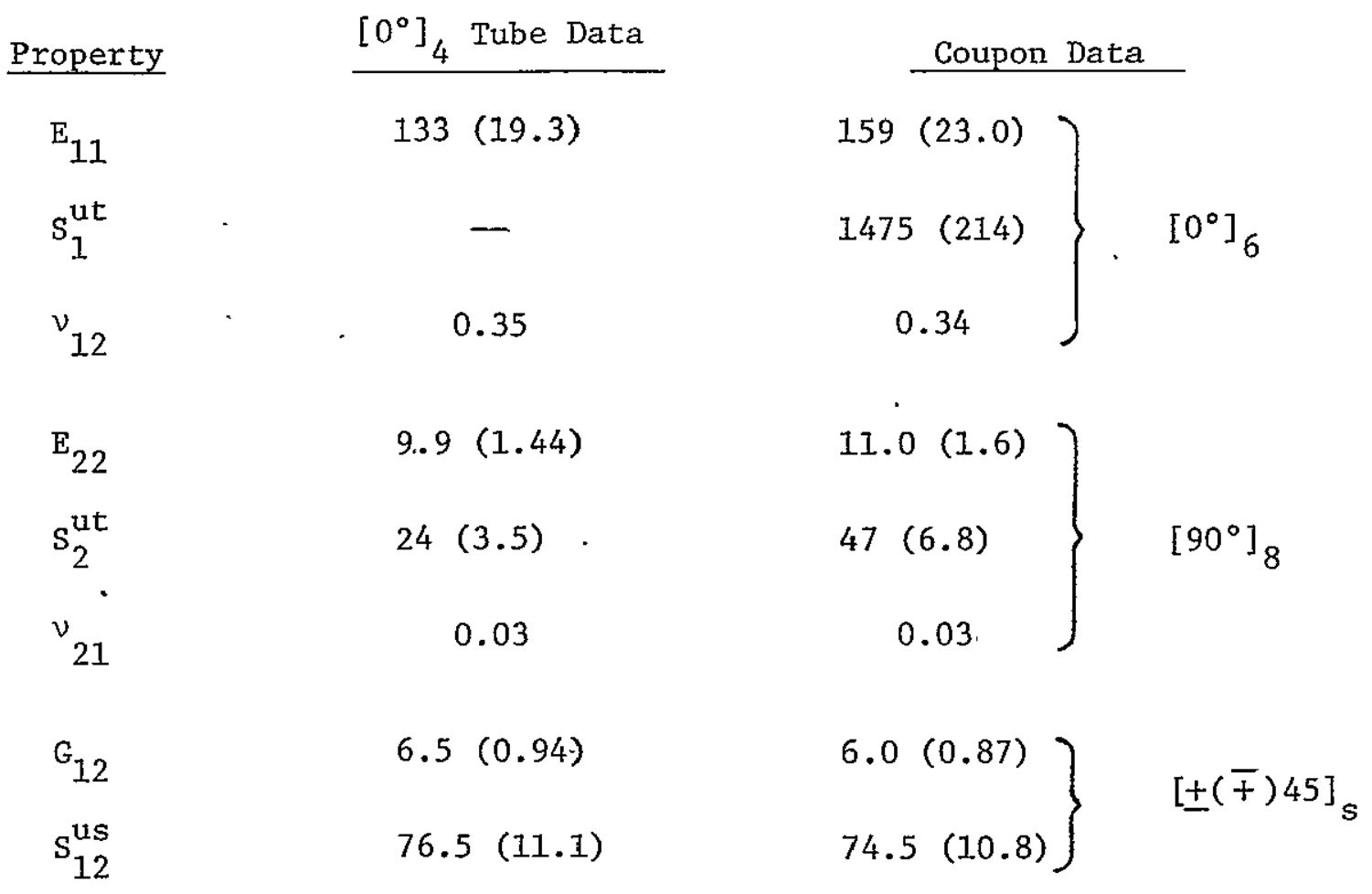

Strength values are reported in MPa ( $\mathrm{ksi}$ ) units; moduli are GPa (10 $0^{3} \mathrm{ksi}$ ). Subscript 1 refers to the fiber direction; subscript 2 is the transverse direction. Shear strengths and moduli were obtained from coupon tests using Rosen's analysis of [ +45$]$ coupons together with the following expressions: (12)

$$
\begin{aligned}
G_{12} & =\frac{\sigma_{x}}{2\left(\varepsilon_{x}-\varepsilon_{y}\right)} \\
s_{12}^{\text {us }} & =\frac{s_{x}^{u t}}{2}
\end{aligned}
$$

where $x$ is parallel to the long direction of the coupon and $y$ is parallel to the width. As can be seen from the table, measured elastic coefficients are in close agreement, but some discrepancy is noted in the transverse strength of $\left[0^{\circ}\right]_{4}$ tubes as compared to tensile tests of $\left[90^{\circ}\right]_{8}$ coupons. Thin-walled $\left[0^{\circ}\right]$ tubes are difficult to manufacture, and these lower strengths are probably due to a fine network of longitudinal cracks formed during specimen fabrication. The fragility problem in thin-wall tubes disappeared, of course, when testing $[+45]_{s}$ and $[0 / 90]_{s}$ tubes. Although these cross-plied tubes are fabricated in essentially the same manner as $\left[0^{\circ}\right]_{4}$ tubes, hoop stiffening due to fiber support greatly increases the durability of the specimen, making cross-plied tubes less susceptible to damage during fabrication or from subsequent handling. 


\section{c. Fatigue Testing of Tubes}

A total of 78 notched specimens were tested during the course of this program, of which 66 tubes were $[ \pm 45]_{\mathrm{s}}$ laminates, and 12 tubes were $[0 / 90]_{\mathrm{S}}$. of the $66[+45]_{s}$ tubes, 35 specimens were tested in uniaxial loading modes of axial tension, internal pressure, or torsion. The remaining $31[ \pm 45]_{\mathrm{s}}$ tubes were tested in three biaxial loading combinations of axial tension and torsion with axial tension: tension ratios of $2: 1,1: 1$, and $1: 2$. Al1 12 of the $[0 / 90]_{s}$ tubes were tested in uniaxial loading modes, 7 tubes by axial tension and 5 tubes by torsion. Cyclic tests were run with a minimum: maximum stress ratio $\mathrm{R}=0.1$ to avoid cycling through the stress free state. Axial tension, torsion, and biaxial cyclic tests were run at $5 \mathrm{~Hz}$. Internal pressure cycling was done at $0.5 \mathrm{~Hz}$, a limitation of the testing system. Al1 quasi-static tests to fallure were conducted at a stress rate of $414 \mathrm{kPa} /$ $\sec (60 \mathrm{psi} / \mathrm{sec})$. This rate was applied to the axial loading during biaxial static tests.

A set of tests for any particular loading mode consisted of 8 or more cyclic fatigue tests followed by 2 residual strength tests. Two quasistatic strength tests were run on $[+45]$ s tubes for each uniaxial loading mode. For purposes of this report, these tests will be considered fatigue (1 cycle to failure) tests, separate from residual strength tests.

Fatigue test results for each loading mode were plotted as S-N curves. Regression analysis was used to determine the best fit of data points to equations of the form

$$
\sigma_{\max }=\mathrm{AN}^{\mathrm{B}}
$$

where $A$ and $B$ are constants, $\sigma_{\max }$ is the maximum cyclic stress, and $N$ is the number of cycles to failure. These equations were then used to select peak loads for two residual strength tests, one after 100 cycles of loading, one after 10,000 cycles. A typical residual strength test for 100 cycles was conducted according to the following procedure:

1. The regression equation was used to calculate the peak cyclic stress resulting in fajlure at 100 cycles:

$$
\sigma=A(100)^{B}
$$

2. A speciman was cycled at $80 \%$ of this value for 100 cycles at $5 \mathrm{~Hz}$ (or $0.5 \mathrm{kz}$ in internal pressure loading),

$$
\sigma_{\text {test }}=0.8 \mathrm{~A}(100)^{\mathrm{B}}
$$

3. The specimen was then loaded quasi-statical1y to failure.

This procedure was repeated using a cyclic test duration of 10,000 cycles. 
All tube testing was carried out in the SwRI biaxial testing facility: see Figure 5. This system consists of a biaxial actuator capable of applying $+44.5 \mathrm{kN}(+10,000 \mathrm{lb})$ axial tension/compression, $69 \mathrm{MPa}(10,000 \mathrm{psi})$ internal pressure, and/or $\pm 339 \mathrm{~cm}-\mathrm{N}(+3,000$ in $-1 \mathrm{~b})$ torsion. The biaxial actuator is closed-loop, servo controlled, and can be driven in load, displacement, or strain control for either or both axial or torsional loading. A 1 testing during this program was done in load control. Tubular specimens were held in specially designed hydraulic grips. Internal pressurization was accomplished by hydraulically inflating a rubber bladder* inside the tubular specimen. An early problem with internal pressure testing resulted from the extrusion of the bladder through the $0.47-\mathrm{cm}(3 / 16-i n$.$) hole in a specimen.$ This was resolved by covering the hole inside with a shaped piece of $0.2-\mathrm{mm}$ (0.008-in.) shim stock. This cover effectively prevented extrusion of the bladder, but was free to slide about over the hole to minimize local inhomogeneities in loading. Inactive loading modes were held at zero under load control.

All tubes were instrumented with 350 -ohm strain gages located at the center of the gage section, $180^{\circ}$ around the tube from the hole.t Biaxial and torsion specimens were instrumented with 3 -gage strain rosettes for measurement of strain on 3 axes. The remaining tubes contained single $0.31-\mathrm{cm}$ (1/8-in.) strain gages oriented in the appropriate direction. Peak strains during cyclic loading were recorded on a strip chart recorder.

\footnotetext{
* Minor Rubber Co., Inc., Bloomfield, New Jersey 07003.

†icro Measurement, Romulus, Michigan 48174.
} 


\section{A. Test Matrix}

As was discussed in the previous section, 78 tests were performed on two different fiber orientations. Most of the work was done for $[+45]_{S}$ notched tubes which were tested in three uniaxial and three biaxial loading modes. Each loading mode was composed of two parts, cyclic fatigue and residual strength. An S-N curve was determined for each loading mode by 8 or more fatigue tests, and regression analysis was used to fit these data for each mode to an equation of the form

$$
\sigma_{\max }=\mathrm{AN}^{\mathrm{B}}
$$

The equation was then used to set stress levels for residual strength tests, two tests per loading mode. A defined "runout" was set at $10^{5}$ cycles. Any specimen survịing $10^{5}$ cycles was loaded to failure, providing an extra residual strength data point. Numbers of tests for each loading mode are shown in Table 1 . Only 1 imited work was done with $[0 / 90]_{s}$ tubes at the end of the program. Some problems were encountered in obtaining $S-N$ data for this fiber orientation; fatigue failures were recorded for torsional loading only. Residual strength results on $[0 / 90]_{s}$ tubes come from tubes surviving $10^{5}$ or more cycles.

\section{B. Fatigue Test Results: Untaxia1 Loading}

Both $[+45]_{\mathrm{s}}$ and $[0 / 90]_{\mathrm{s}}$ tubes were tested in uniaxial fatigue, although testing of $[\overline{0} / 90]_{s}$ tubes was limited and accomplished at the end of the program. Test results for the ten $[+45]_{s}$ tubes loaded in axial tension are shown in Table 2. Initially, two tubes (numbers 46 and 59) were loaded quasistatically to failure by axial tension at an applied stress rate of $414 \mathrm{MPa} /$ $\mathrm{sec}(60 \mathrm{psi} / \mathrm{sec})$. These results, as shown in Table 2, were 205 and $202 \mathrm{MPa}$ (29.7 and $29.3 \mathrm{ksi}$ ), respectively. Six tubes were then cycled at $5 \mathrm{~Hz}$ with peak stresses ranging from 108 to $183 \mathrm{MPa}(15.6$ to $26.5 \mathrm{ksj})(\mathrm{R}=0.1)$. Cyclic life tended to decrease with increasing applied stress as would be expected. Specimen number 76 failed after 24 cycles at the highest peak cyclic stress of $183 \mathrm{MPa}(26.5 \mathrm{ksi})$; specimen number 77 failed after 70,922 cycles at the lowest applied stress, $108 \mathrm{MPa}(15.6 \mathrm{ksi})$. None of these tubes survived "runout," 105 cycles. These points are plotted on an S-N diagram in Figure 6. Photographs of the failed specimens are shown in the Appendix. Constants $A$ and $B$ for the curve fit equation were found to be

$$
\begin{aligned}
& A=202 \mathrm{MPa}(29.3 \mathrm{ksi}) \\
& B=-0.0586
\end{aligned}
$$

where $\sigma_{\max }$ is in units of MPa or (ksi). Table 3 shows the constants A and B for all six loading modes used on $[+45]_{s}$ tubes. Using the equation 


$$
\begin{aligned}
\left(\sigma_{x}\right)_{\max } & =\sigma_{\max }=202 \mathrm{~N}^{-0.0586} \mathrm{MPa} \\
& =\left(29.3 \mathrm{~N}^{-0.0586} \mathrm{ksi}\right)
\end{aligned}
$$

a specimen would be expected to fail at 100 cycles of load if the peak stress was $154 \mathrm{MPa}(22.4 \mathrm{ksi})$. Tube number $108 \mathrm{~A}$ was cycled 100 times at $80 \%$ of this value, $123 \mathrm{MPa}(17.9 \mathrm{ksi}$ ), then loaded to failure. The recorded residual strength was $219 \mathrm{MPa}(31.8 \mathrm{ksi})$. In a similar manner, tube number 104 was cycled 10,000 times at a peak stress of $80 \% \times 118 \mathrm{MPa}=94.4 \mathrm{MPa}$ (x $17.1 \mathrm{ksi}$ $=13.7 \mathrm{ksi}$ ), then loaded to failure, showing a residual strength of $212 \mathrm{MPa}$ $(30.8 \mathrm{ksi})$. These residual strength points are also shown in Figure 6 . It is interesting to note the residual strengths 212 and $219 \mathrm{MPa}$ (30.8 and 31.8 ksi) are greater than the static strengths of 205 and $188 \mathrm{MPa}$ (29.7 and 27.3 $\mathrm{ksi}$.

A total of 12 tests were conducted on $[+45]_{S}$ tubes in the internal pressure mode, results of which are shown in Table 4. Two tubes (numbers 50 and 65) were tested statically to failure, recording strengths of 246 and $210 \mathrm{MPa}$ ( 35.7 and $30.5 \mathrm{ksi}$ ). One tube, number 91, survived 101,275 cycles of loading at an applied peak stress of $117 \mathrm{MPa}$ (17.0 ksi), well past the defined "runout" of $10^{5}$ cycles. This tube was subsequently loaded to failure, providing an extra residual strength value. Test data for this loading mode are not so well behaved as the axial fatigue, points. Tube number 100 failed at 82 cycles under an applied peak hoop stress of $203 \mathrm{MPa}(29.5 \mathrm{ksi})$, while tube number 98 failed after 9 cycles at a peak stress of $197 \mathrm{MPa}$ (28.5 ksi). This same "reversal" can also be seen for tube numbers 83 and 101 or specimens 97 and 78 . As can be seen in the photographs of the broken specimens shown in the Appendix, some failures did not initiate at the $0.48-\mathrm{cm}$ (3/16-in.) diameter drilled hole. This was probably caused by irregularities in applied stress due to the aluminum shim preventing bladder extrusion through the hole. These data points, and the fitted equation

$$
\begin{aligned}
\left(\sigma_{y}\right)_{\max } & =\sigma_{\max }=228 \mathrm{~N}^{-0.0405} \mathrm{MPa} \\
& =\left(33.0 \mathrm{~N}^{-0.045} \mathrm{ksi}\right)
\end{aligned}
$$

are plotted in Figure 7. Three residual strength points are shown for this loading mode. Tube number 99 was cycled 100 times at a peak applied stress of $150 \mathrm{MPa}(21.8 \mathrm{ksi})$, recording a residual strength of $238 \mathrm{MPa}$ (34.5 ksi). Tube number 94 was cycled 10,000 times at $123 \mathrm{MPa}(17.9 \mathrm{ksi})$, and had a residual strength of $212 \mathrm{MPa}(30.8 \mathrm{ksi})$. Tube number 91 "ran out" at $117 \mathrm{MPa}$ $(17.0 \mathrm{ksi})$, later failing under a quasi-static stress of $275 \mathrm{MPa}$ (39.9 ksi). Some of these residual strengths were also greater than the measured static strengths, as was found in the case of the axial loading results.

Due to the symmetry of the $[+45]_{s}$ laminate, results from axial fatigue and internal pressure fatigue should be quite similar. Comparing Figures 6 and 7 , it can be seen that tubes loaded by internal pressure tended to have 
somewhat higher strengths than did those tubes loaded by axial tension. The cyclic rate for tubes tested with internal pressure was $0.5 \mathrm{~Hz}$ as compared to $5 \mathrm{~Hz}$ for the tubes loaded by axial tension. Also, the small shim plate covering the aperture may have had a strengthening effect on the internally pressurized tubes.

Thirteen $[+45]_{s}$ tubes were tested with uniaxial torsional fatigue. of these tests, $\overline{1}$ were fatigue tests and 2 were residual strength tests as previously described; see Table 5. These data points were also somewhat scattered with cyclic peak stresses ranging from 110 to $207 \mathrm{MPa}$ (16.0 to $30.0 \mathrm{ksi}$ ). Fatigue 1 ives ranged from 3 cycles to 92,155 cycles, but cyclic life did not always increase with reduced peak stress, as shown by tube numbers $85,66,79$, and 64 . The fitted equation

$$
\begin{aligned}
\left(\tau_{x y}\right)_{\max } & =\tau_{\max }=209 \mathrm{~N}^{-0.0488} \mathrm{MPa} \\
& =\left(30.3 \mathrm{~N}^{-0.0488} \mathrm{ksi}\right)
\end{aligned}
$$

is similar to the equation derived from internal pressure fatigue data (see Table 4) even though this type of loading results primarily in tensile and compressive stresses in the fibers rather than shear of the matrix. The residual strengths 187 and $174 \mathrm{MPa}$ (27.0 and $25.3 \mathrm{ksi}$ ) of tube numbers 102 and 105 , respectively, were not greater than the static test results of 232 and $177 \mathrm{MPa}(33.6$ and $25.7 \mathrm{ksi})$, although, again, they are quite close. Stress versus cycles data, residual strengths, and the fitted equation for torsional fatigue of $[+45]_{s}$ notched tubes are plotted in Figure 8 .

Only limited fatigue testing, 12 tubes, was done on $[0 / 90]$ s test specimens. Fatigue failures within the defined $10^{5}$ cycle runout were difficult to achieve; no axial fatigue tests of $[0 / 90]_{\text {s }}$ tubes resulted in fatigue failures (see Table 6). Tube number 129 was cycled first at a peak axial stress of $207 \mathrm{MPa}(30.0 \mathrm{ksi})$. This tube survived 101,204 cycles of loading and was subsequently loaded to failure. Its residual strength was $612 \mathrm{MPa}(88.7 \mathrm{ksi})$. Tube number $163 \mathrm{~A}$ was the second tube tested. It was 1oaded for 100,180 cycles at $448 \mathrm{MPa}(65 \mathrm{ksi})$. When fatigue failure did not occur, peak stress was increased to $483 \mathrm{MPa}(70 \mathrm{ksi})$. The specimen survived 104,867 additional cycles at $483 \mathrm{MPa}(70 \mathrm{ksi})$ and 100,860 additional cycles at $500 \mathrm{MPa}$ (72.5 ksi). Finally, the tube was loaded to failure; a strength of $698 \mathrm{MPa}$ (101.2 ksi) was noted. Tube number 7 was the next specimen to be tested, and a cyclic peak stress was set for $698 \mathrm{MPa}(85 \mathrm{ksi})$. This tube failed on the first cycle at some point before $586 \mathrm{MPa}(85 \mathrm{ksi})$. For the next test, number 167 , peak stress was reduced to $517 \mathrm{MPa}(75 \mathrm{ksi})$. This tube also failed before the first peak load was attained. All cyclic tests were run at $5 \mathrm{~Hz}$.

To summarize the testing thus far, [0/90]s tubes cycles at stresses of $497 \mathrm{MPa}(72 \mathrm{ksi})$ or less lasted $10^{5}$ or more cycles; a tube cycled at $517 \mathrm{MPa}$ (75 ksi) failed on the first load before peak load was attained. Residual strength tests on tubes which ran out indicated strengths ranging from 612 to $698 \mathrm{MPa}(88.7$ to $101.2 \mathrm{ksi}$ ). Results thus far seemed to indicate a tube surviving the first cycle of loading would survive $10^{5}$ cycles. In an effort 
to see if this was a stress rate induced effect, 2 tests were run at much slower loading rates. It was thought possible that a tube loaded slowly might survive that first crucial cycle, after which the cyclic rate could be increased. A peak stress of $586 \mathrm{MPa}$ ( $85 \mathrm{ksi}$ ) was set for tube number 162 , to be applied at $9.7 \mathrm{MPa} / \mathrm{sec}(1.4 \mathrm{ksi} / \mathrm{sec})$. This tube failed at $572 \mathrm{MPa}$ $(82.9 \mathrm{ksi})$ before attaining the set peak. Tube number 166 was tested at the same rate towards a set peak stress of $517 \mathrm{MPa}$ (75 ksi); this tube failed at $489 \mathrm{MPa}(70.9 \mathrm{ksi})$.

It appears, therefore, that the $S-N$ curve for $[0 / 90]_{S}$ notched tubes in axial fatigue is very flat (no "wearout"), making fatigue tests quite difficult. If a specimen survives the first loading cycle, stress relaxation takes place in the matrix, resulting in a more homogeneous stress state within the tube. With all fibers bearing the load equally, stress concentration effects caused by the hole are considerably reduced. For this reason, residual strengths of axially $[0 / 90]_{s}$ cycle specimens were considerably higher than the static strengths, as shown in Table 6 .

Only five $[0 / 90]_{s}$ notched tubes were tested in torsional fatigue; see Table 7. A malfunction in the torsional actuator resulted in less than intended applied shear stresses on tube numbers 128 and 131 . Listed stress values were estimated from strain data. These tubes survived $10^{5}$ cycles and were loaded to failure. Strengths of 83.4 and $92.4 \mathrm{MPa}(12.1$ and $13.4 \mathrm{ksi})$ were measured for tubes 128 and 138 , respectively. A peak torsional stress of $96.5 \mathrm{MPa}$ ( $14 \mathrm{ksi}$ ) was set for cycling of tube number 163B, but this tube also failed prior to attaining the set peak stress. The measured strength was $91.0 \mathrm{MPa}$ (13.2 ksi). Two tubes, numbers 168 and 169 , did finally fail due to fatigue loading. Specimen number 168 fajled after 48 cycles at a peak shear stress of $86.2 \mathrm{MPa}(12.5 \mathrm{ksi})$, and tube number 169 failed at 2,705 cycles under a peak cyclic stress of $76.5 \mathrm{MPa}$ (11.1 ksi). These results are plotted in Figure 9. Regression analysis constants were calculated for these data points (see Table 8 ), but the small number of test specimens casts some doubt on the validity of the results.

Peak strains were recorded on a strip chart recorder throughout most of the uniaxial tests. High strains and long test duration caused premature strain gage fallure in many of the tests. However, some gages survived entire fatigue tests until ultimate failure of the tube occurred. Plots of normalized strain $\varepsilon / \varepsilon_{0}\left(\varepsilon_{0}=\right.$ strain on first cycle) versus cycles indicated the onset of failure could be detected for certain matrix dominated loading modes. Figures 10,11 , and 12 show plots of normalized strain for two $[+45]_{s}$ notched tubes of each uniaxial loading mode. Notice in Figures 10 and $1 \bar{I}$ that strain increased quite rapidly just prior to failure for both axial tension and internal pressure fatigue. This may be the result of accumulated anelastic and/or inelastic strain, probably thermally enhanced, due to micromechanical damage in the matrix. A $[+45]_{s}$ loaded by axial tension or internal pressure is in a state of shear relative to the fiber directions, a matrix dominated type of loading. Figure 12 shows strain results from two $[ \pm 45]_{\mathrm{S}}$ tubes loaded in torsion. This loading results primarily in tension or compression loading of the fibers. Inminent failure was not indicated by peak strain changes in this fiber dominated loading mode, indicating a different mechanism is responsible for ultimate failure, as would be expected. Failure of $[+45]_{s}$ tubes loaded in torsion is probably a result of fiber breakage or 
pullout, which when initiated results in sudden catastrophic faflure. Figures 13 and 14 show the limited strain results from $[0 / 90]$ s notched tubes loaded by axial tension or torsion. The fiber dominated axial fatigue strain results show no indication of failure in Figure 13, very similar to the torsion results of $[+45]_{s}$ tubes shown in Figure 14. Strain measurements in the matrix dominated torsion tests on $[0 / 90]_{S}$ tubes, shown in Figure 14, look very much like the strain results from axial or internal pressure fatigue of $[445]_{\mathrm{s}}$. tubes shown in Figures 10 and 11 .

\section{Fatigue Test Results: Biaxial Loading}

Biaxial fatigue tests were conducted on only $[+45]_{s}$ notched laminates. Three biaxial loading modes were examined; all were some ratio of axial tension and torsion, to avoid cyclic rate and bladder extrusion problems with internal pressure fatigue. The test format for biaxial fatigue was the same as for uniaxial fatigue. Eight or more fatigue tests were run at some fixed axial:torsion ratio in order to define an $\mathrm{S}-\mathrm{N}$ curve. Regression analysis was performed on these data to determine an equation

$$
\sigma_{\text {max }}=\text { AN }^{B}
$$

where $A$ and $B$ are constants, $N$ is the number of cycles, and $\sigma_{\text {max }}$ is axial stress. This equation was then used to choose loads for two residual strength tests.

Results for the first biaxial load ratio, axial: torsion $=2: 1$, are shown in Table 9. Ten tubes were tested, eight tubes in fatigue and two tubes for residual strength. None of these fatigue tests survived the $10^{5}$ cycle runout. Applied cyclic axial peak stresses ranged from 93.1 to $165 \mathrm{MPa}$ (13.5 to $24.0 \mathrm{ksi}$ ), with cycles times from 38,624 down to 6 cycles. Little scatter was noted in these data; cyclic life increased as peak stress was reduced for all eight tubes. Residual strength tests were run in the same manner as the uniaxial residual strength tests. The regression analysis curve

$$
\begin{aligned}
\sigma_{\text {axial }} & =190 \mathrm{~N}^{-0.0601} \mathrm{MPa} \\
& =\left(27.6 \mathrm{~N}^{-0.0601} \mathrm{ksi}\right)
\end{aligned}
$$

as well as the fatigue points and residual strength points are plotted in Figure 15. All of the regression constants for fatigue of $[+45]_{s}$ notched tubes, both uniaxial and biaxial fatigue, are listed in Table 3 .

Results for the second biaxial mode, axial:torsion ratio 1:1, are shown in Table 10. Again, ten tubes were tested, eight in fatigue and two for residual strength. Little scatter was noted in $\mathrm{S}-\mathrm{N}$ data for this mode, as can be seen in the plot shown as Figure 16 . These results are similar to the biaxial axial:torsion ratio $2: 1$ results. Some difference can be seen in the regression constants in Table 3 . 
The final biaxial loading ratio was axial:torsion $=1: 2$, for which 11 tests were run. Nine fatigue tests and two residual strength tests were conducted; one fatigue test went 105 cycles (see Table 11). Results are plotted in Figure 17; there is much more scatter in these data than was present for the first two biaxial loading modes. Fatigue lives could not be predicted with enough accuracy to space $S-N$ points, evenly across the $S-N$ diagram. Regression constants for this mode are also listed in Table 3.

Because specimens were tested in load control, damage at failure was extensive; specimens were usually torn into two pieces. This made determination of the failure mechanism difficult, because the initial failure surface could not be easily identified. However, there appears to be little difference in failure mode between static, fatigue, or residual strength tests for the $[+45]_{S}$ or $[0 / 90]_{S}$ tubes, as can be seen in the failed specimen photographs shown in the Appendix. In all but two cases, failure occurred at the hole, as expected. Slight differences can be seen in the internally pressurized tubes, where damage appears to be less severe. However, this is a result of bladder rupture caused by extrusion and puncturing just after ultimate failure, which released the load. No such load release occurred for axially or torsionally tested tubes, and therefore the damage was much more extensive.

Some differences can be seen in the failure photographs of $[0 / 90]_{\mathrm{s}}$ tubes, also shown in the Appendix. Failure among the axially fatigued specimens appeared to initiate at the top (or bottom) of the hole, and resulted in a relatively clean fracture perpendicular to the $0^{\circ}$ plies. Little transverse cracking of the $0^{\circ}$ plies was noted. Torsionally fatigued $[0 / 90]_{s}$ tubes showed extensive transverse cracking of the $0^{\circ}$ plies, a result of the shearing stress. These results are somewhat similar to the results for $[+45]_{s}$ tubes tested in axial or internal pressure fatigue where much cracking parallel to the fibers was also present. 


\section{DATA ANALYSIS AND CORRELATION}

\section{A. Data Analysis Approach}

A very conmon approach in describing the fatigue life of metals is to observe that $\mathrm{S}-\mathrm{N}$ data for many alloys can be accurately represented by a $10 \mathrm{~g}-$ log linear relationship. This approach has also been used in representing fatigue life data for filamentary composites. Accordingly, all experimental S-N data generated during the present program were fitted to the power law (i.e., log $\log$ linear) equation:

$$
\sigma_{\max }=\mathrm{AN}^{-\mathrm{B}}
$$

where $\sigma_{\max }$ is the maximum applied cyclic stress, $\mathrm{N}$ is the number of cycles to failure, and $A$ and $B$ are constants determined from the curve fit. The curve fitting technique involves the transformation of $\mathrm{Eq}$. (1) into an equation linear in $\log \sigma_{\max }$ and $\log N$. Then, the method of least squares, or simple linear regression, is employed. Even though the number of test data points is somewhat limited, it is believed that the S-N curves fitted to Eq. (1) are representative of the loading modes and fiber orientations.

Stress concentration factor calculations were made using the LekhnitskiiSavin stress functions (13) for an anisotropic sheet containing a hole. Iaminate stresses were calculated for the case of an infinite composite laminate containing a unit radius circular hole, subjected to a remote unit stress in the $X$ direction; see Figure 18. Stresses were calculated in polar coordinates $(0 \leq \theta \leq \pi / 2)$ for both $[ \pm 45]_{s}$ and $[0 / 90]_{s}$ laminates with plies of the follow ing properties.

$$
\begin{aligned}
& E_{11}=133 \mathrm{GPa}\left(19.3 \times 10^{6} \mathrm{psi}\right. \\
& E_{22}=9.9 \mathrm{GPa}\left(1.44 \times 10^{6} \mathrm{psi}\right) \\
& G_{12}=6.5 \mathrm{GPa}\left(0.94 \times 10^{6} \mathrm{psi}\right) \\
& v_{12}=0.35
\end{aligned}
$$

A plot of the tangential stress at the hole boundary versus angle around the hole for $a[+45]_{S}$ laminate is shown as Figure 19 . This case represents the case of a $[+\overline{45}]_{\mathrm{s}}$ tube subjected to an axial unit stress $\left(\sigma_{\mathrm{x}}=1\right)$. In order to generalize these tangential normal stress results for the case of a unit stress, imposed by internal pressure $\left(\sigma_{y}=1\right)$, the axial results for a $[+45]_{\mathrm{s}}$ were rotated 90 degrees; see Figure 20. To calculate tangential normal stresses around the hole for the case of a unit shear load imposed by torsion $\left(\tau_{x y}=1\right)$, stresses were superposed from tension-compression loading of a $[0 / 90]_{S}$ laminate; see Figure 21 . Plots of tangential normal stress for internal pressure and torsional loading are shown as Figures 22 and 23. To 
obtain tangential normal stresses for biaxial loadings, the appropriate uniaxial results are added according to the selected biaxial stress ratio. Figures 24,25 , and 26 show tangential normal stress at the hole boundary versus $\theta$ for the three biaxial load ratios tested during this program, $\sigma_{x}: r_{x y}=$ $2: 1,1: 1$, and $1: 2$.

\section{B. Prediction of Biaxial Fatigue Life from Uniaxial Data}

If a scheme could be developed to predict biaxial fatigue behavior from uniaxial fatigue restilts, the primary value of such a scheme would be to reduce the amount of fatigue testing for biaxial loading modes. In addition, a simpler test machine could be employed. Such a scheme was developed during this program, and preliminary results indicate that this scheme is feasible.

If one knows the fatigue behavior of a particular laminate under two or more uniaxial loading modes, an interaction equation can be written to predict laminate behavior for multiaxial loading. The interaction equation employed here is known as the Hill(14) failure theory for anisotropic materials, and for plane stress of a laminate it can be expressed as:

$$
\frac{\sigma_{x}^{2}}{\vec{x}^{2}}-\sigma_{x} \sigma_{y}\left(\frac{1}{\bar{x}^{2}}+\frac{1}{\bar{y}^{2}}-\frac{1}{\bar{z}^{2}}\right)+\frac{\sigma_{y}^{2}}{\frac{\bar{Y}}{2}^{2}}+\frac{\tau_{x y}^{2}}{\vec{s}^{2}}=1
$$

where $\sigma_{x}, \sigma_{y}$, and $\sigma_{x y}$ are average laminate stresses in the laminate coordinates $x$ and $y$. The laminate strengths in the laminate coordinates $x, y$, and $z$ are $\bar{X}, \bar{Y}, \bar{z}$, and $\bar{S}$.

An extension of Eq. (2) to include fatigue as well as static behavior is made by replacing the static strengths by fatigue functions $X^{*}(N), Y^{*}(N)$, $Z^{\prime}(N)$, and $S^{\prime}(N)$, where $N$ is the number of fatigue cycles associated wth failure at a certain stress level. The only known previous investigations on the use of a static failure theory to predict fatigue strength were conducted by Rotem and Hashin $(15,16)$ and Sims and Brogdon $(17)$. In both of these previous works, the use of a static strength theory to predict fatigue strength appeared to be successful. However, these previous test results were limited to uniaxial loading modes, and no attempt was made to predict fatigue results for biaxial loading with uniaxial fatigue functions.

Thus, the final form of the interaction equation for fatigue can be written as:

$$
\frac{\sigma_{x}^{2}}{X^{\prime}(N)^{2}}-\sigma_{x^{\prime}} \sigma_{y}\left(\frac{1}{X^{\prime}(N)^{2}}+\frac{I}{X^{\prime}(N)^{2}}-\frac{1}{Z^{\prime}(N)^{2}}\right)+\frac{\sigma_{y}^{2}}{Y^{\prime}(N)^{2}}+\frac{\tau_{x y}^{2}}{X^{\prime}(N)^{2}}=1
$$

A comparison of theoretical and experimental results for biaxial fatigue loading will now be given. 
The experimental fatigue data found during the present investigation for uniaxial loading are expressed in equation form as: $(R=0.1)$

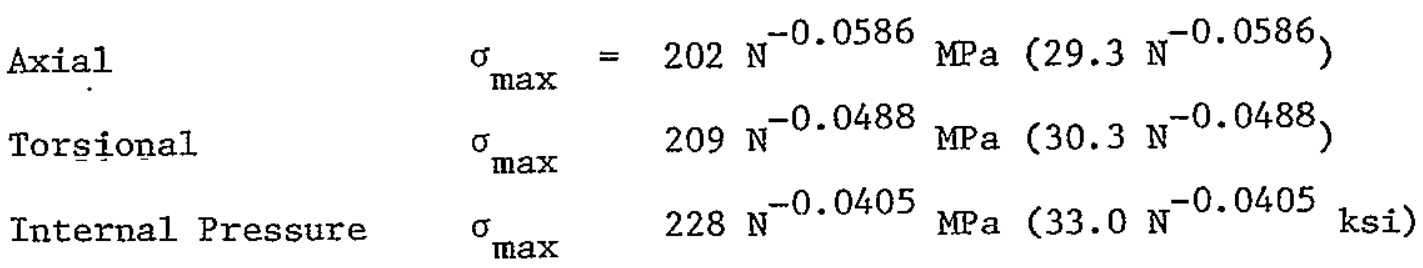

For biaxial loading, the experimental fatigue data were found to be expressable as: $(R=0.1)$

$\begin{array}{lll}\text { Axial-Torsion } 1: 1 & \sigma_{\max }=154 \mathrm{~N}^{-0.0563} \mathrm{MPa}\left(22.3 \mathrm{~N}^{-0.0563 \mathrm{ksi})}\right. \\ \text { Axial-Torsion } 2: 1 & \sigma_{\max }=190 \mathrm{~N}^{-0.0601} \mathrm{MPa}\left(27.6 \mathrm{~N}^{-0.0601} \mathrm{ksi}\right) \\ \text { Axial-Torsion } 1: 2 & \sigma_{\max }=103 \mathrm{~N}^{-0.0471} \mathrm{MPa}\left(14.9 \mathrm{~N}^{-0.0471} \mathrm{ksi}\right)\end{array}$

For the $\left[ \pm 45^{\circ}\right]_{S}$ laminate under axial-torsional loading, Eq. (3) reduces to:

$$
\frac{\sigma_{\mathrm{x}}^{2}}{\mathrm{X}^{\prime}(\mathrm{N})^{2}}+\frac{\tau_{\mathrm{xy}}^{2}}{\mathrm{~S}^{\prime}(\mathrm{N})^{2}}=1
$$

The experimental uniaxial fatigue functions are then used in the above equation to predict biaxial fatigue behavior. A comparison of experimental and theoretical results is contained in Table 12 where axial stresses are given in $\mathrm{MPa}$ (ksi). For the limited experiment results shown, the agreement is quite good.

\section{Discussion}

An attempt was made to determine the effect of the small circular hole on the fatigue results. The overall effect of the hole is to create a stress concentration which produces a failure in the center section of the tube at the hole. An interesting question arises as to the effect of the hole size on the SCF. In theory, one would expect the same SCF from large or small holes. However, it has been experimentally observed that for hole diameters of less than $2.5 \mathrm{~cm}$ ( 1.0 in.), the tensile strength depends on the hole size. $(18,19)$ A theoretical model which accounts for the hole size effect has been developed by Whitney and Nuismer, $(20)$ and limited experimental data support the theory. For the hole size in this investigation, it is suspected that the effective SCF is less than the theoretical SCF predicted by Figures 
19, 22-26. But since hole size was not a parameter in the present investigation, this statement cannot be made with certainty*

The use of a fatigue fallure theory to predict biaxial loading fatigue behavior from uniaxial fatigue results appears to be successful. However, more test data are needed to confirm this fully. 


\section{CONCLUSIONS AND RECOMMENDATIONS}

Fatigue 1tfe curves for T300/934 [445]s tubular specimens, each containing a circular aperture, were determined for axial tension, corsion, and internal pressure loading modes. The data showed relatively littele scatter with respect to a Iinear representation between $\log \sigma$ and $\log N$. The $S-N$ curve fox a cyclic fatigue by internal pressure was slightly higher than for cyclic axial tension loading, although the curves should be identical except for tube curvature effects. It is not known whether the curvature effect was the principal agent in causing the difference between these two $\mathrm{S}-\mathrm{N}$ curves, or if the difference was due to time-dependent effects associated with the two loading frequencies involved, or if indeed it can be attributed to the lack of a more complete data set. As a related matter of interest, it was noticed that the $S-N$ curves for cyclic axial tenston and for cyclic torsion of the $[+45]_{s}$ laminates were nearly identical.

Residual strengths after application of $10^{2}$ and $10^{4}$ cycles at $80 \%$ of the peak cyclic failure stress levels were generally (but not always) higher than the static strength.

Difficulties were encountered in establishing reliable S-N relationships for $[0 / 90]$ s laminates. In the case of cyclic axial tension, a fiber dominated mode, the $\mathrm{S}-\mathrm{N}$ curve is flat, and $\mathrm{I}$ ts Location apparently is sensitive to minor tube-to-tube fabrication irregularities. In cyclic torsion, which is a matrix dominated mode, the $\mathrm{S}-\mathrm{N}$ relation was somewhat easier to establish, although it is probably affected by loading frequency.

A comparison of the S-N curves for axial tension:torsion biaxial fatigue of $[+45] \mathrm{s}$ tubes reveals that the $(1: 2) \mathrm{s}-\mathrm{N}$ curve was lowest, followed by the $(1: \bar{I})$ curve, and finally the $(2: 1) \mathrm{S}-\mathrm{N}$ curve. These findings are in complete agreement with the maximum stress concentration factors at the aperture for these loading modes. An examination of Figures $24-26$ indicates that the maximum stress concentration factors for the $(1: 2),(1: 1)$, and $(2: 1)$ tension:torsion loading modes are, respectively, $13.2,7.7$, and 5.

The Hill plane stress failure criterion was adapted for preducting fatigue life of laminates under biaxial loads. Using S-N results from uniaxial fatigue tests on tubes each containing a hole, it was possible to predict the $S-N$ relationship of identical tubes loaded biaxially, with renarkable success. This constitutes an important first step in lifetime prediction of biaxially-loaded laminates. In oxder to gain further confidence in the method, however, it is recommended that similar work be undertaken to attempt to predict biaxial fatigue of notched laminates from uniaxial results on unnotched coupons, together with appropriate stress concentration calculations. Should this prove feasible, a fuxther stride would be to use the fatigue life behavior of unnotched laminae to predict biaxial fatigue of notched laminates. Any progress made toward achieving either of the above two generalizations of the present work would be of great value to structural designers. In addition, the effect of compression loading on fatigue life (uniaxial or biaxial) in the presence of an aperture is an important topic to address. 


\section{REFERENCES}

1. Boller, $\mathrm{K}$. , in "Composite Materials: Testing and Design," ASTM STP 460, American Society for Testing and Materials, 1969, p. 217.

2. Salkind, M. J., "Fatigue of Composites," Composite Materials: Testing and Design (Second Conference) ASTM STP 497, American Society for Testing and Materials, 1972, pp. 143-169.

3. Halpin, J. C., Jerina, K. L., and Johnson, T. A., "Characterization of Composites for the Purpose of Reliability Evaluation," Analysis of Test Methods for High Modulus Fibers and Composites, ASTM STP 521, Axnerican Society for. Testing and Materials, 1973, pp. 5-64.

4. Stinchcomb, W. W., Reifsnider, K. L., and Williams, R. S., "Critical - Factors for Frequency-Dependent Fatigue Processes in Composite Materials," Experimental Mechanics, Vo1. 16, Sept. 1976, pp. 343-348.

5. Pipes, R. Byron, Kulkarni, S. V., and McLaughlin, P. V., "Fatigue Damage in Notched Composite Laminates," Proceedings of the Army Symposium on Solid Mechanics, 1976 - Composite Materials: The Influence of Mechanics of Failure on Design, Sept. 1976, pp. 212-221.

6. Kulkarni, S. V., Mclaughlin, P. V., Pipes, R. B., and Rosen, B. W., "Fatigue of Notched Fiber Composite Laminates: Analytical and EXperimental Evaluation," presented at the Fourth ASTM Conference on Composite Materials, Valley Forge, May 1976.

7. Lucas, J. J., and Sainsbury-Carter, J. B., "Effect of Specimen Geometry on Fatigue Strength of Boron and Glass Epoxy Composites," Journal of Materials, JMLSA, Vol. 7, No. 4, Dec. 1972, pp. 586-589.

8. Nevedunsky, J.'J., Lucas, J. J., and Salkind, M. J., "Early Fatigue Damage Detection in Composite Materials," Journal of Composite Materials, Vo1. 9, 1975, pp. 394-408.

9. Salkind, M. J., "Early Detection of Fatigue Damage in Composite Materials," Journal of Aircraft, Vol. 13, No. 10, Sept. 1976, pp. 764-769.

10. Francis, P. H., Walrath, D. E., and Weed, D. N., "Investigation of First P1y Failure of Graphite/Epoxy Laminates Subjected to Biaxial Static and Fatigue Loadings," SwRI Final Report, Contract No. F3361575-C-5115, March 1977.

11. Weed, D. N., and Francis, P. H., "Process Development for the Fabrication of High-Quality Composite Tubes," Fibre Science and Technology, Vo1. 10, Apri] 1977, pp. 89-100.

12. Rosen, B. W., "A Simple Procedure for Experimental Determination of the Longitudinal Shear Modulus of Unidirectional Composites," Journal of Composite Materials, Vo1. 6, No. 4 (Oct. 1972), pp. 552-554. 
13. Lekhnitskii, S. G., Theory of Elasticity of an Anisotropic Elastic Body, Holden-Day, Inc., San Francisco, 1963, p. 171.

14. Hill, R., Mathematical Theory of Plasticity, Oxford University Press, New York, 1950, p. 318.

15. Hashin, Z., and Roten, A., "A Fatigue Failure Criterion for Fibex Reinforced Materials," Journal of Composite Materials, Vo1. 7, (Oct. 1973), pp. 448-464.

16. Rotem, A., and Hashin, Z., "Fatigue Failure of Angle Ply Laminates," AIAA Journal, Vo1. 14, No. 7 (July 1976), Pp. 868-872.

17. Sims, D. F., and Brogdon, V. H., "The Fatigue Behavior of Composites Under Different Loading Modes," ASTM Symposium on Fatigue of Filamentary Composite Materials, (Nov. 1976), Denver, Colorado.

18. Waddoups, M. E., Eisenmann, J. R., and Kaminski, B. E.; "Macroscopic Fracture Mechanics of Advanced Composite Materials," Journal of Composite Materials, Vo1. 5,"1971, p. 446.

19. Whiteside, J. B., Danie1, I. M., and Rowlands, R. E., "The Behavior of Advanced Filamentary Composite Plates with Cutouts, "Air Force Technical Report AFFDL-TR-73-48, June 1973.

20. Whitney, J. M., and Nuismer, R. J., "Stress Fracture Criteria for Laminated Composites Containing Stress Concentrations," Journal of Composite Materials, Vol. 8, July 1974, pp. 253-264. 
TABLES 
TABLE 1. TESTS CONDUCTED FOR EACH LOADTNG MODE

Loading Mode

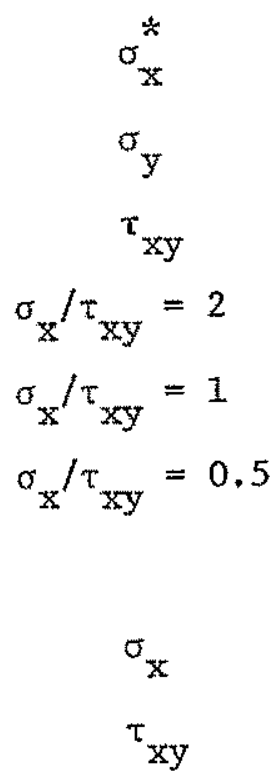

* $\mathrm{x}$ direction is parallel to the tube longitudinal axis.
Residual Strength

Fatigue Tests Tests

$[ \pm 45]$. Tubes

8

2

9

3

11

2

8

2

8

2

8

3

$[0 / 90]_{s}$ Tubes

4

3

3

2

59

19 
TABLE 2. UNIAXIAL FATIGUE OF $[+45]_{S}$ TUBES. AXTAL LOADING $(R=0 . \overline{1})$

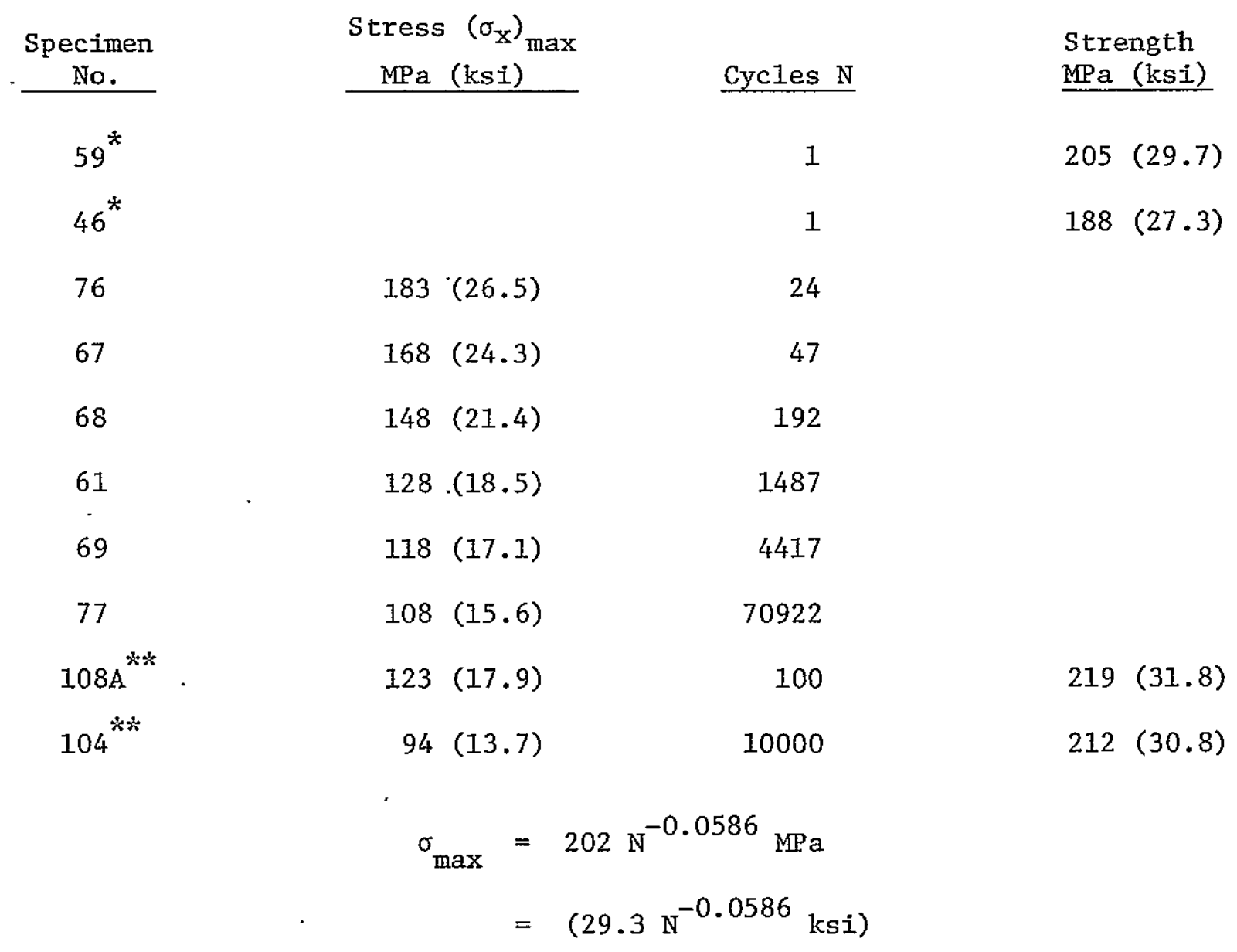

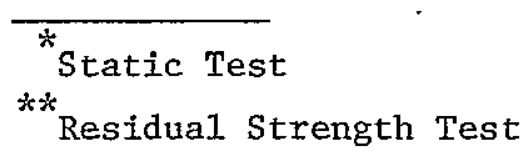


TABLE 3. REGRESSION ANALYSIS CONSTANTS FOR $[+45]_{S}$ FATIGUE TESTS $(R=0.1)$

\begin{tabular}{lccc}
\multicolumn{1}{c}{ Loading Mode } & Ratio & MPa (ksi) & B \\
\cline { 2 - 2 } & - & $202(29.3)$ & -0.0586 \\
Interna1 Pressure & - & $228(33.0)$ & -0.0405 \\
Torsion. & - & $209(30.3)$ & -0.0488 \\
Axial:Torsion & $1: 0.5$ & $190(27.6)$ & -0.0601 \\
Axial:Torsion & $1: 1$ & $154(22.3)$ & -0.0563 \\
Axial:Torsion & $1: 2$ & $103(14.9)$ & -0.0471 \\
&. &
\end{tabular}


TABLE 4. UNTAXIAL FATTGUE OF $[+45]_{\mathrm{S}}$ TUBES. INTERNAL PRESSURE LOADING $(\bar{R}=0.1)$

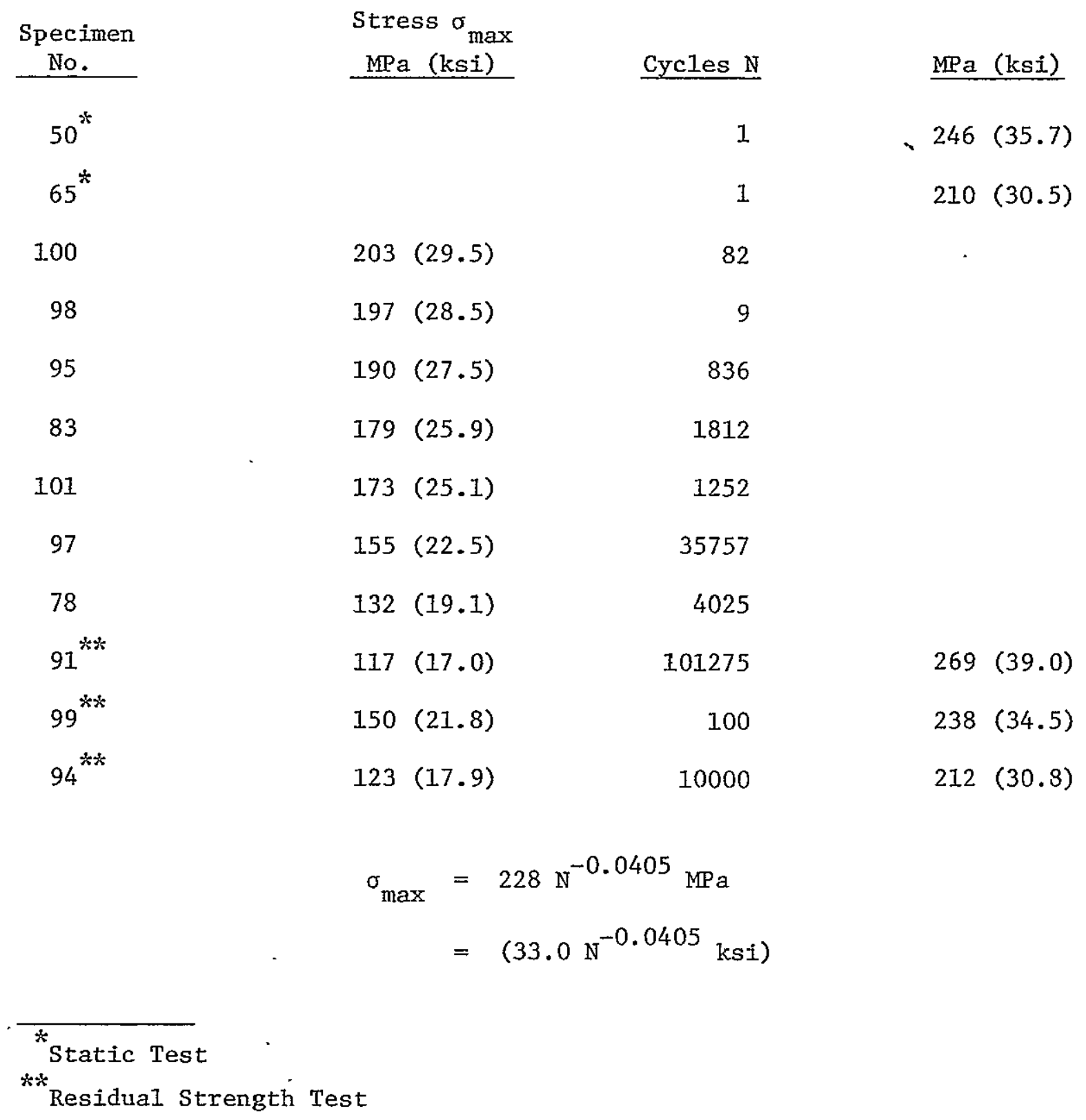


TABLE 5. UNIAXIAL FATIGUE QF $[+45]_{\mathrm{S}}$ TUBES. TORSIONAL LOADING $(R=\overline{0} .1)$

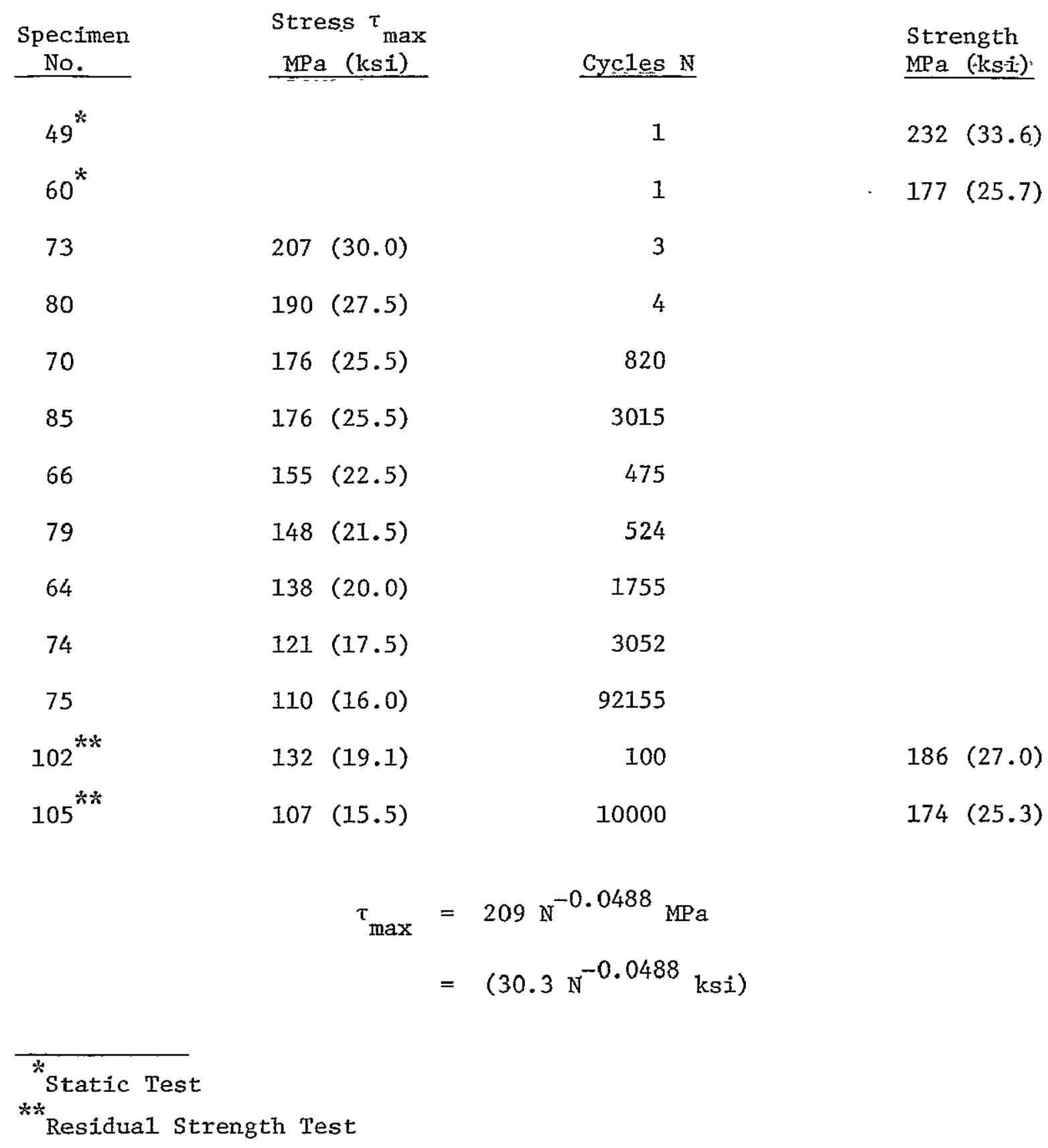


TABLE 6. UNIAXIAL FATIGUE OF $[0 / 90]_{\mathrm{s}}$ TUBES. AXIAL LOADING

\begin{tabular}{|c|c|c|c|}
\hline $\begin{array}{c}\text { Specimen } \\
\text { No. } \\
\end{array}$ & $\begin{array}{l}\text { Stress } \sigma_{\max } \\
\mathrm{MPa}(\mathrm{ksi}) \\
\end{array}$ & Cycles $N$ & $\begin{array}{l}\text { Strength } \\
\mathrm{MPa} \text { (ksi) }\end{array}$ \\
\hline $162^{*}$ & & 1 & $572(82.9)$ \\
\hline $166^{*}$ & & 1 & $489(70.9)$ \\
\hline 167 & $517(75)^{* * * x}$ & $I$ & \\
\hline 7 & $586(85)^{* \hbar \hbar}$ & 1 & \\
\hline \multirow[t]{3}{*}{$163 \mathrm{~A}^{2 * x}$} & $500(72.5)$ & 100860 & $698(101.2)$ \\
\hline & $483(70.0)$ & 104867 & \\
\hline & $448(65.0)$ & 100180 & \\
\hline $38^{* * *}$ & $496(72.0)$ & 101701 & $677(98.2)$ \\
\hline $129^{* *}$ & $207(30.0)$ & 101204 & $612(88.7)$ \\
\hline $\begin{array}{l}{ }^{*} \text { Static } \\
{ }^{*} * \text { Residu } \\
\text { *** }\end{array}$ & Test & . & \\
\hline
\end{tabular}


TABLE 7. UNTAXIAL FATIGUE OF $[0 / 90]_{s}$ TUBES. TORSION LOADING $(\mathrm{R}=0.1)$

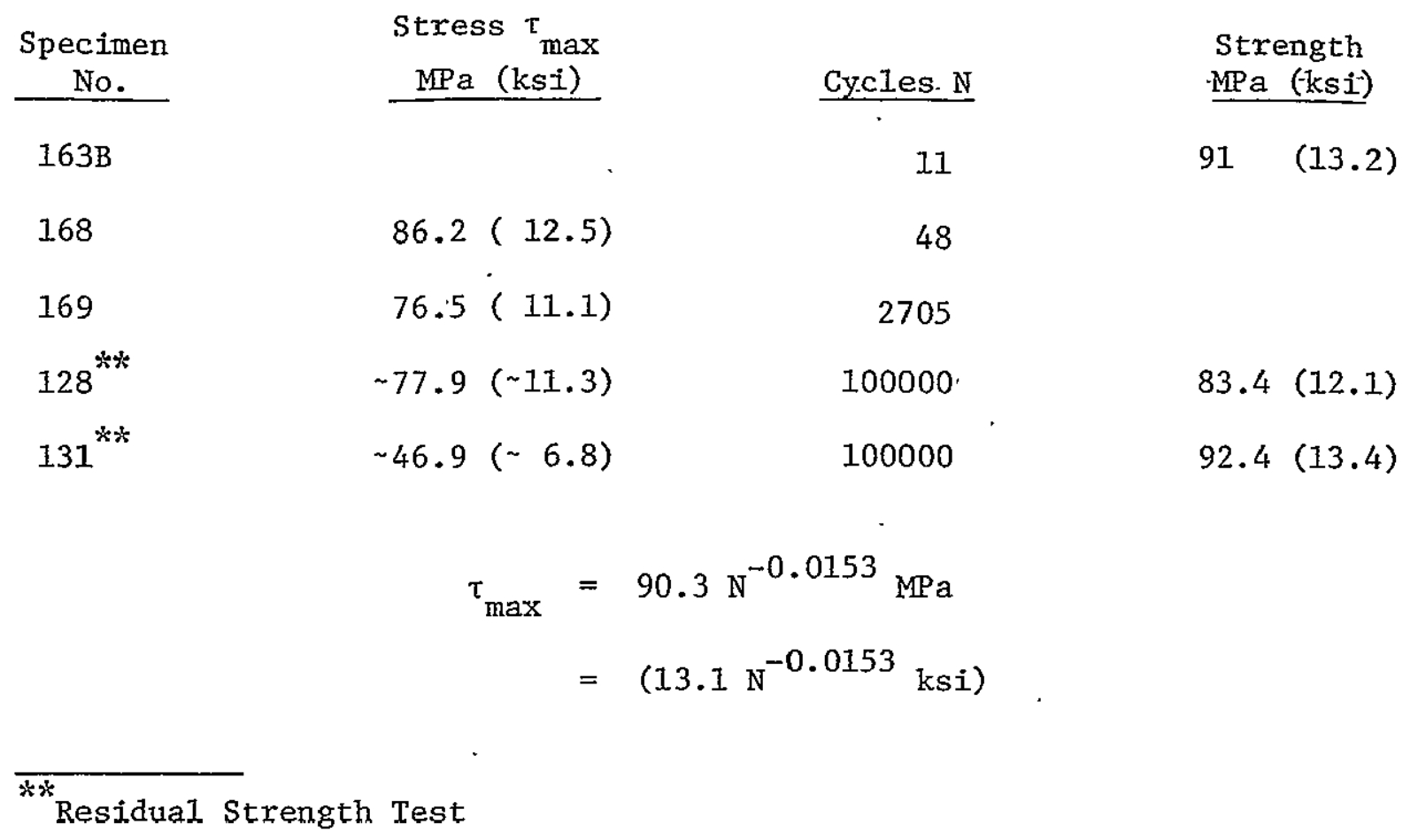


TABLE 8. REGRESSION ANALYSIS CONSTANTS FOR

$[0 / 90]_{S}$ FATIGUE TESTS $(\mathrm{R}=0.1)$

Loading Mode

Axial

Torsion $\underline{\text { Ratio }}$

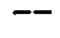

$-$
MPa (ksii)

A

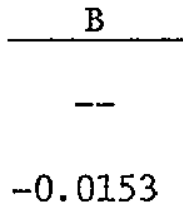

$\sigma_{\max }=\mathrm{AN}^{\mathrm{B}}$ 
TABLE 9. BIAXIAL FATIGUE OF $[+45]_{S}$ TUBES.

AXIAL:TORSION LOADING 1:0.5 $(R=0.1)$

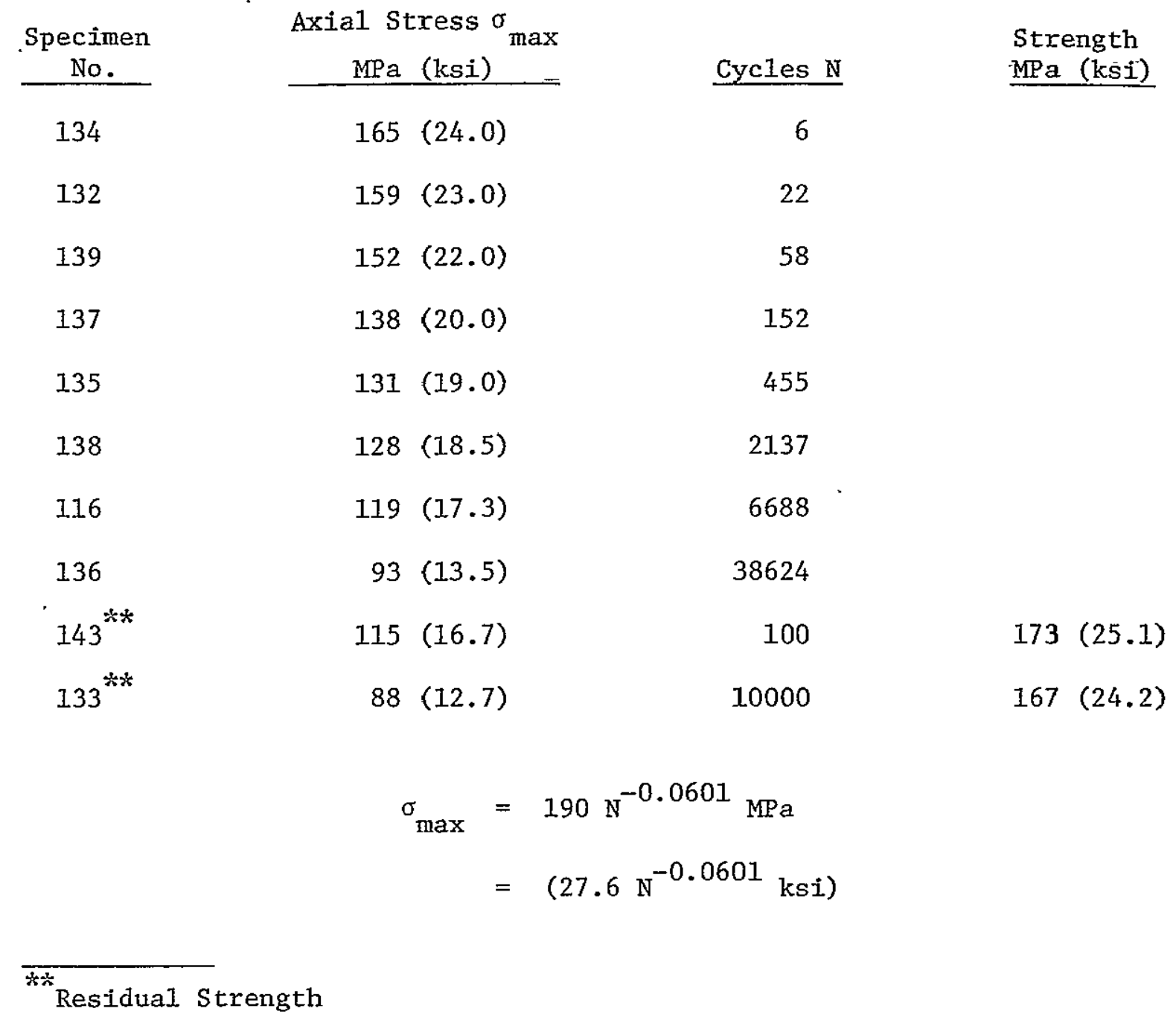



TABLE 10. BTAXIAL FATIGUE OF $[+45]_{\mathrm{S}}$ TUBES.
AXIAL:TORSION LOADING $1: 1(\overline{\mathrm{R}}=0.1)$

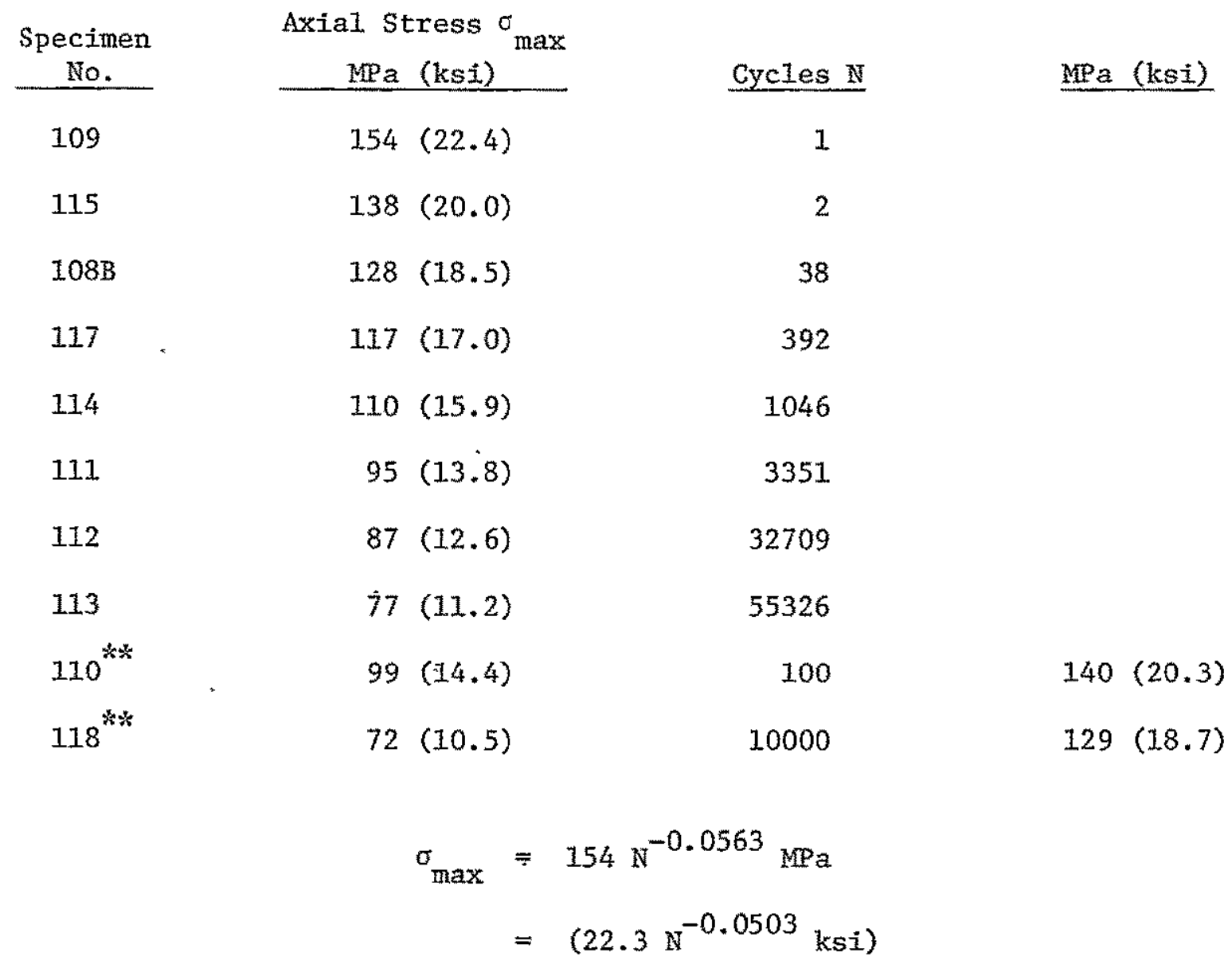

Residual Strength Test 
TABLE 11. BIAXIAL TATIGUE OF $[ \pm 45]_{S}$ TUBES. AXIAL:TORSTON LOADING $1: 2(\bar{R}=0.1)$

Specimen

No.

151

145

157

155

150

152

158

159

$161^{* *}$

$160^{* *}$

$156^{* * *}$

Residual Strength

$$
\begin{aligned}
\sigma_{\max } & =103 \mathrm{~N}^{-0.0471} \mathrm{MPa} \\
& =\left(14.9 \mathrm{~N}^{-0.0471} \mathrm{ksi}\right)
\end{aligned}
$$

Axial Stress $\sigma_{\max }$

$\mathrm{MPa}$ (ksi)

$90(13.0)$

$86(12.5)$

$80(11.6)$

Cÿclès N

86

47

822

$76(11.0)$

2837

$72(10.5)$

6865

$69(10.0)$

1062

$69(10.0)$

1354 .

$65(9.5)$

825

$66(9.6)$

100

179. $(25.9)$

$53(7.7)$

$10000^{\circ}$

$213(30.9)$

$55(8.0)$

100000

$152(22.1)$

MPa (ksi) 
TABLE 12. COMPARISON OF EXPERIMENTAL AND THEORETICAL AXIAL FATIGUE STRESSES FOR BIAXIAL LOADING OF GRAPHITE/EPOXY TUBES

Axial Tension-Torsion: MPa (ksi)

\begin{tabular}{|c|c|c|c|c|c|c|c|c|}
\hline & \multirow[b]{2}{*}{ Cycles } & \multicolumn{2}{|c|}{$1: 1$} & \multicolumn{3}{|c|}{$2: 1$} & \multicolumn{2}{|c|}{$1: 2$} \\
\hline & & Theory & Experiment & Theory & Exper & riment & Theory & Experiment \\
\hline & $10^{5}$ & $77.8(11.3)$ & $80.4(11.7)$ & $94.5(13.7)$ & 95.3 & $(13.8)$ & $51.6(7.5)$ & $59.8(8.7)$ \\
\hline & $10^{3}$ & $(14.5)$ & (15.1) & $(17.8)$ & 126 & $(18.2)$ & $65.2(9.5)$ & $74.3(10.8)$ \\
\hline
\end{tabular}


FIGURES 
$1250014 * 006$
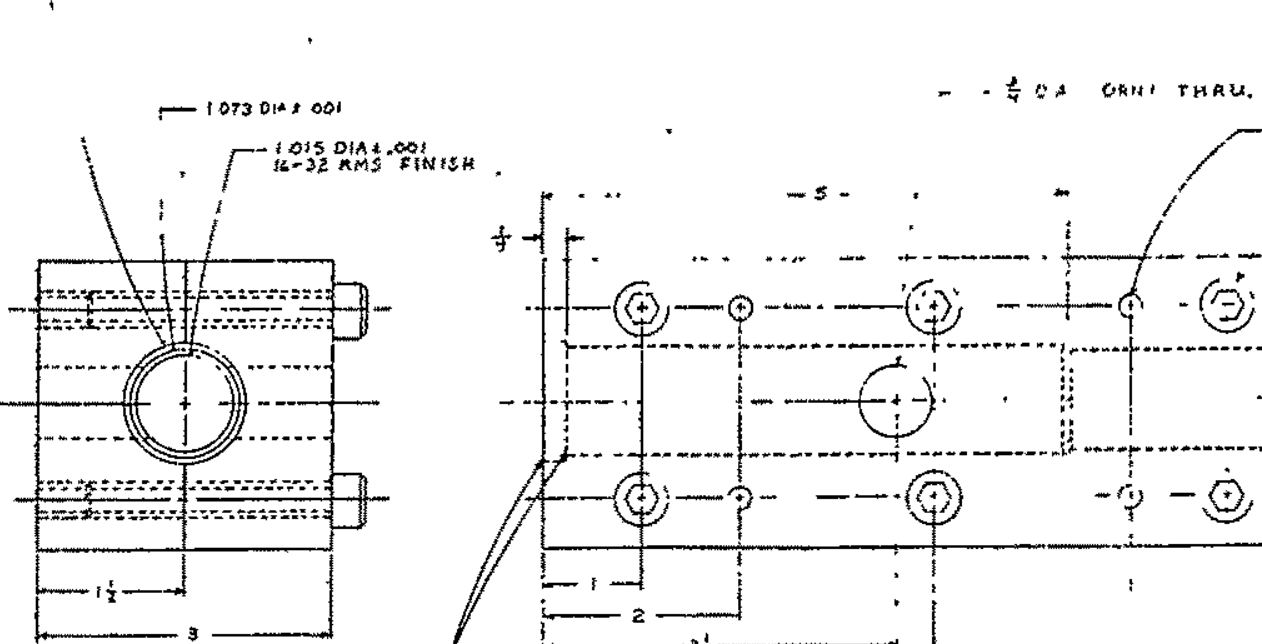

BREAK TO APPROX $D R$

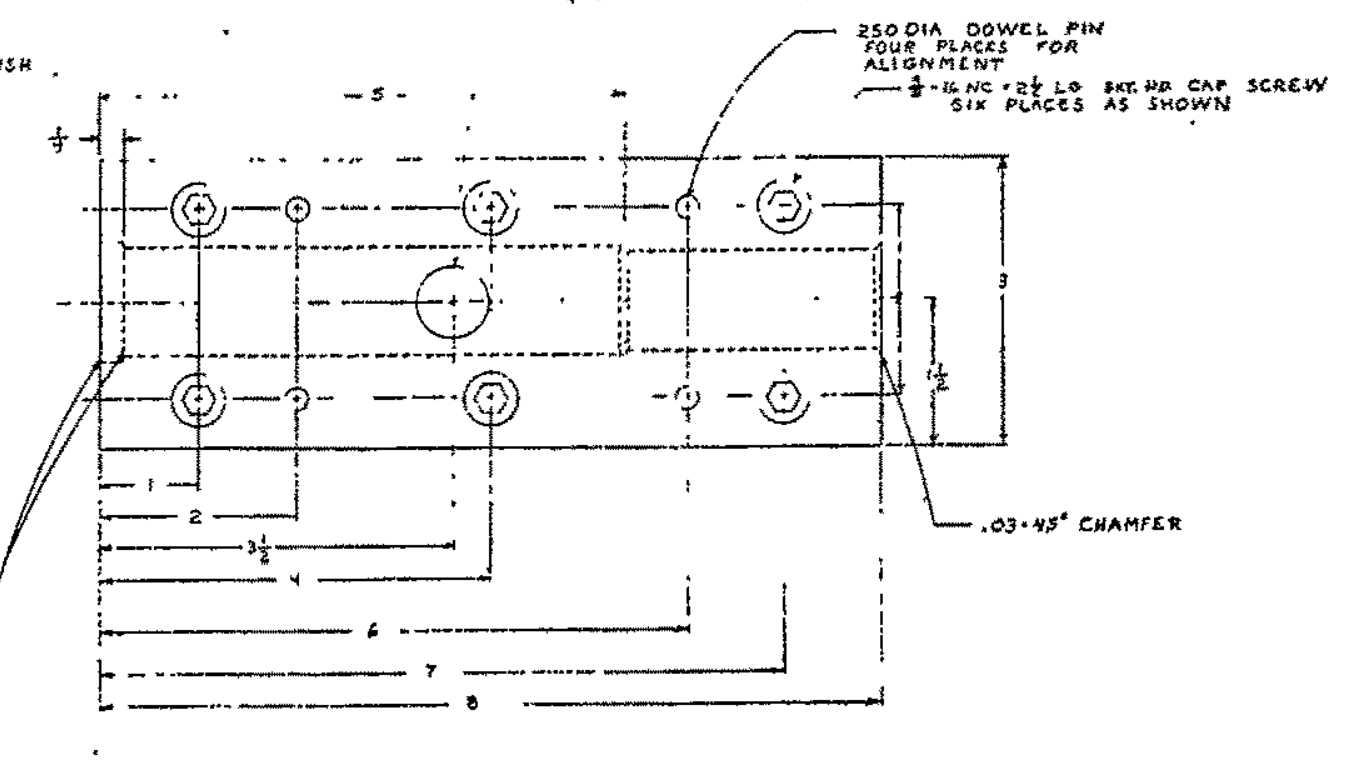

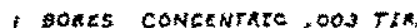

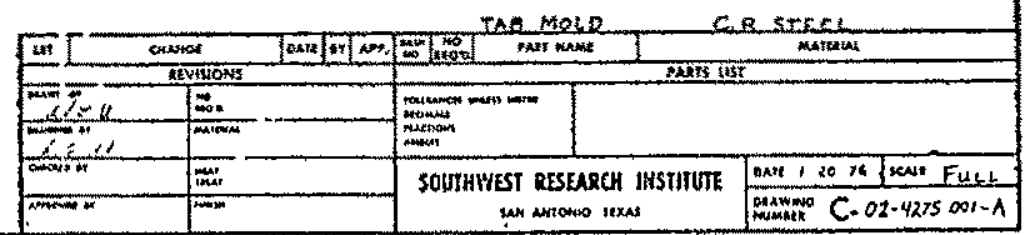

FIGURE 1. TAB MOLD MOUNT ASSEMBLY 


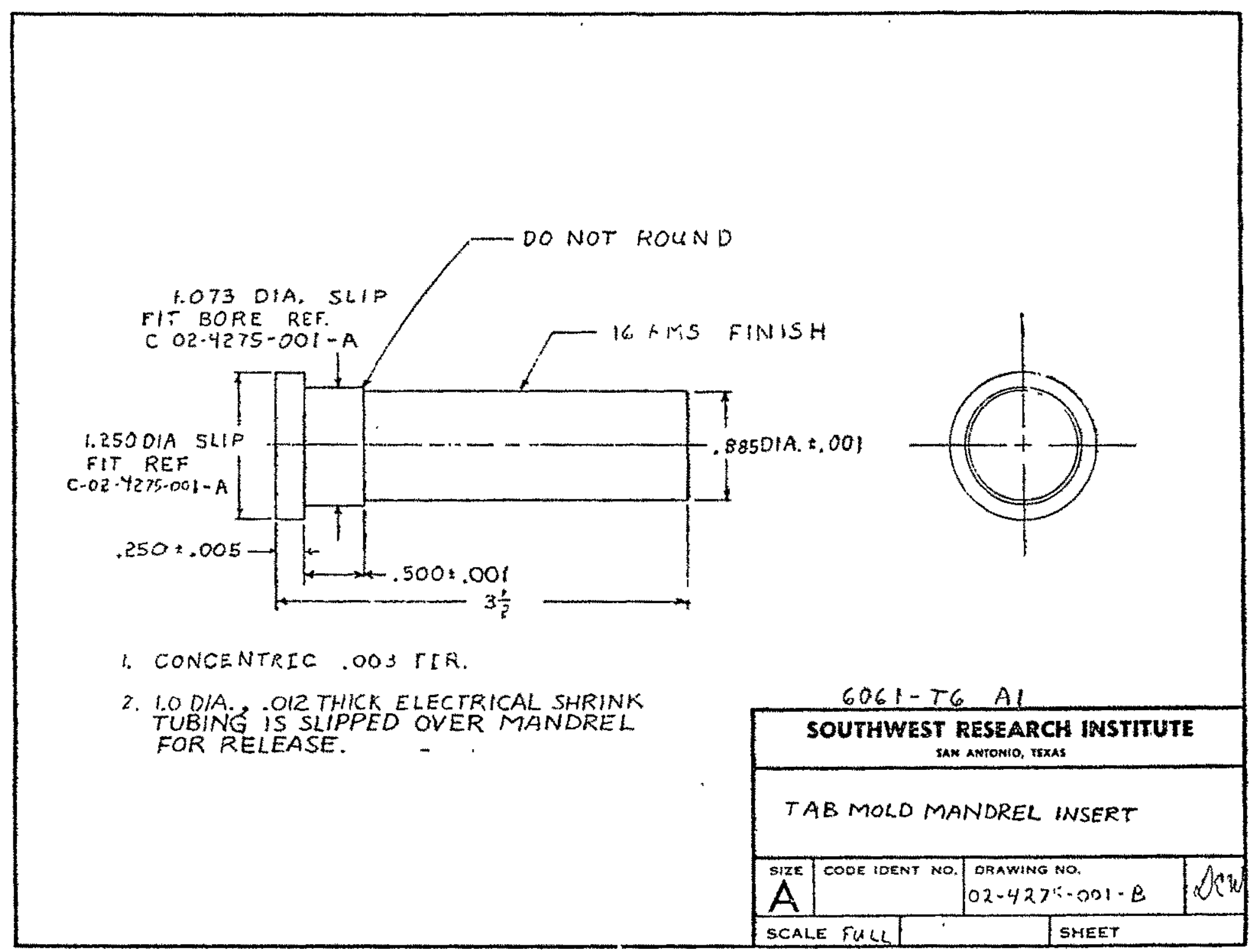

FIGURE 2. TAAB MOLD INSERT 


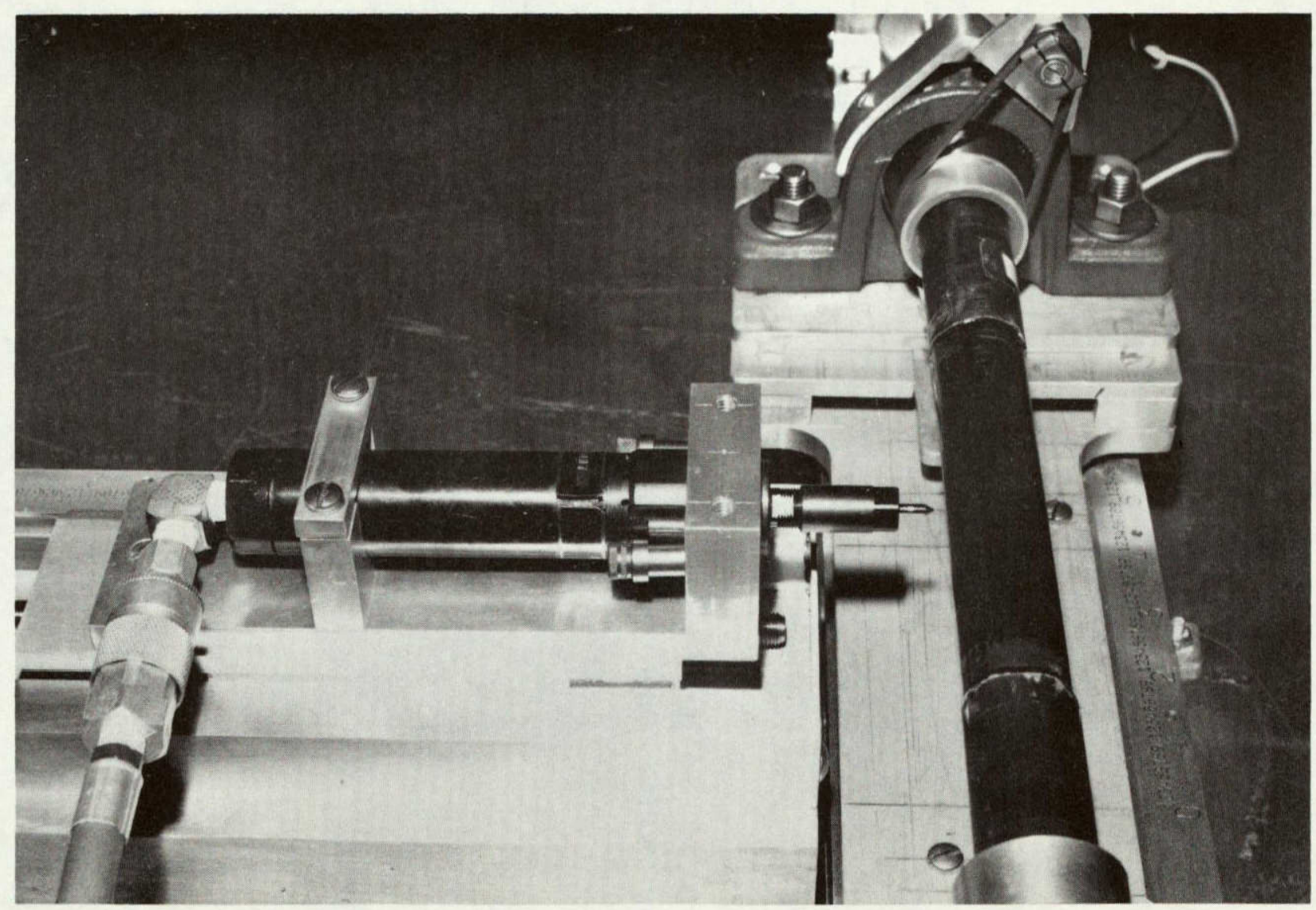

FIGURE 3. SWRI COMPOSITE SPECIMEN NOTCHING FIXTURE 


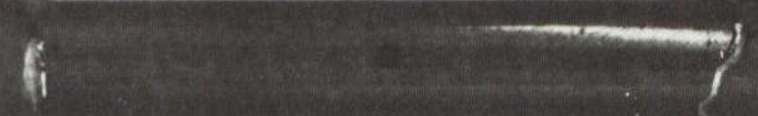

FIGURE 4. GRAPHITE/EPOXY TUBULAR SPECIMENS NOTCHED WITH 0.48-CM (3/16-IN.) HOLES 


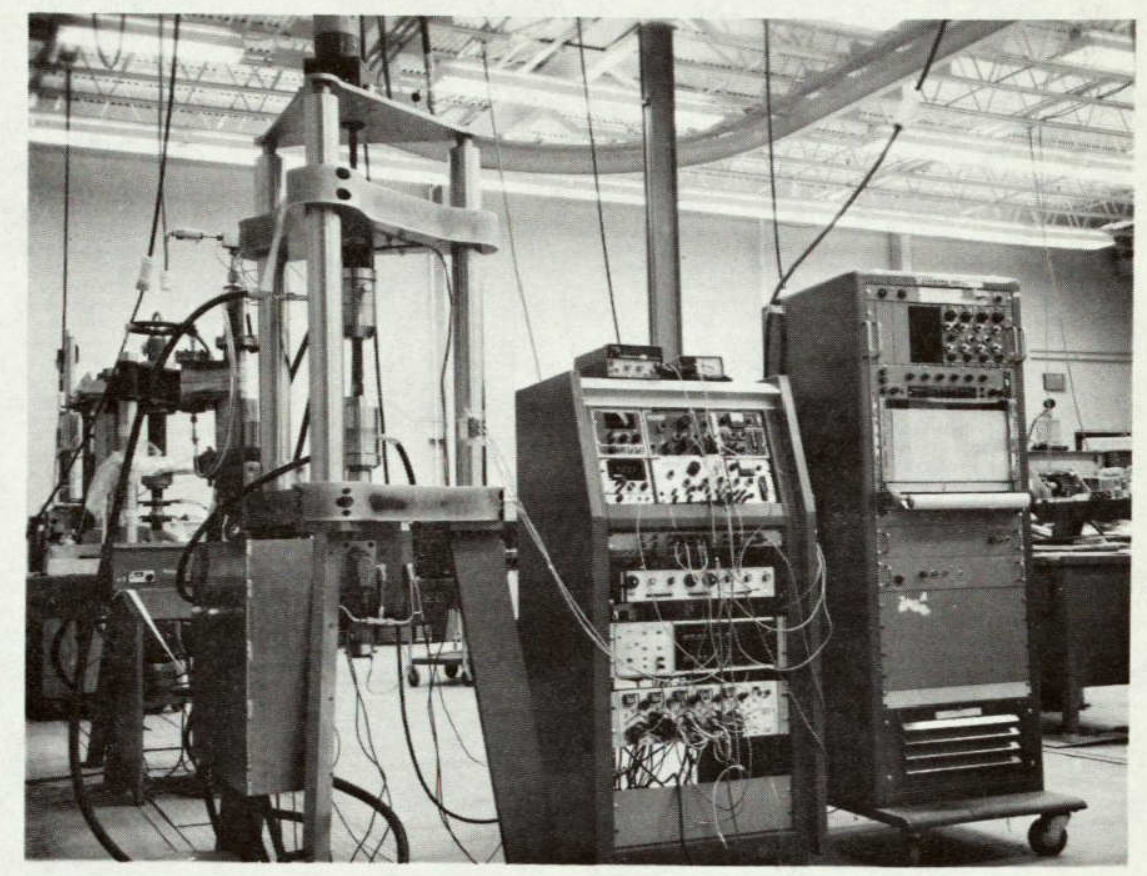

FIGURE 5. SWRI BIAXIAL TESTING FACILITY

ORIGINAL PAGE IS

OF POOR QUALITY 


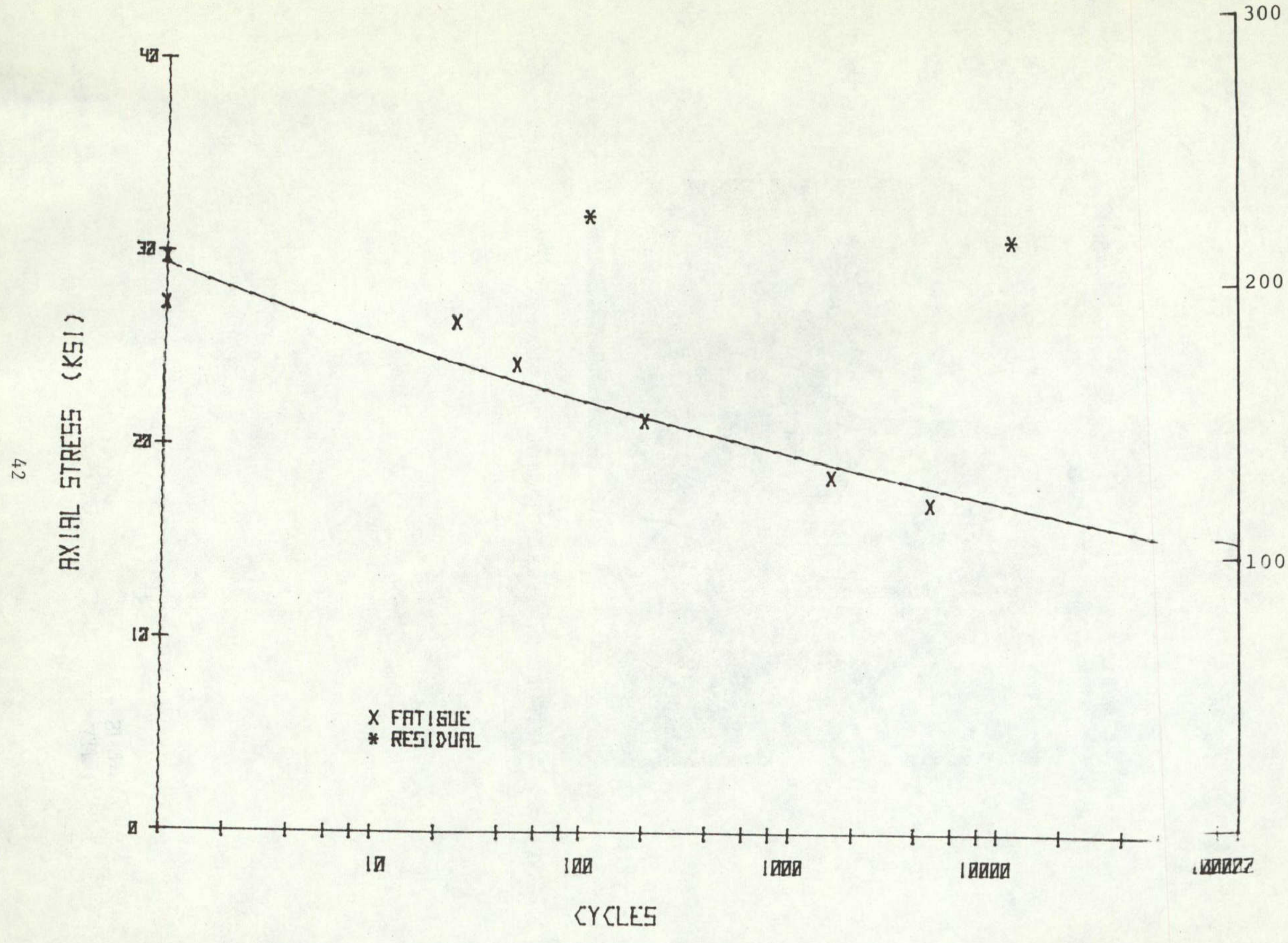

这

FIGURE 6. STRESS VS CYCLES FOR $[ \pm 45]_{S}$ TUBES UNDER AXIAL LOADING 


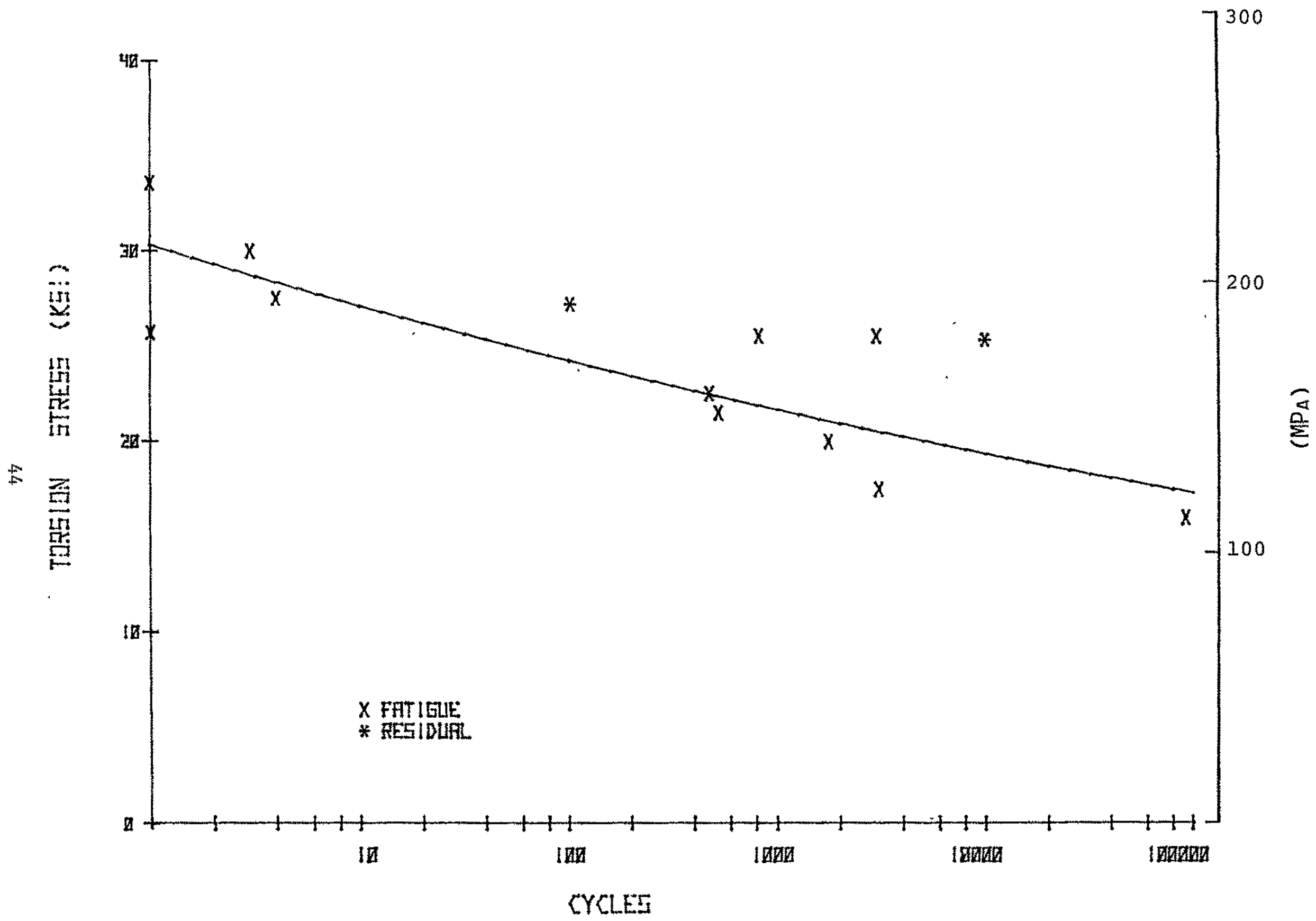

FIGURE 8. STRESS VS CYCLES FOR $[ \pm 45]_{s}$ TUBES UNDER TORSIONAI LOADING 


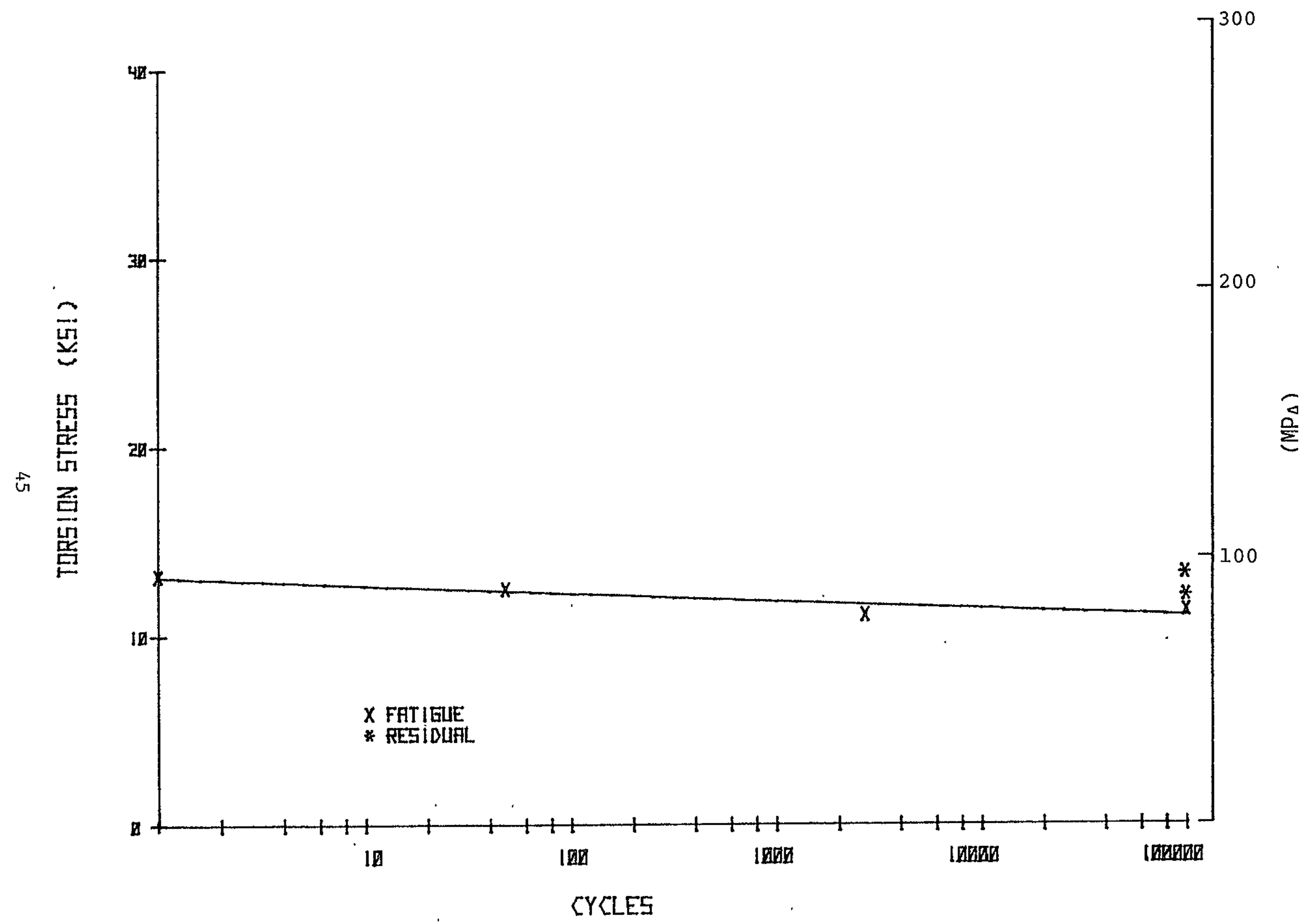

FIGURE 9. STRESS VS CYCLES FOR [0/90] TUBES UNDER TORSIONAL LOADING 


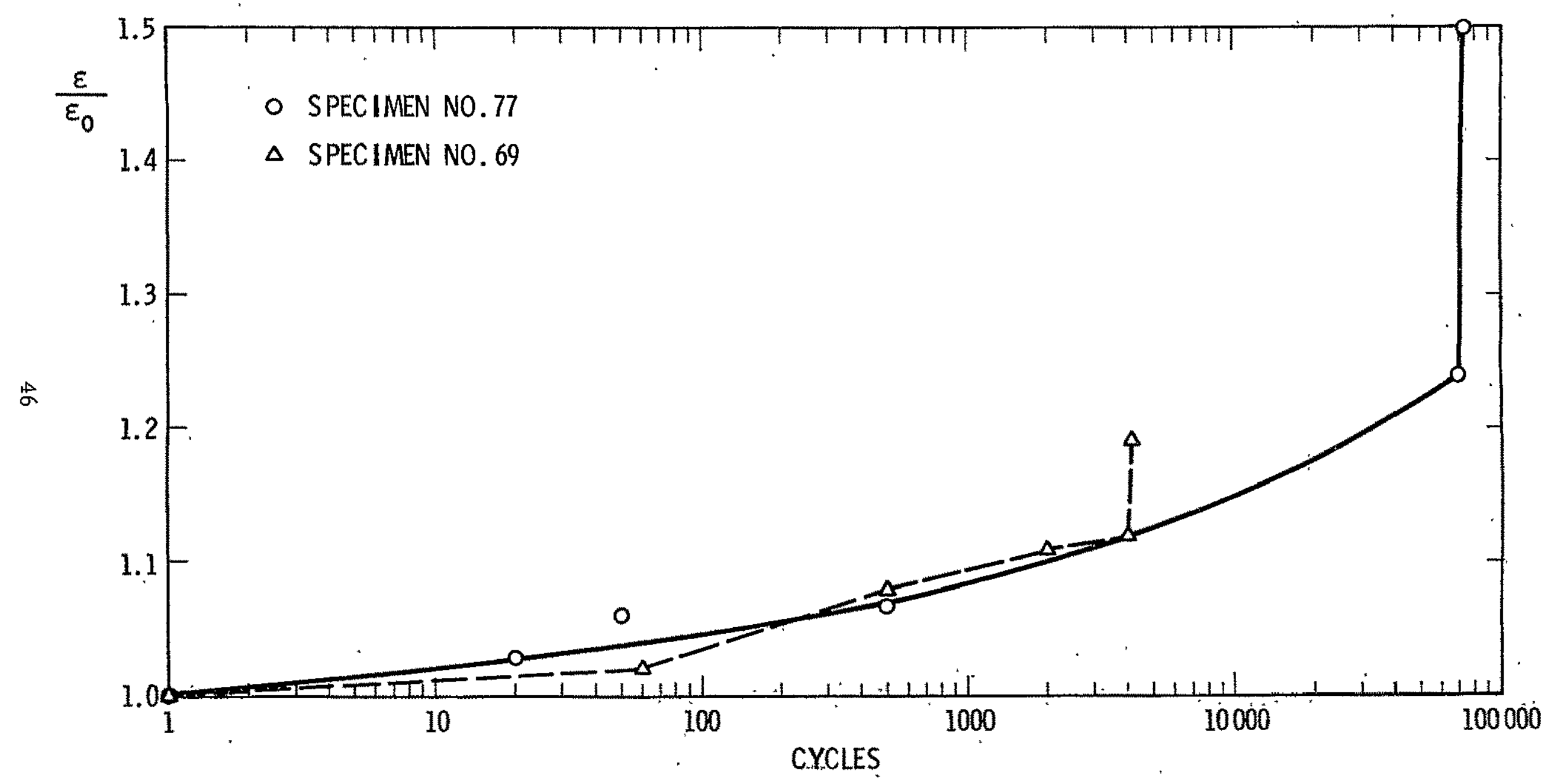

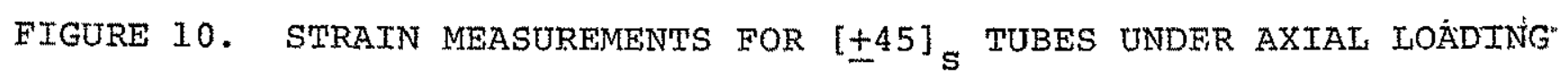




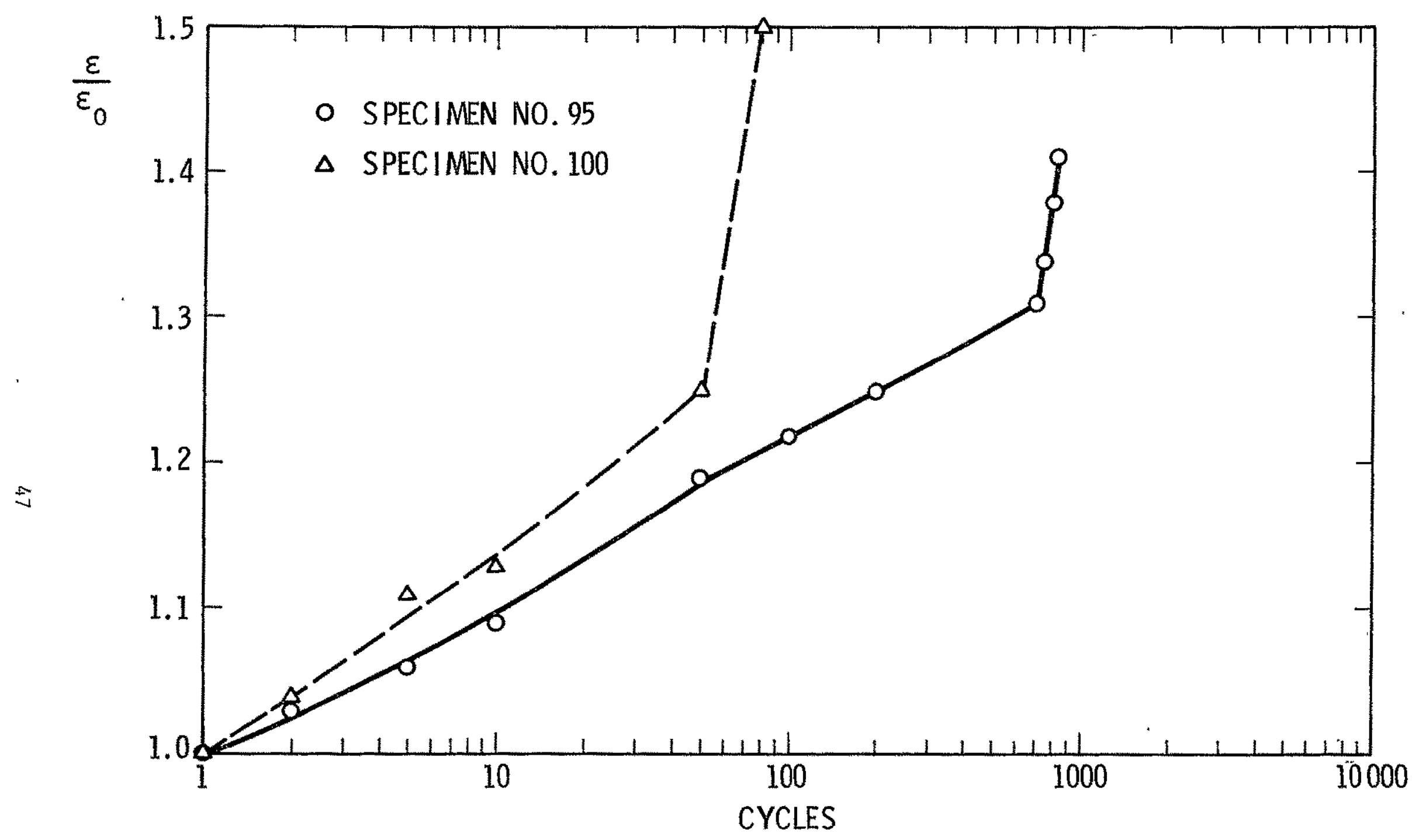

EIGURE 11. STRAIN MEASUREMENTS FOR $[ \pm 45] \mathrm{s}$ TUBES UNDER INTERNAI PRESSURE 


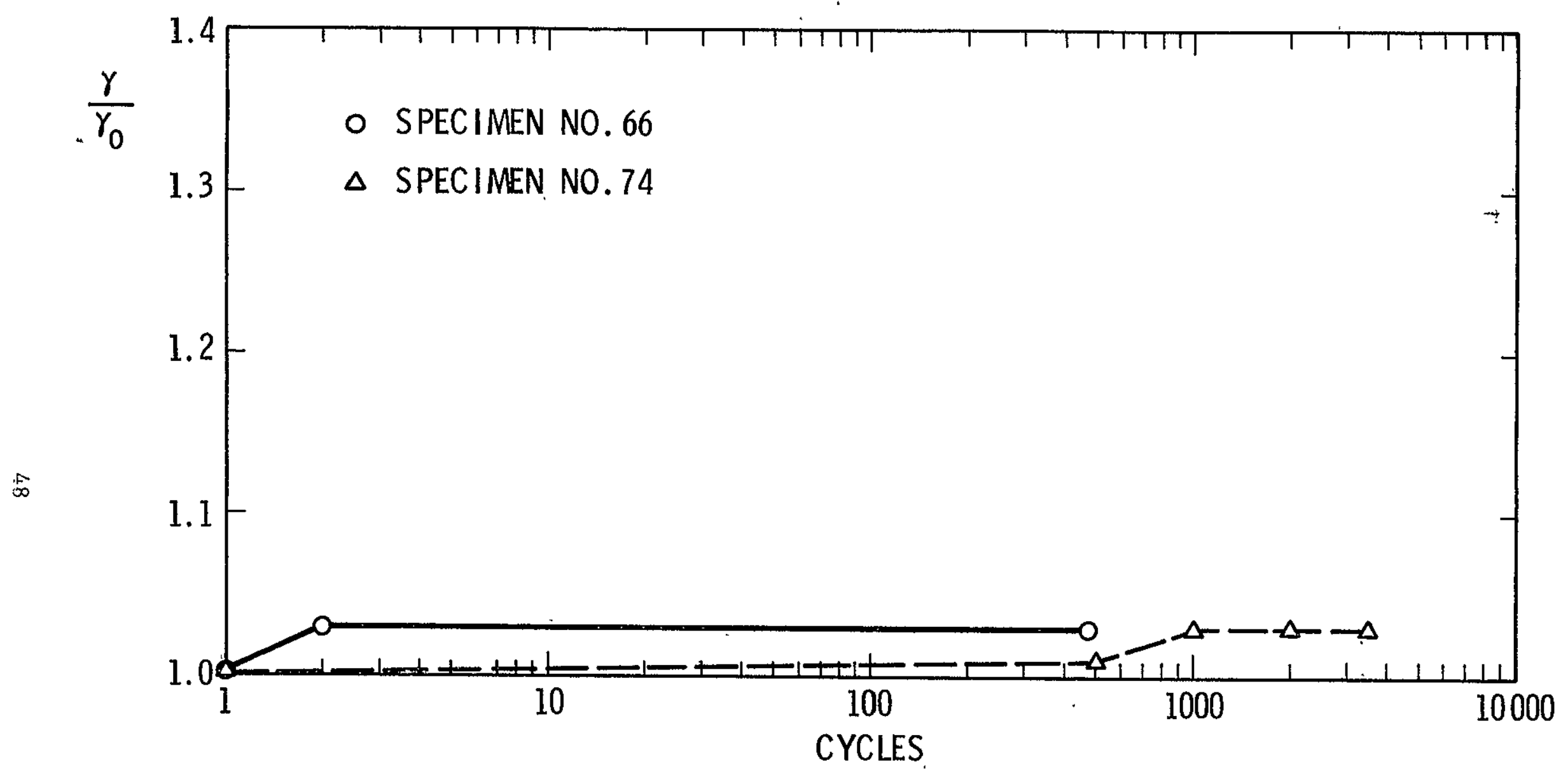

FIGURE 12. STRATN MEASUREMENTS FOR [445] S TUBES UNDER TORSIONAL LOADING 


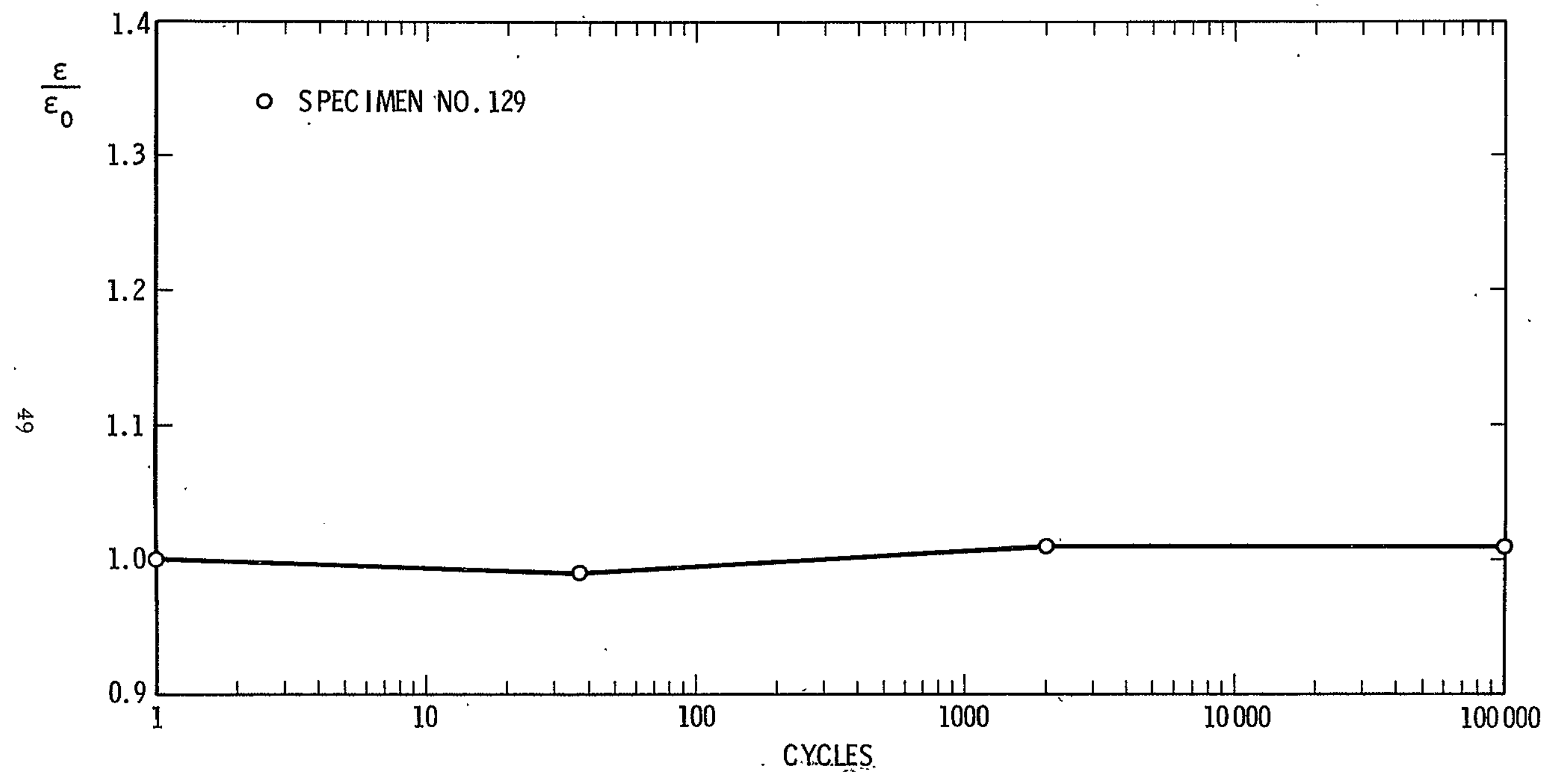

FIGURE 13. STRAIN MEASUREMENTS FOR [0/90] S TUBES UNDER AXIAL LOADING 


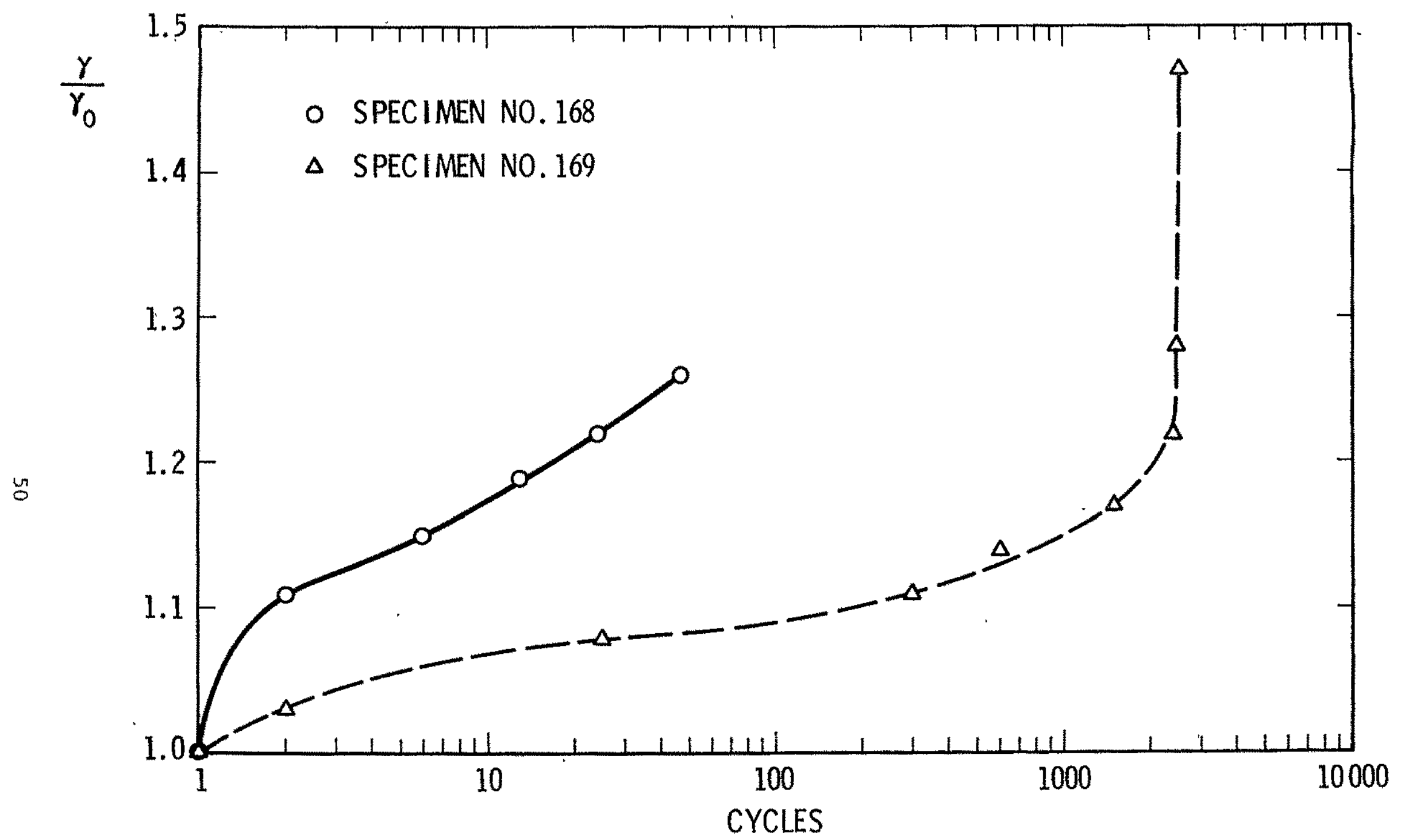

FIGURE 14. STRAIN MEASURFMENTS FOR [0/90] S TUBES UNDER TORSIONAL IOADING 


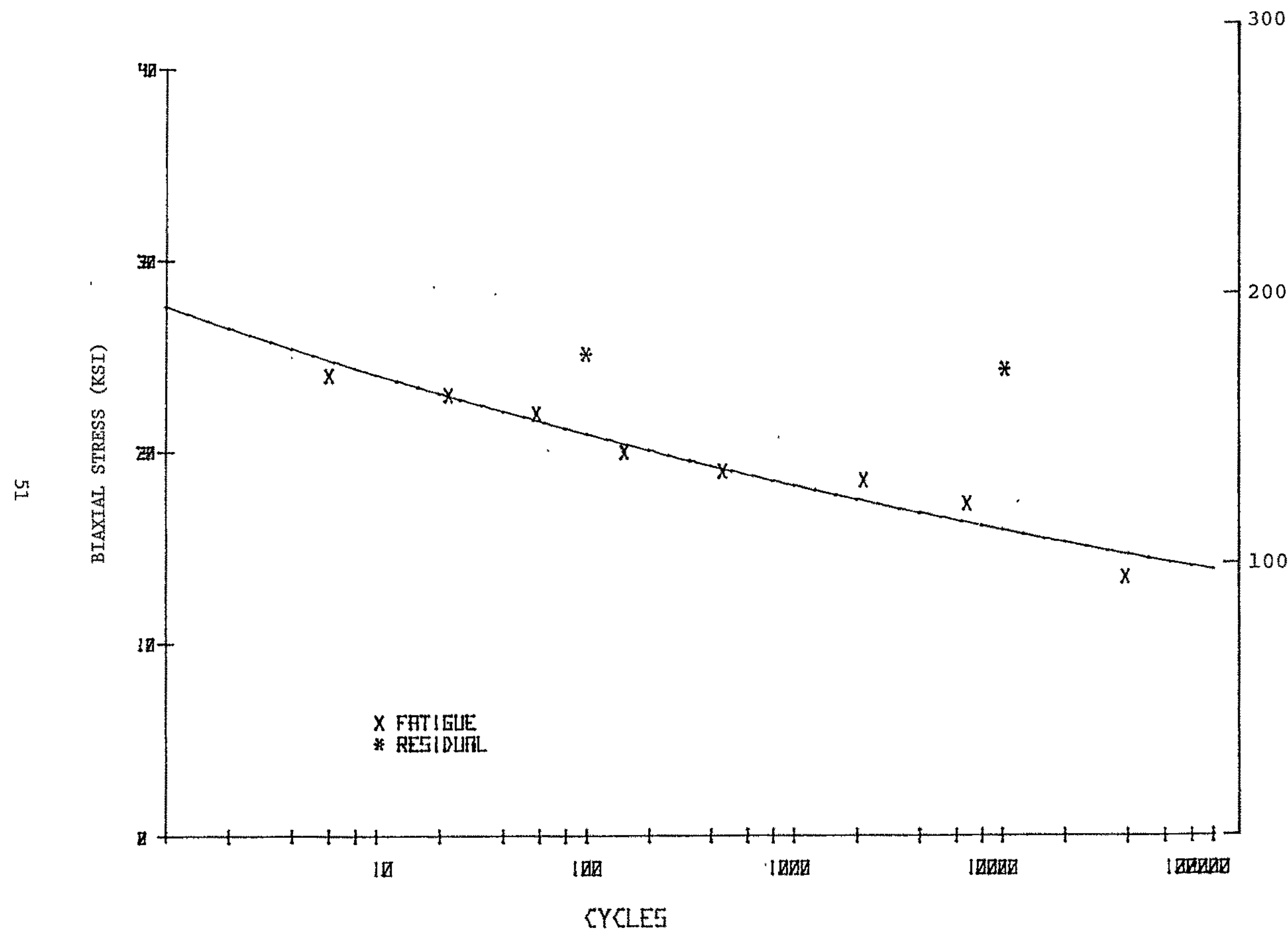

FIGURE 15. STRESS VS CYCLES FOR [+45] TUBES UNDER BIAXIAL IOADING WITH AXIAI:TORSION RATIO OF $2: 1$ 


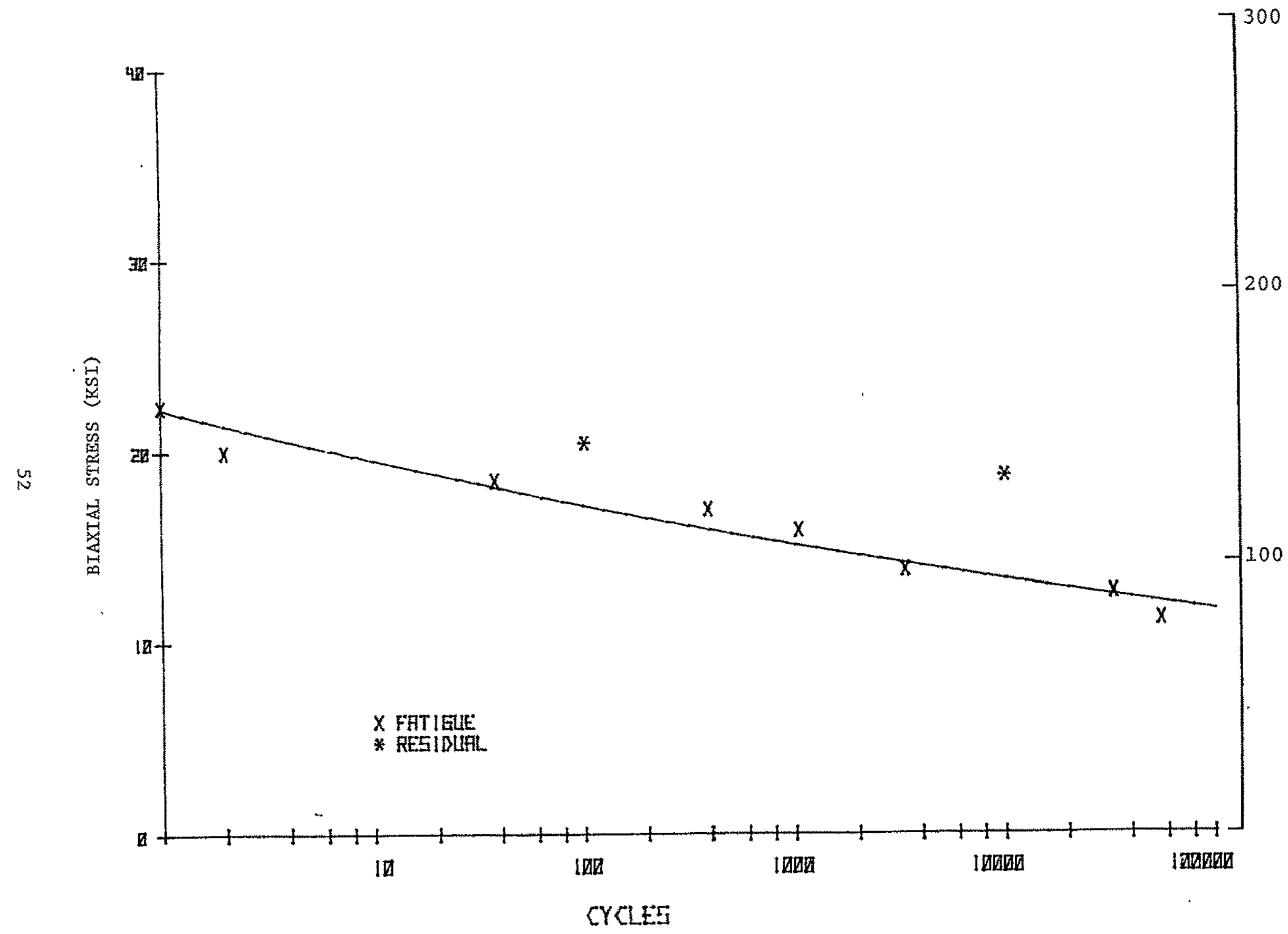

눌

FIGURE 16. STRESS VS CYCLES FOR $[+45]_{S}$ TUBES UNDER BIAXIAL LOADING WITH AXIAL : TORSION RATIO OF 1:I 


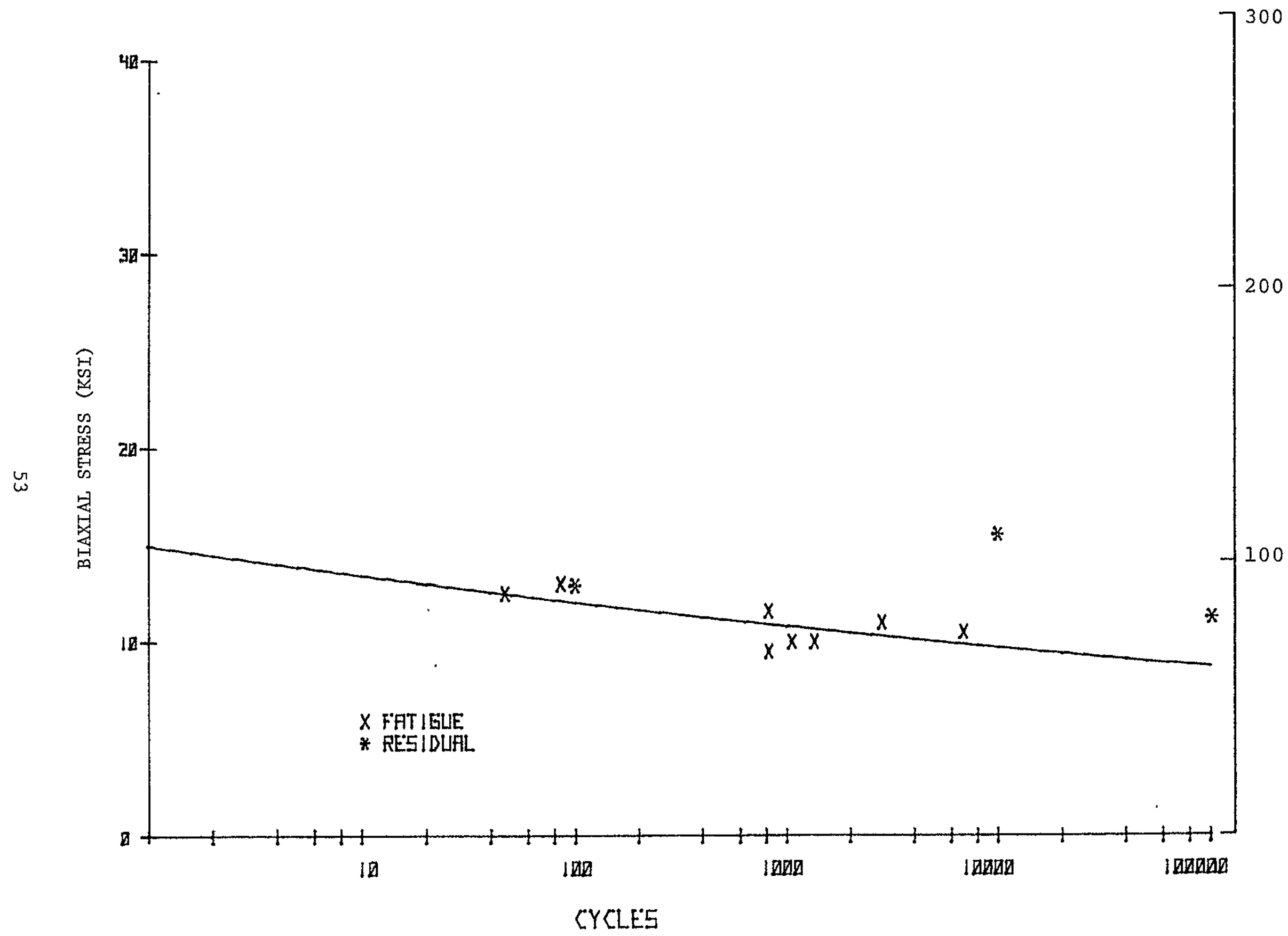

FIGURE 17. STRESS VS CYCLES FOR [+45]s TUBES UNDER BIAXIAL LOADING WITH AXIAL:TORSION RATIO OF $1: 2$ 


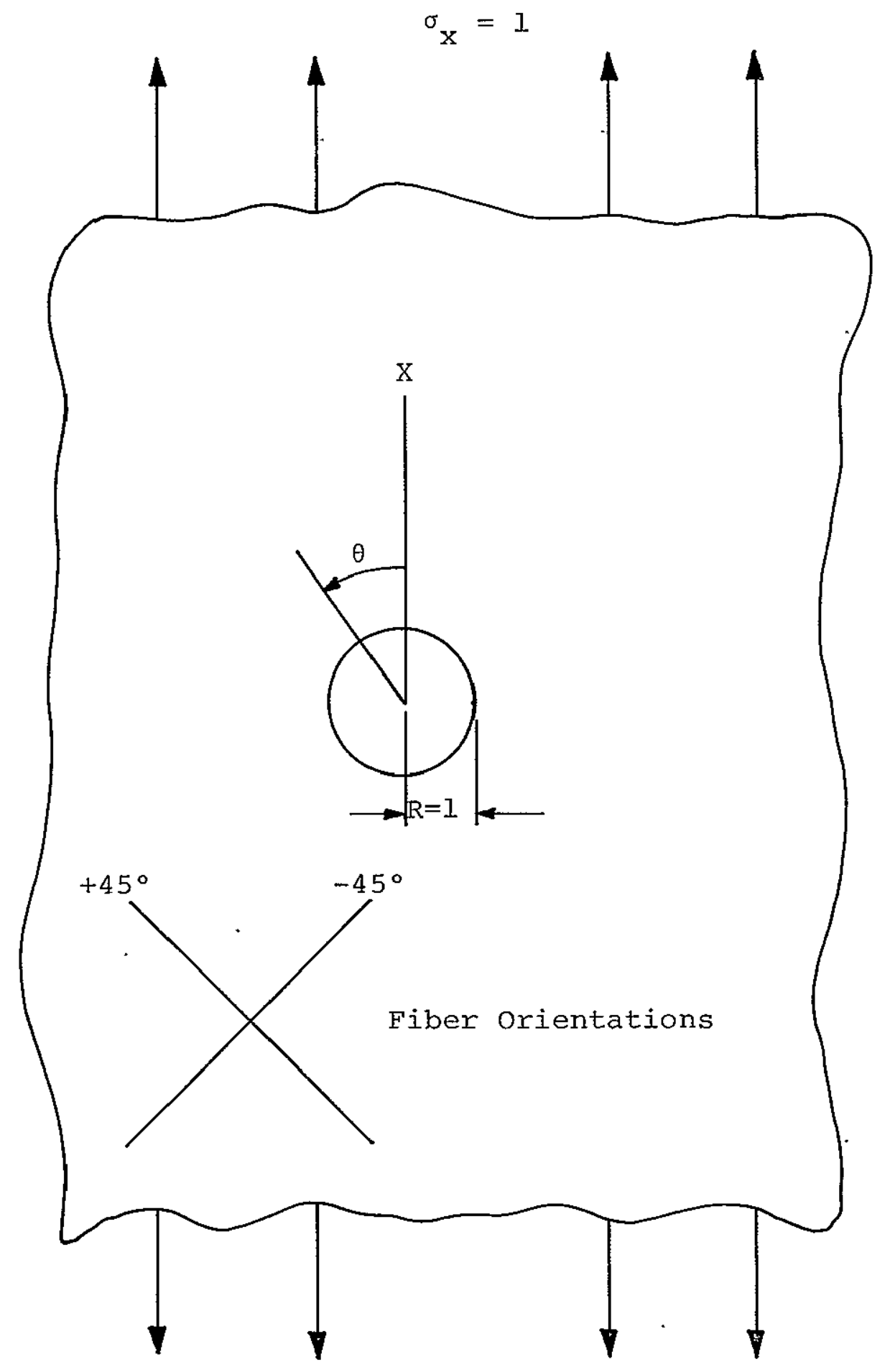

FIGURE 18. COMPOSITE TUBE $[ \pm 45]_{\mathrm{S}}$ SUBJECTED

TO AXIAL TENSILE STRESS, $\sigma_{\mathrm{x}}=1$. 


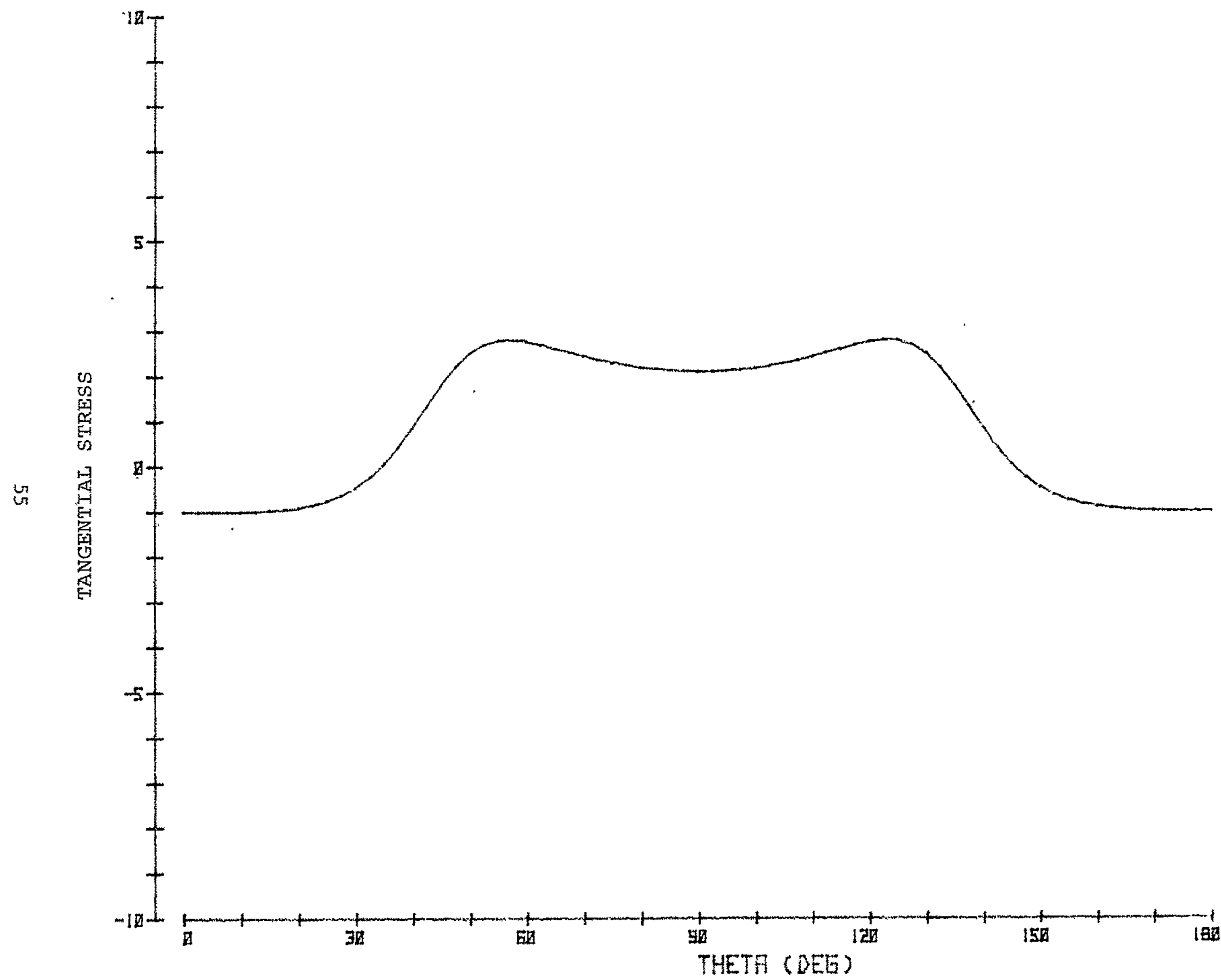

FIGURE 19. TANGENTIAI STRESS AROUND A HOLE IN A $[ \pm 45]_{\mathrm{s}}$ LAMINATE WITH $\sigma_{\mathrm{x}}=1$ 


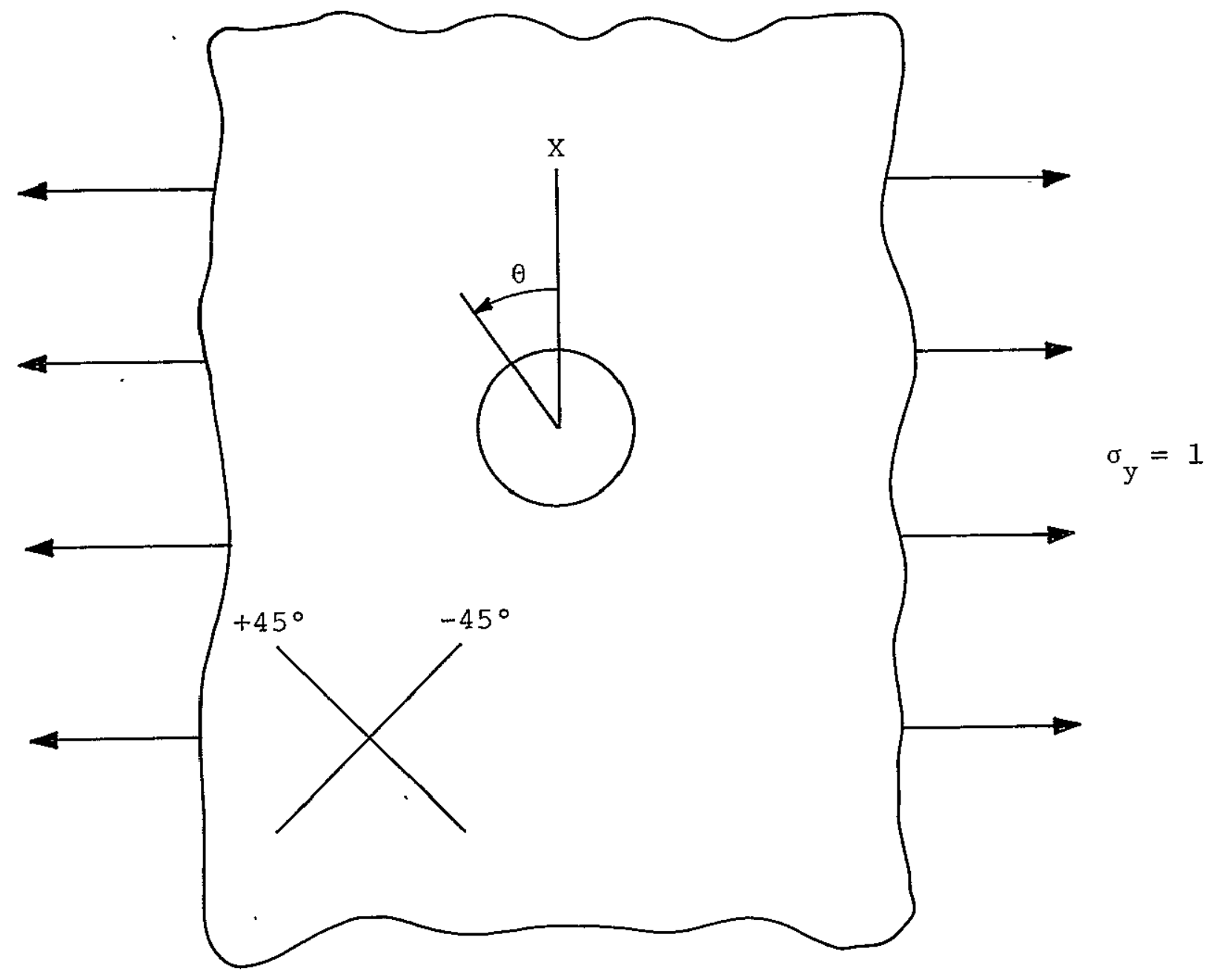

FIGURE 20. COMPOSITE TUBE SUBJECTED TO INTERNAL PRESSURE STRESS, $\sigma_{\mathrm{y}}=1$. 

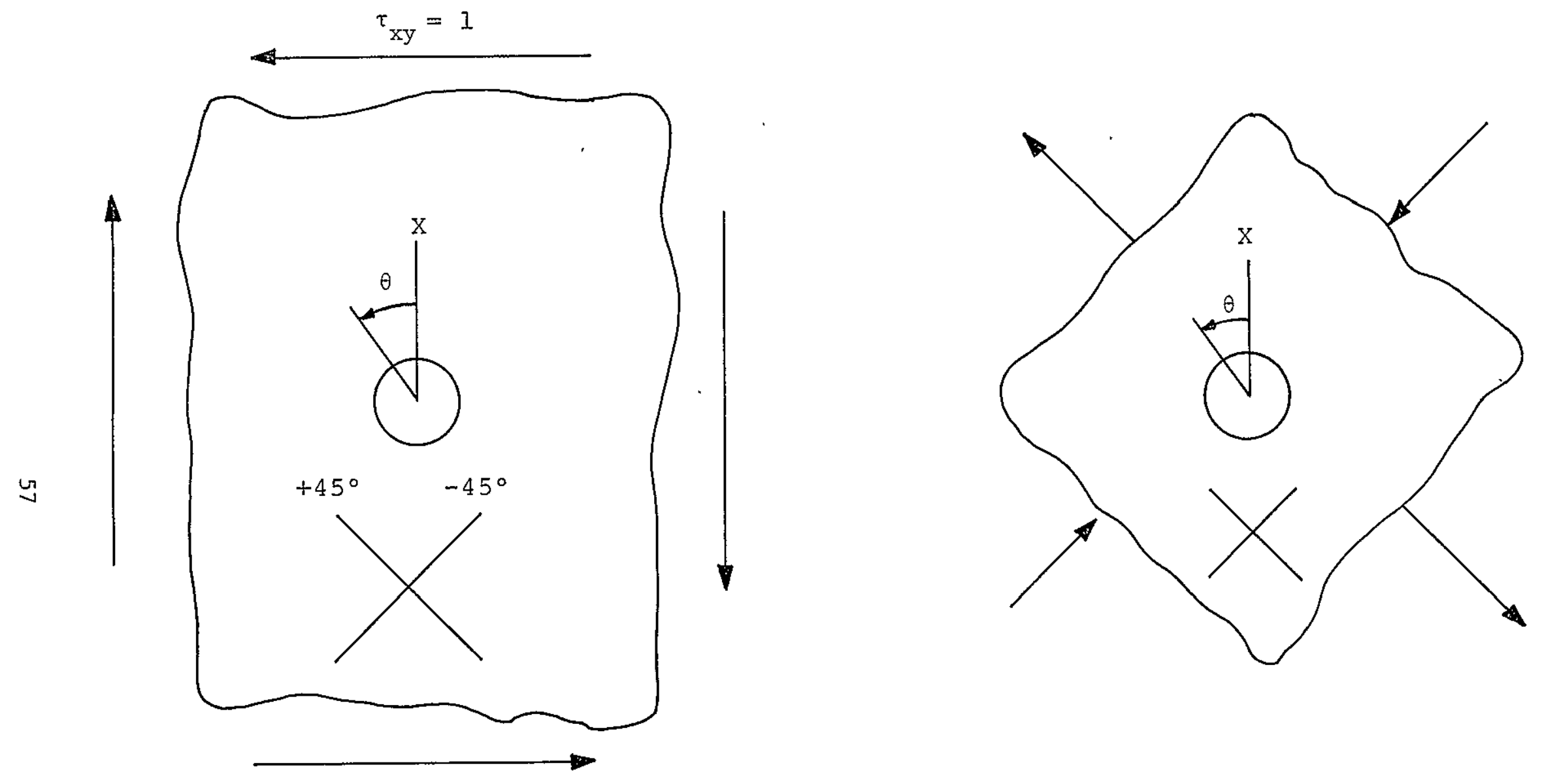

FIGURE 21. COMPOSITE TUBE SUBJECTED TO TORSIONAL STRESS, $\tau_{\mathrm{xy}}=1$. 


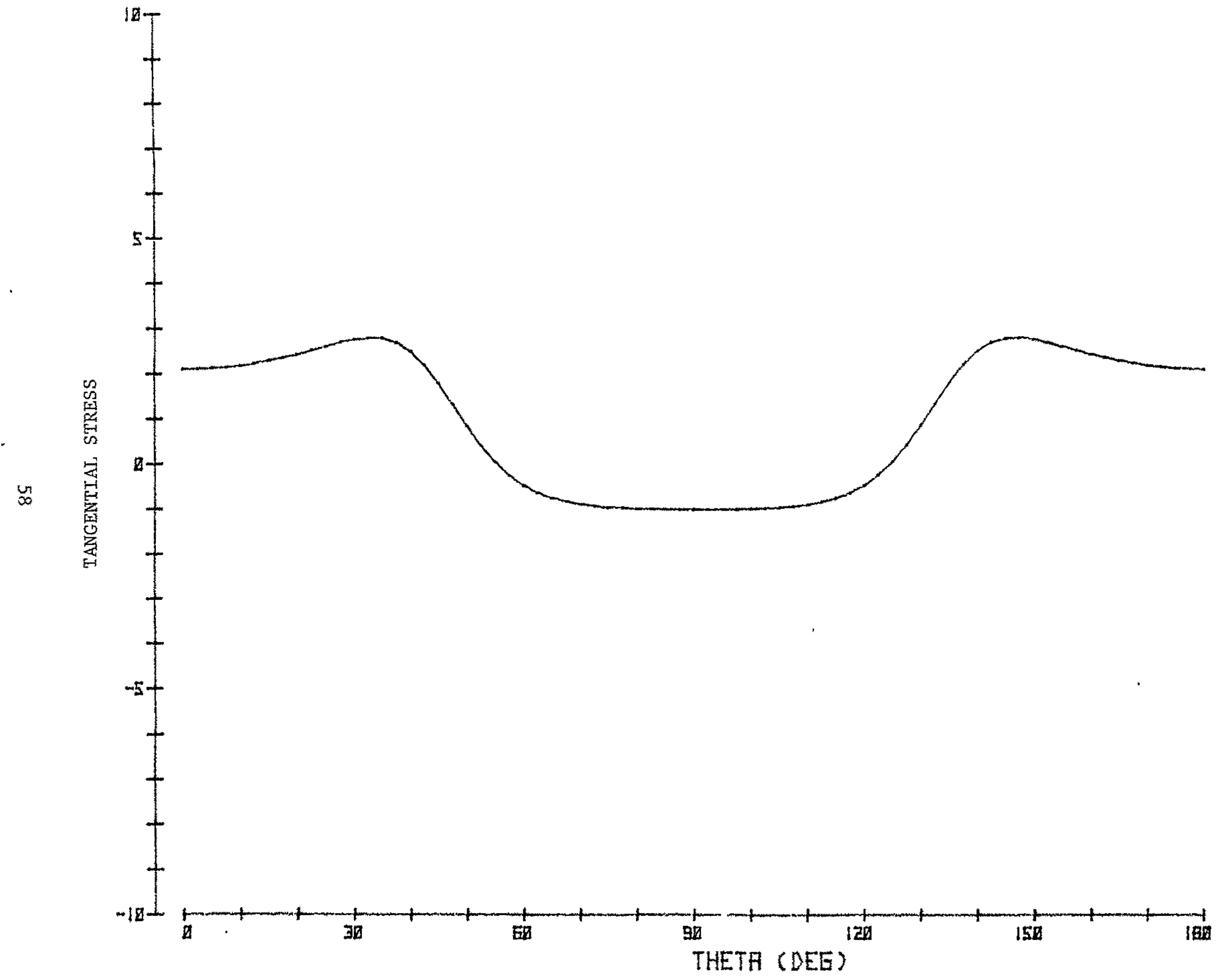

FIGURE 22. TANGENTIAI STRESS AROUND A HOLE IN A $[ \pm 45]_{\mathrm{S}}$ LAMINATE WITH $\sigma_{\mathrm{Y}}=1$ 


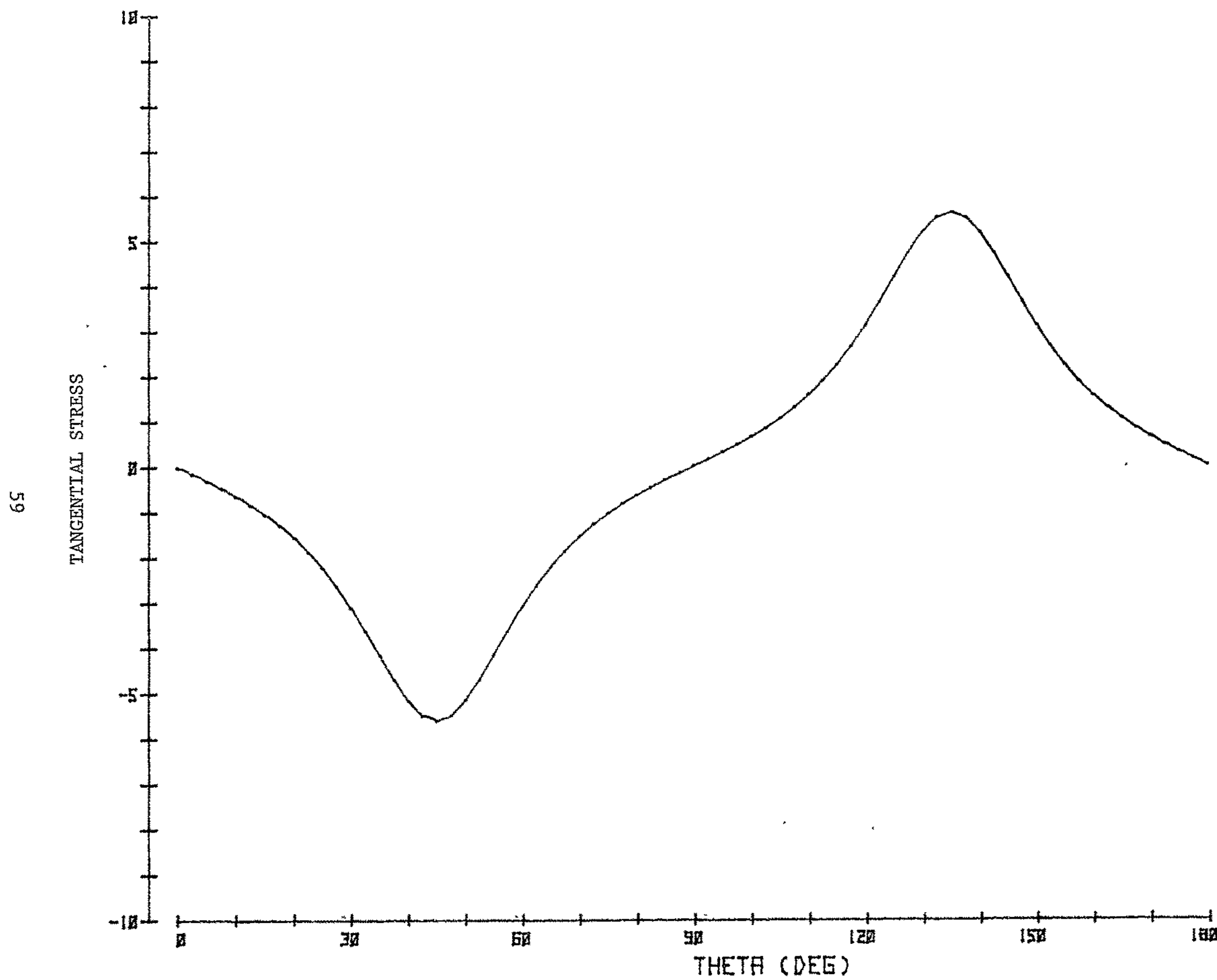

FIGURE 23. TANGENTIAI STRESS AROUND A HOLE IN A $[ \pm 45]_{S}$ LAMINATE WITTH $\tau_{x y}=1$ 


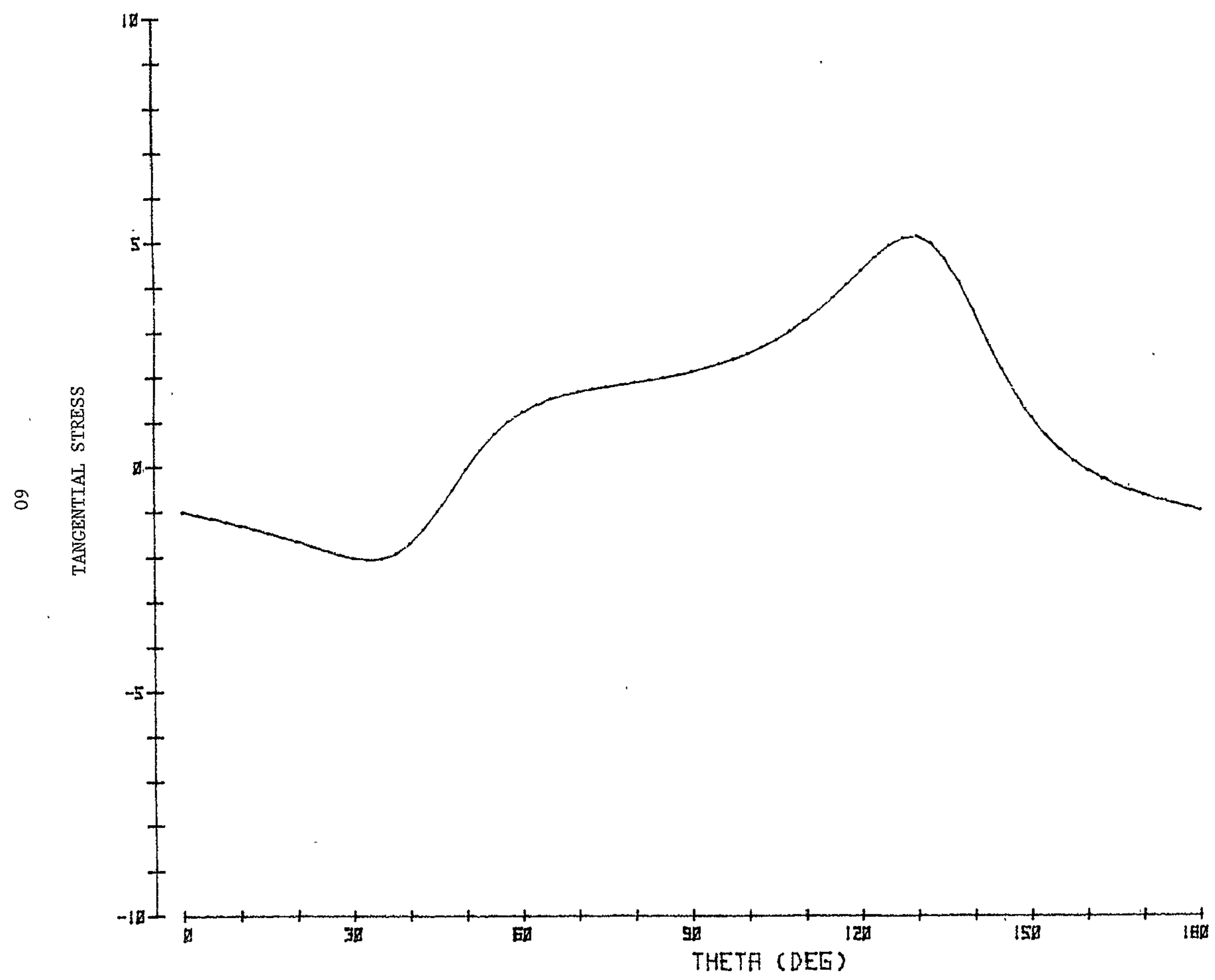

FIGURE 24. TANGENTIAI STRESS AROUND A HOLE IN A [+45]S LAMINATE UNDER BIAXIAI LOADING WITH AXIAI:TORSION RATIO OF $2: 1$ 


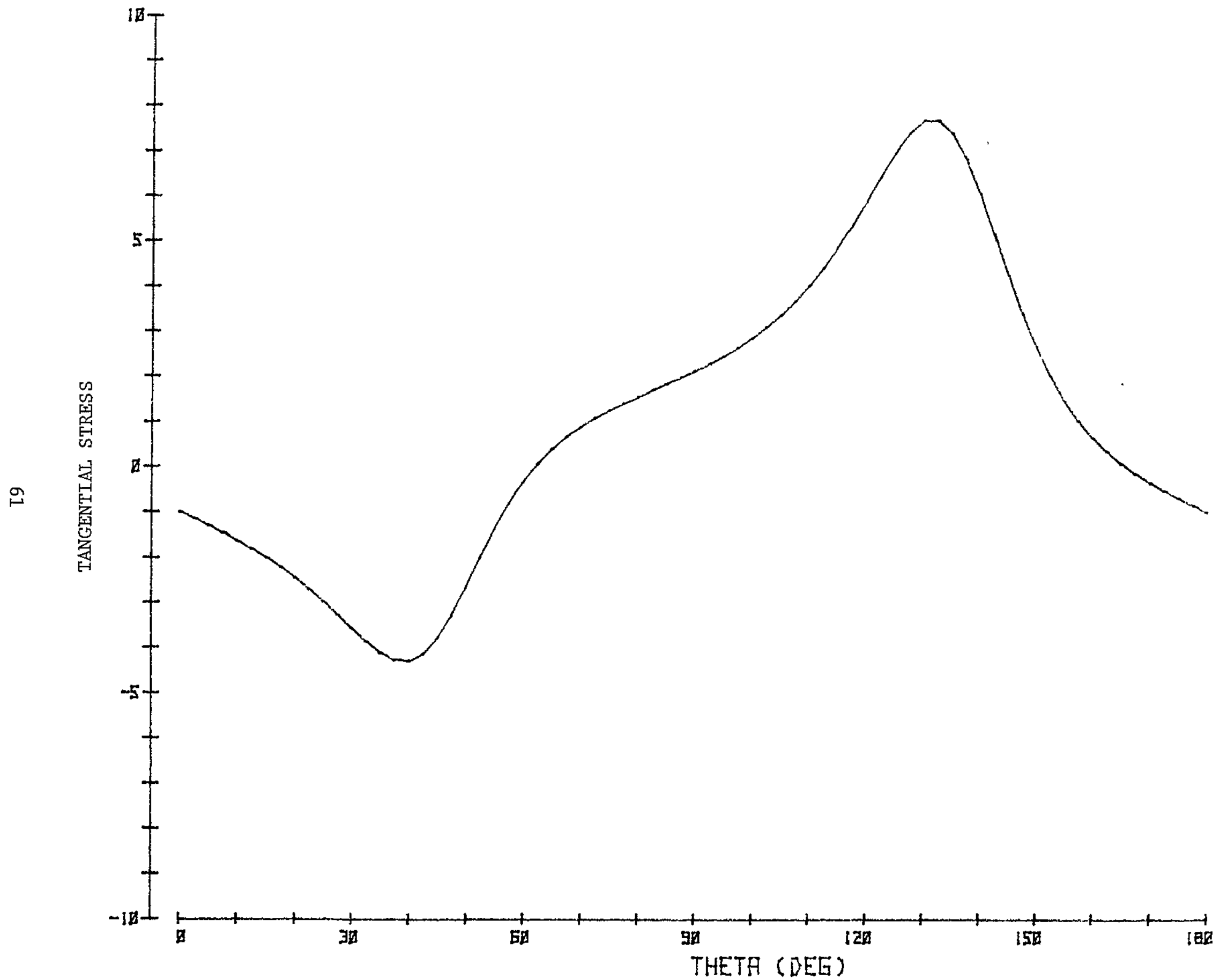

FTGURE 25. TANGENTIAL STRESS AROUND A HOLE IN A [+45] S LAMINATE UNDER BIAXIAL LOADING WITH AXIAL:TORSION RATIO OF $1: 1$ 


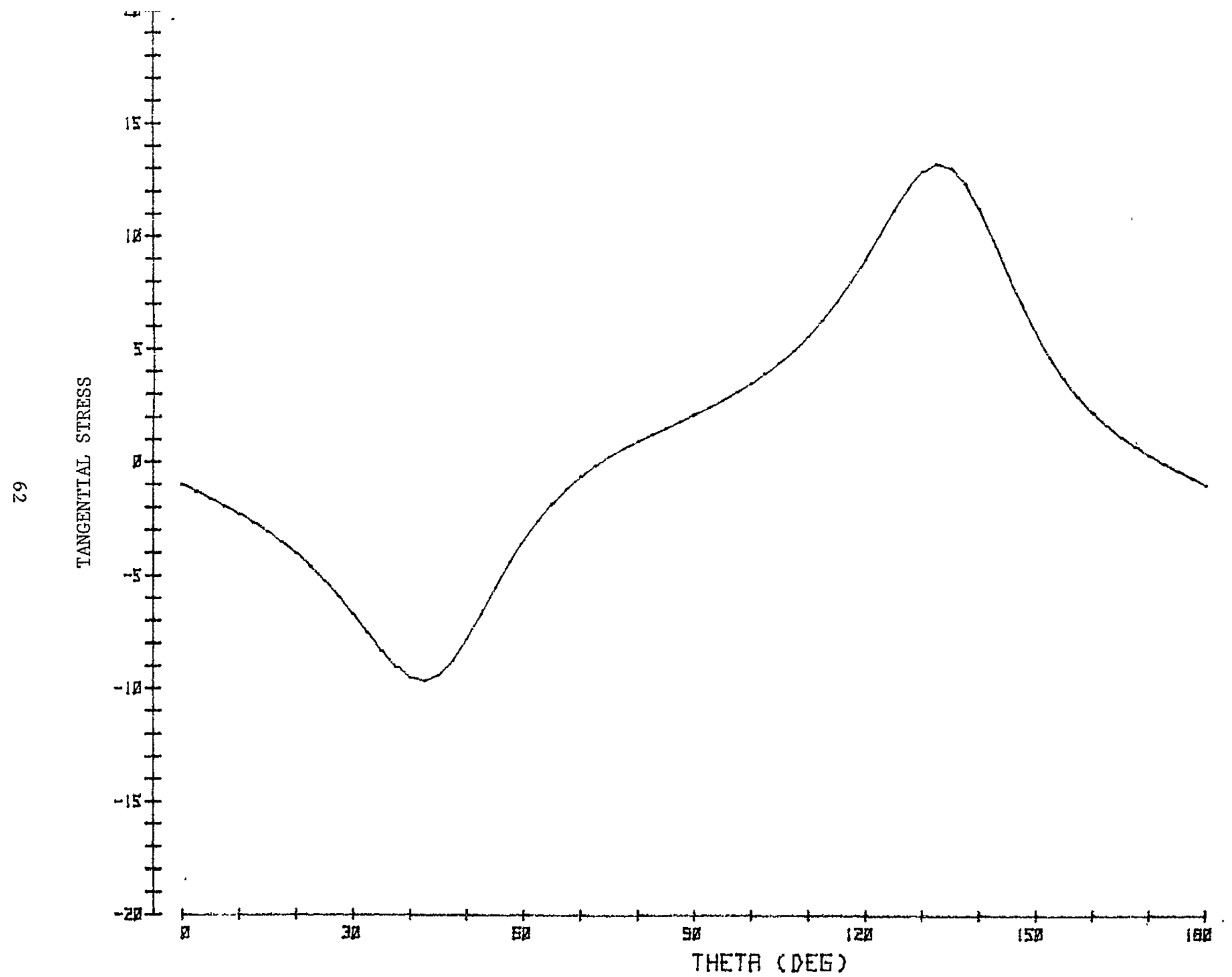

FIGURE 26. TANGENTIAL STRESS AROUND A HOLE IN A [+45]S LAMINATE UNDER BIAXIAL LOADING WITH AXIAL: TORSION RATIO OF $1: 2$ 
APPENDIX A

Photographs of Failed Specimens 
BROKEN SPECIMENS

$[ \pm 45]_{\mathrm{s}}$

AXIAI, FATIGUE 

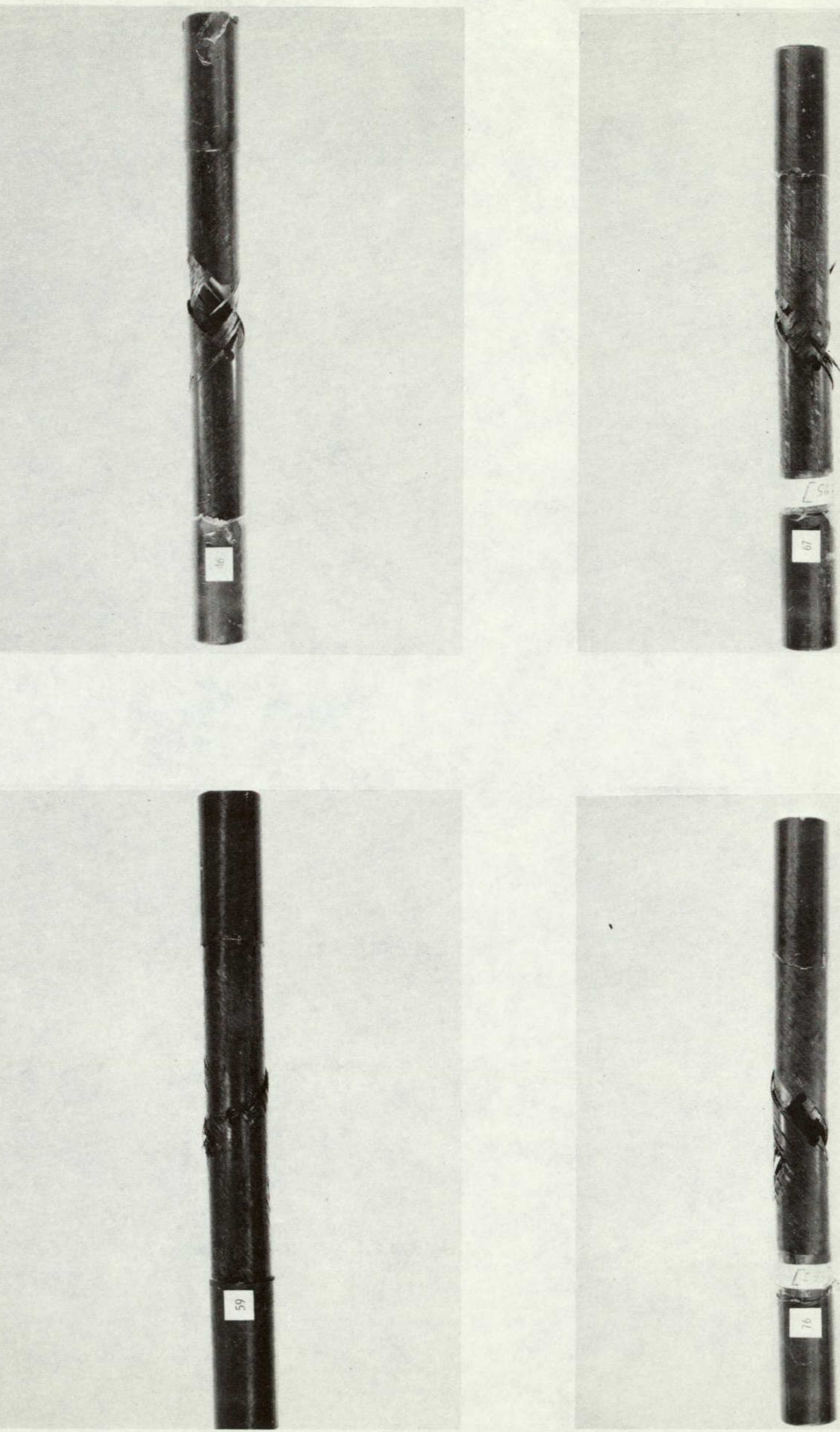

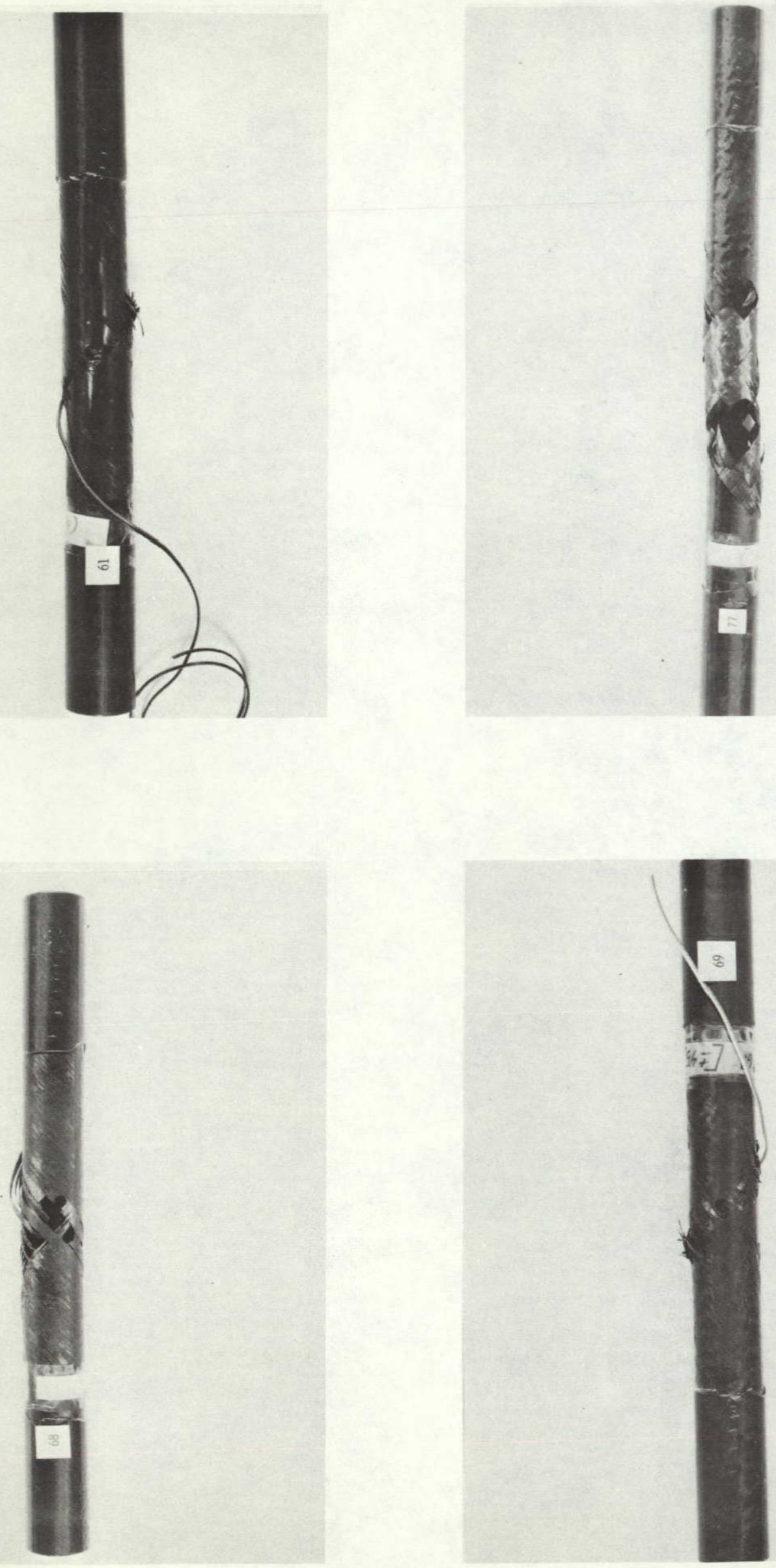

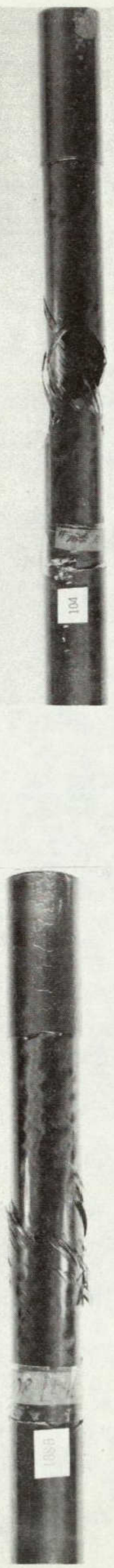

ORIGINAL PAGE IS

67 OF POOR QUALITY 
BROKEN SPECIMENS

$[ \pm 45]_{S}$

INTERNAL PRESSURE FATIGUE 


$$
\begin{array}{ll}
11 \\
11
\end{array}
$$



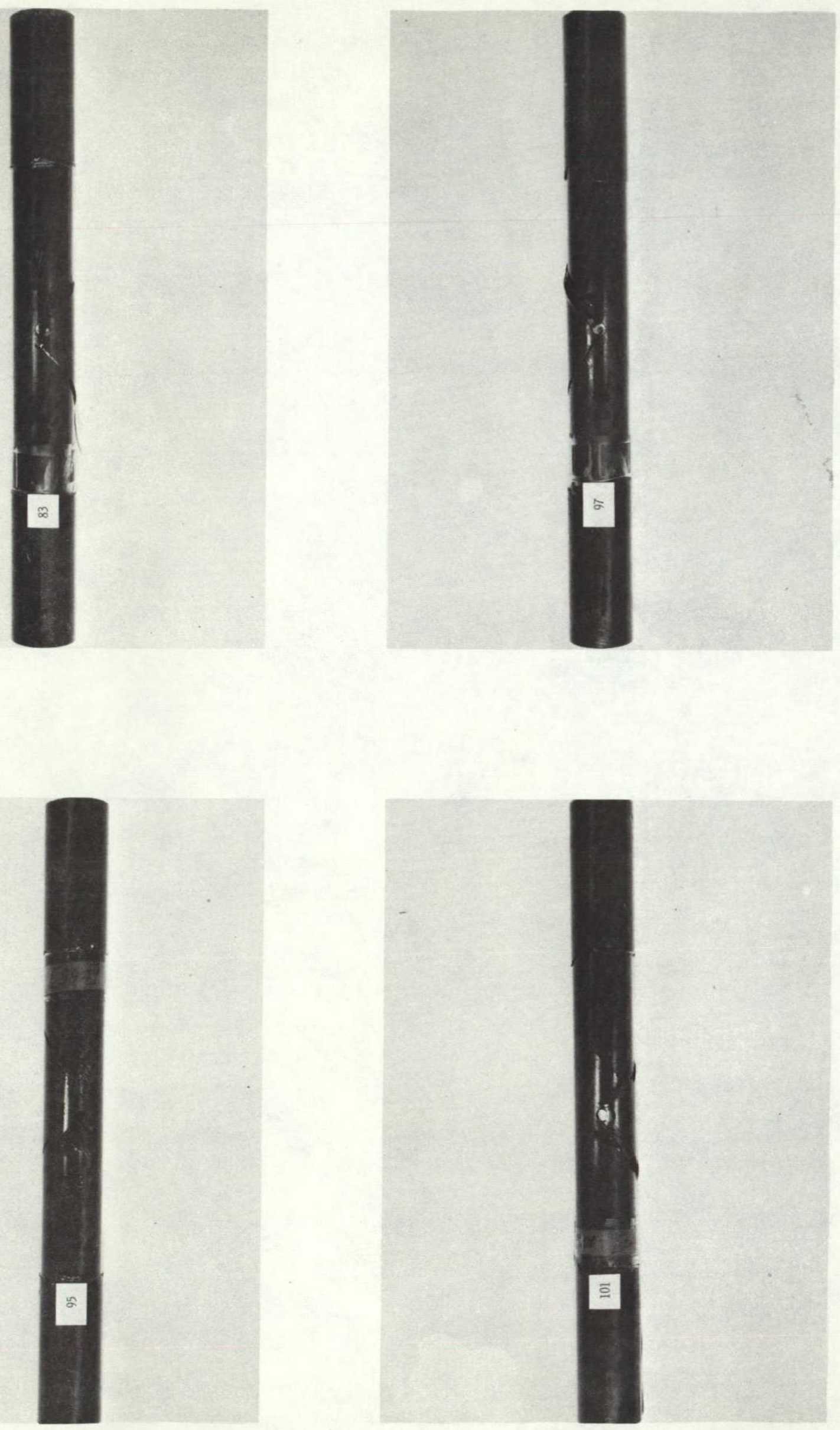

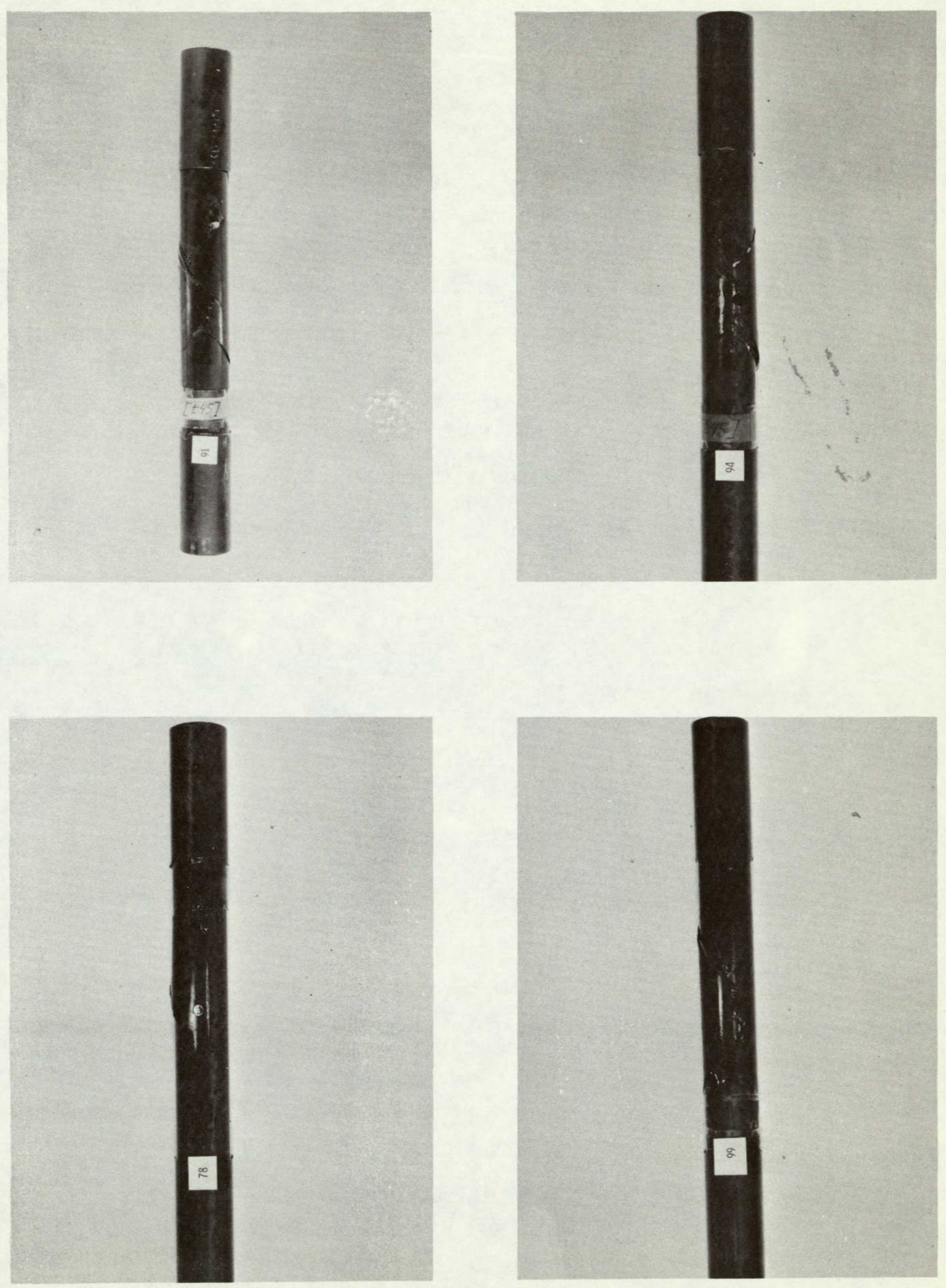

ORIGINAL PAGE IS

OF PחR חTATTTY 
BROKEN SPECIMENS

$[+45]_{S}$

TORSIŌN FATIGUE 


$$
11
$$



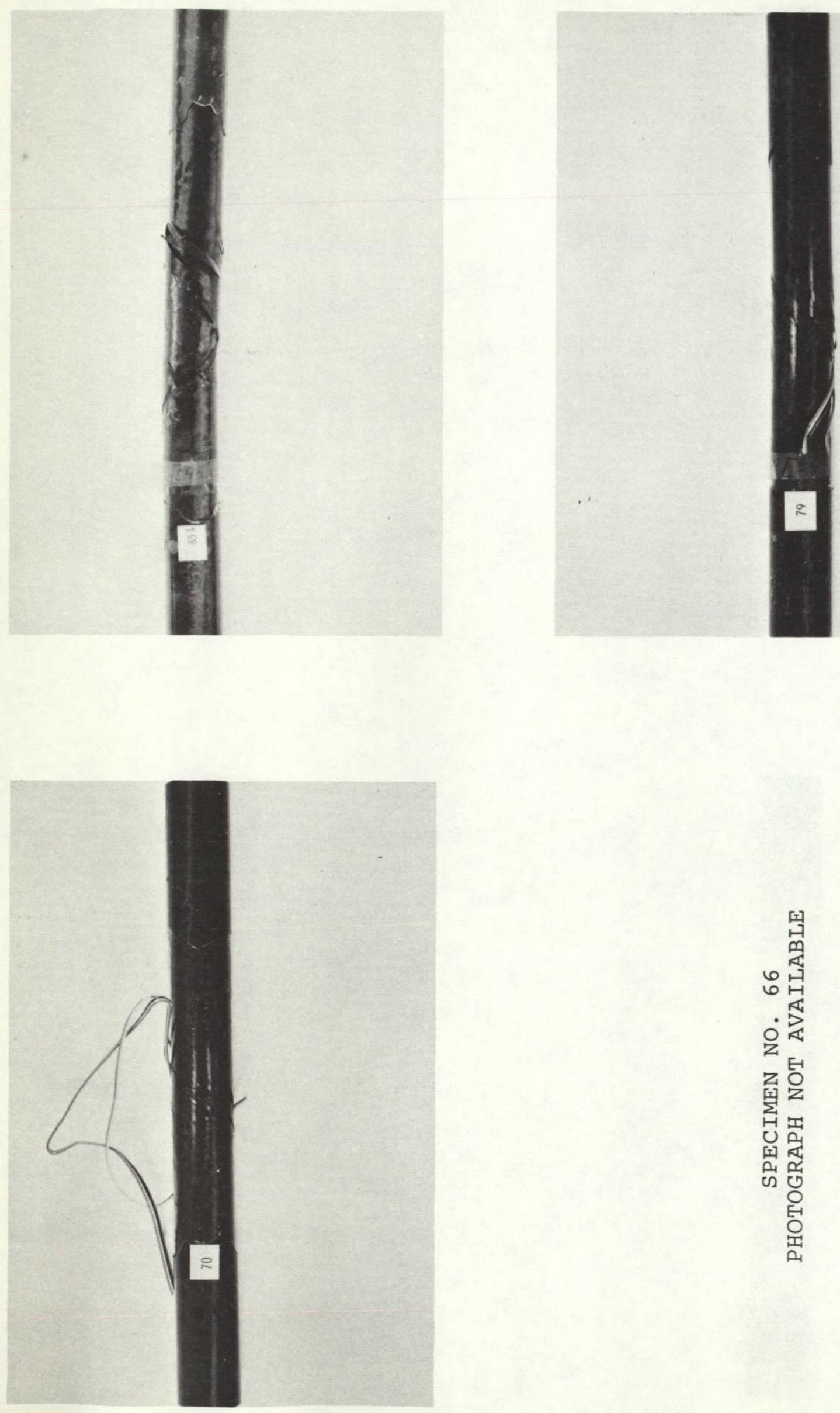

四 

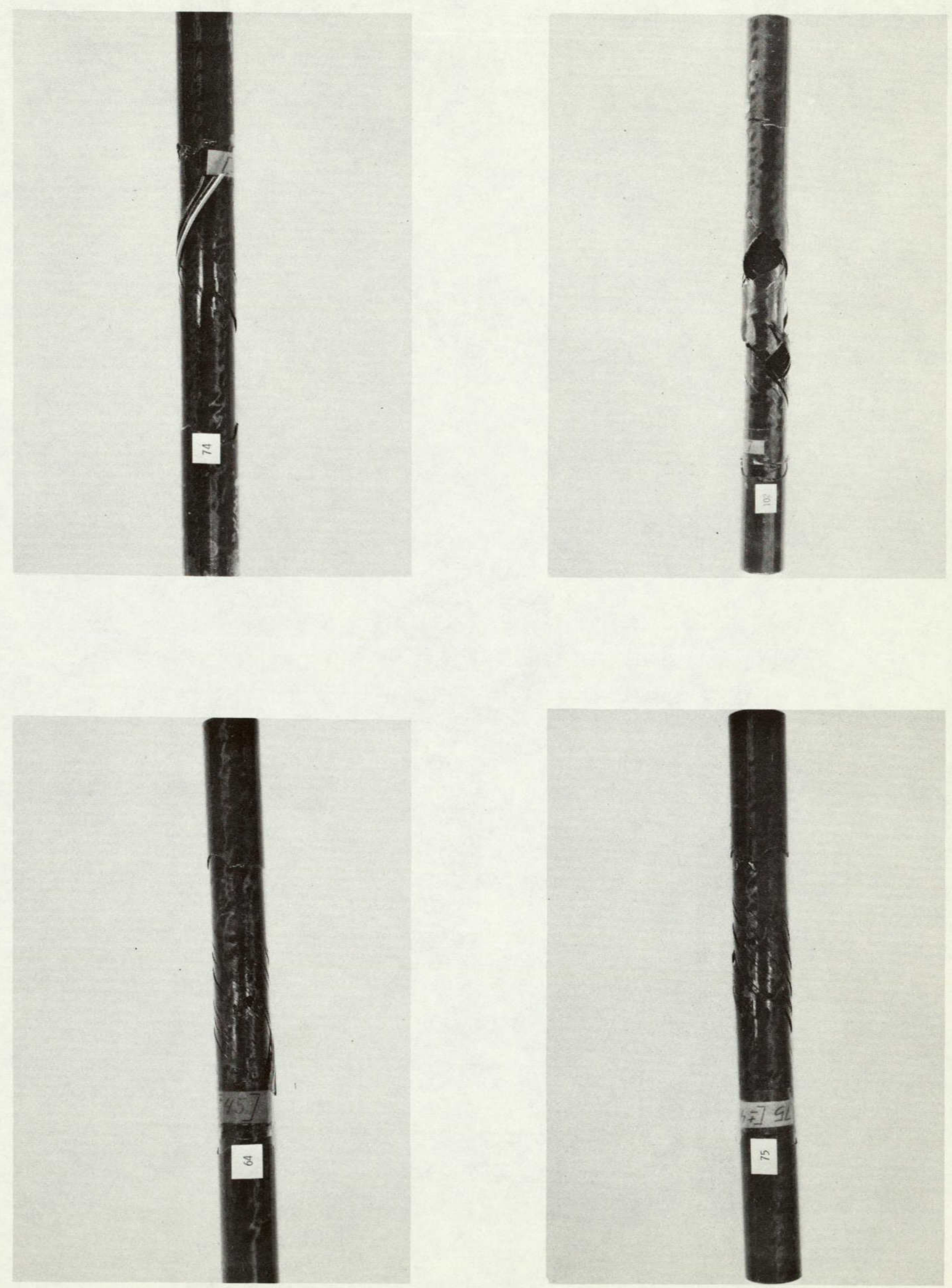

ORIGINAL PAGE IS 


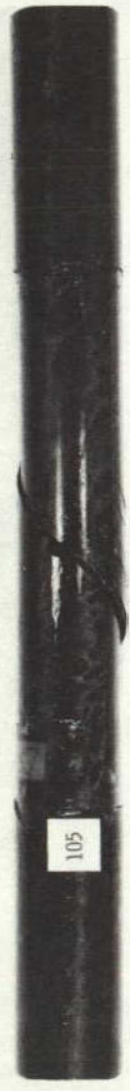

ORIGINAL PAGE IS

OF POOR QUALITY 
BROKEN SPECIMENS

[ \pm 45$]_{S}$

AXIAL: TORSION FATIGUE $1: 0.5$ 

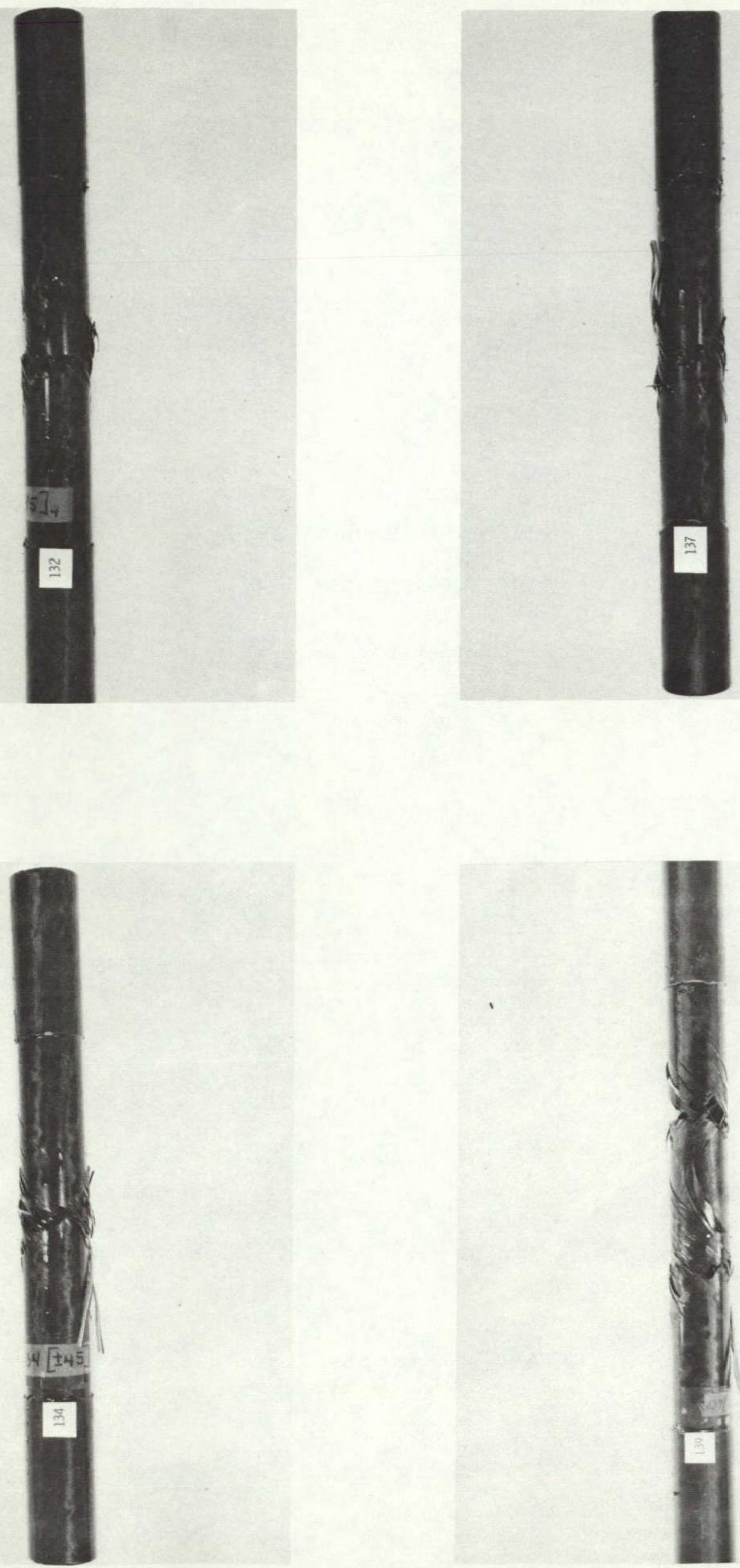

ORIGINAL PAGE IS

OF POOR QUA 

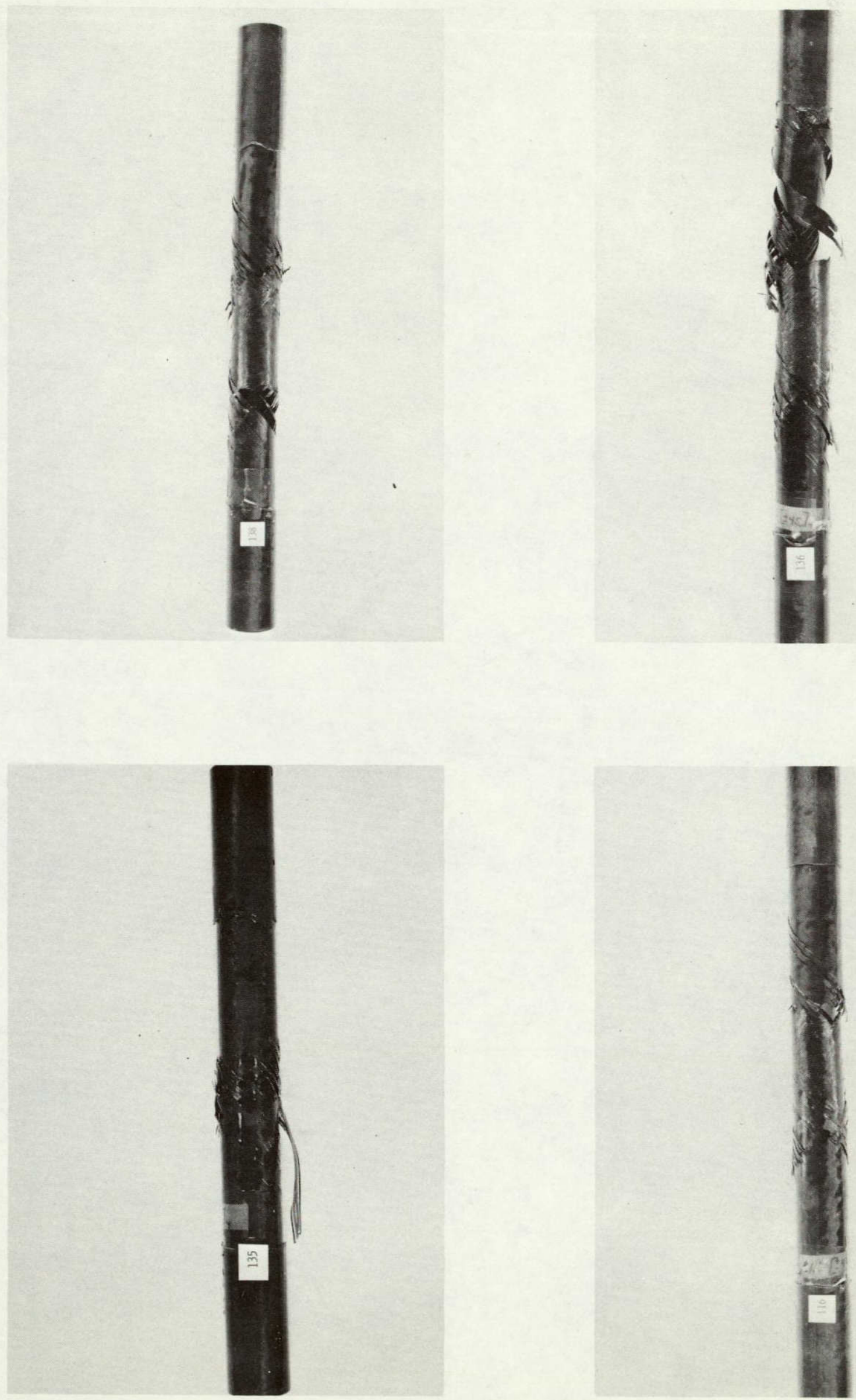

ORIGINAL PAGE IS OF POOR QUALITY 

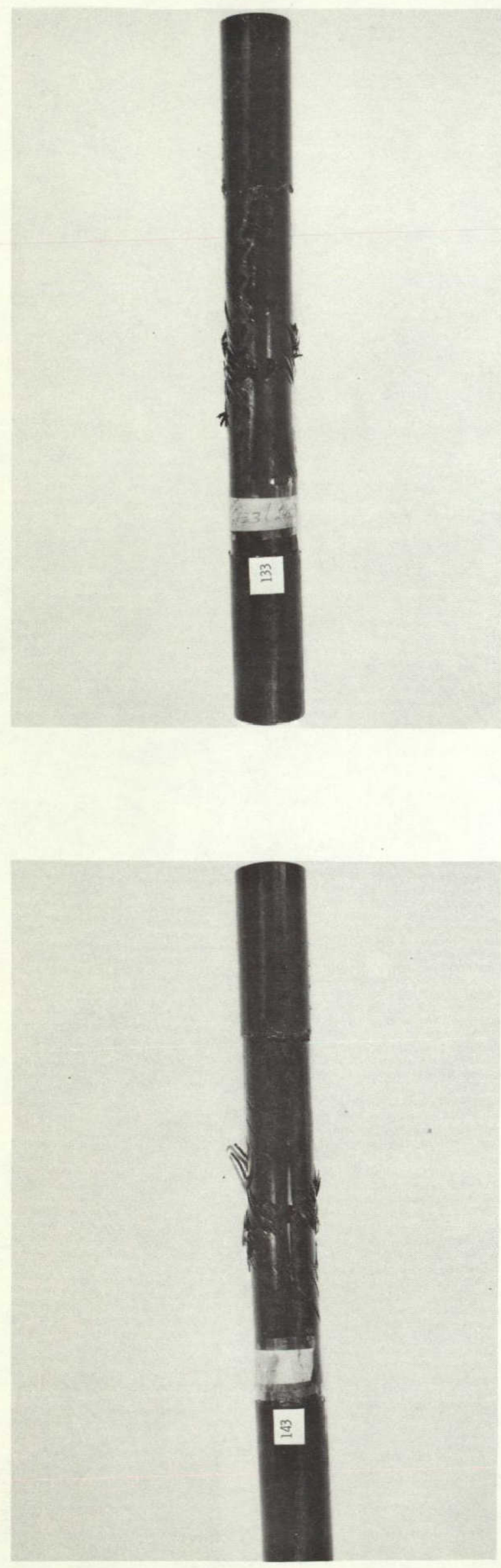
BROKEN SPECIMENS

$[+45]_{s}$

AXIAL: TORSION FATIGUE $1: 1$ 

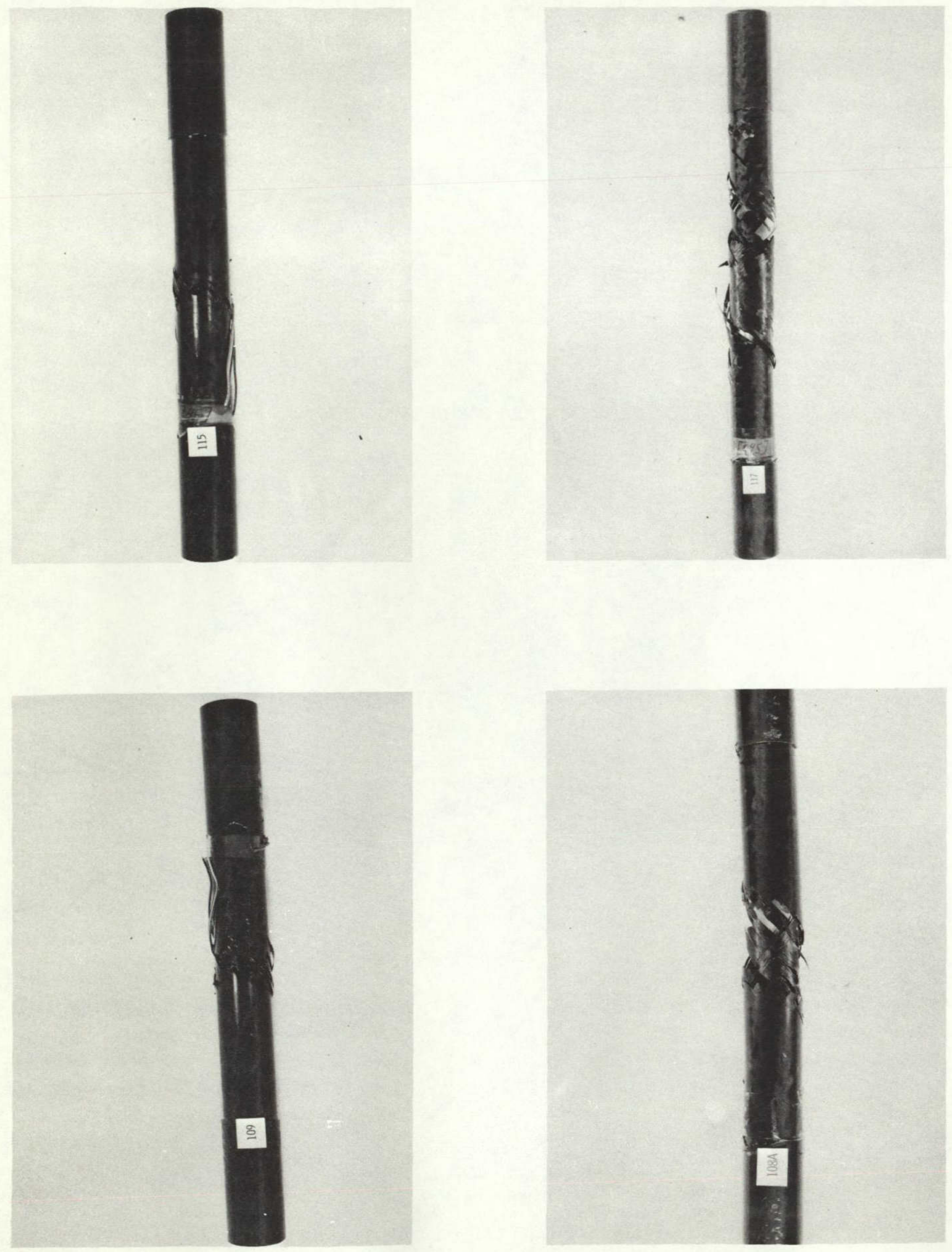

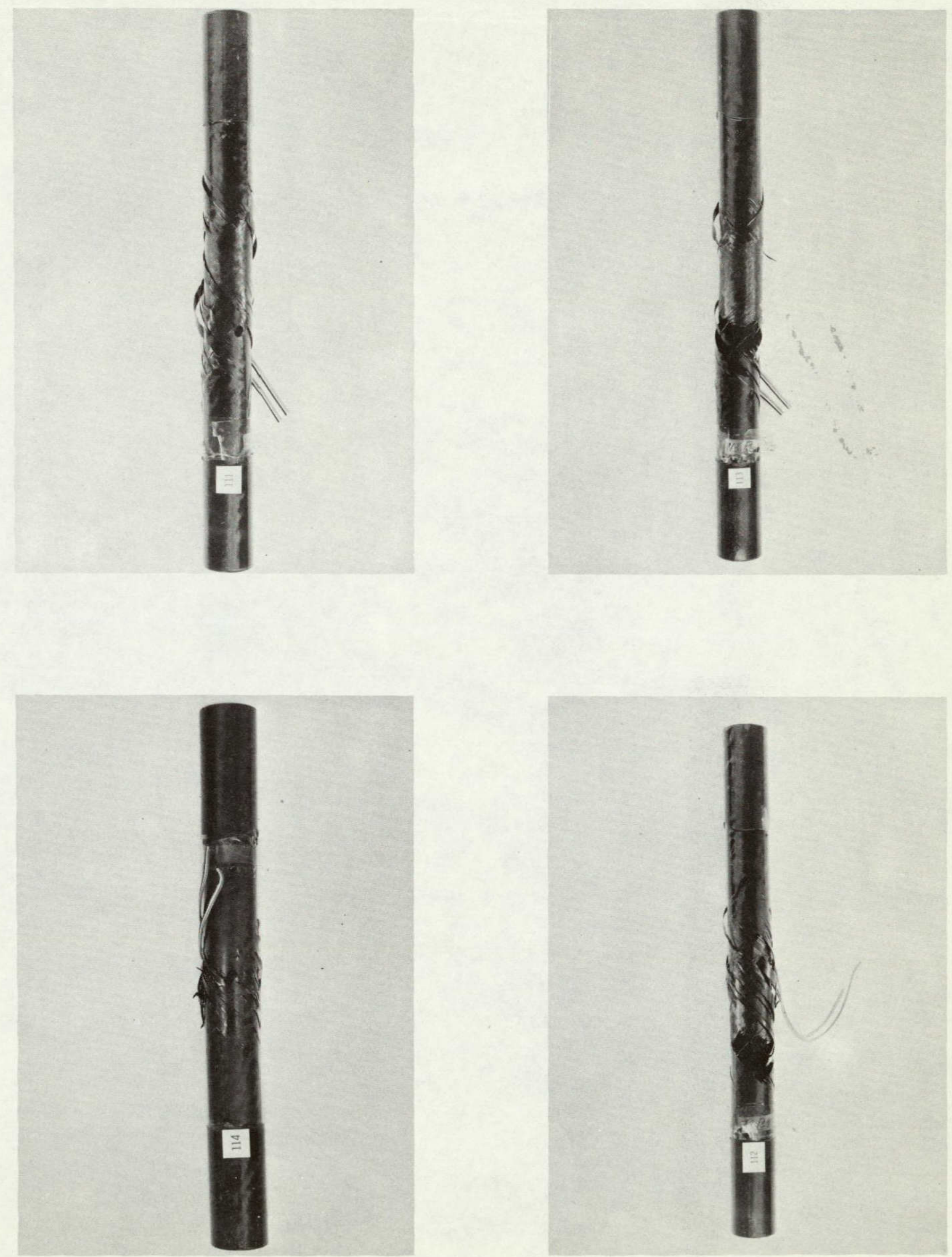

${ }^{83}$ ORIGINAL PAGE IS OF POOR QUALITY 

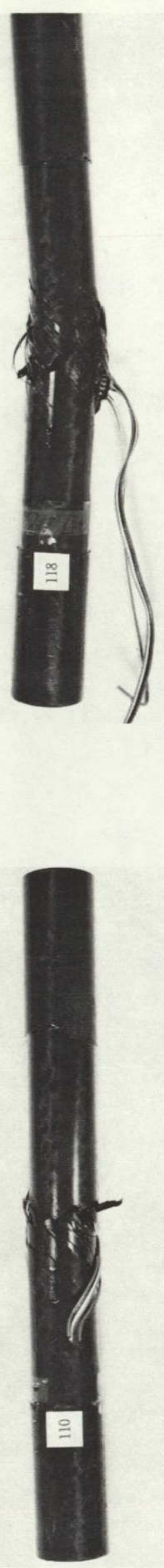

ORIGINAL PAge Is

O. POOR QUALITY 


\section{BROKEN SPECIMENS$$
[ \pm 45]_{5}
$$ \\ AXIAL: TORSION FATIGUE $1: 2$}



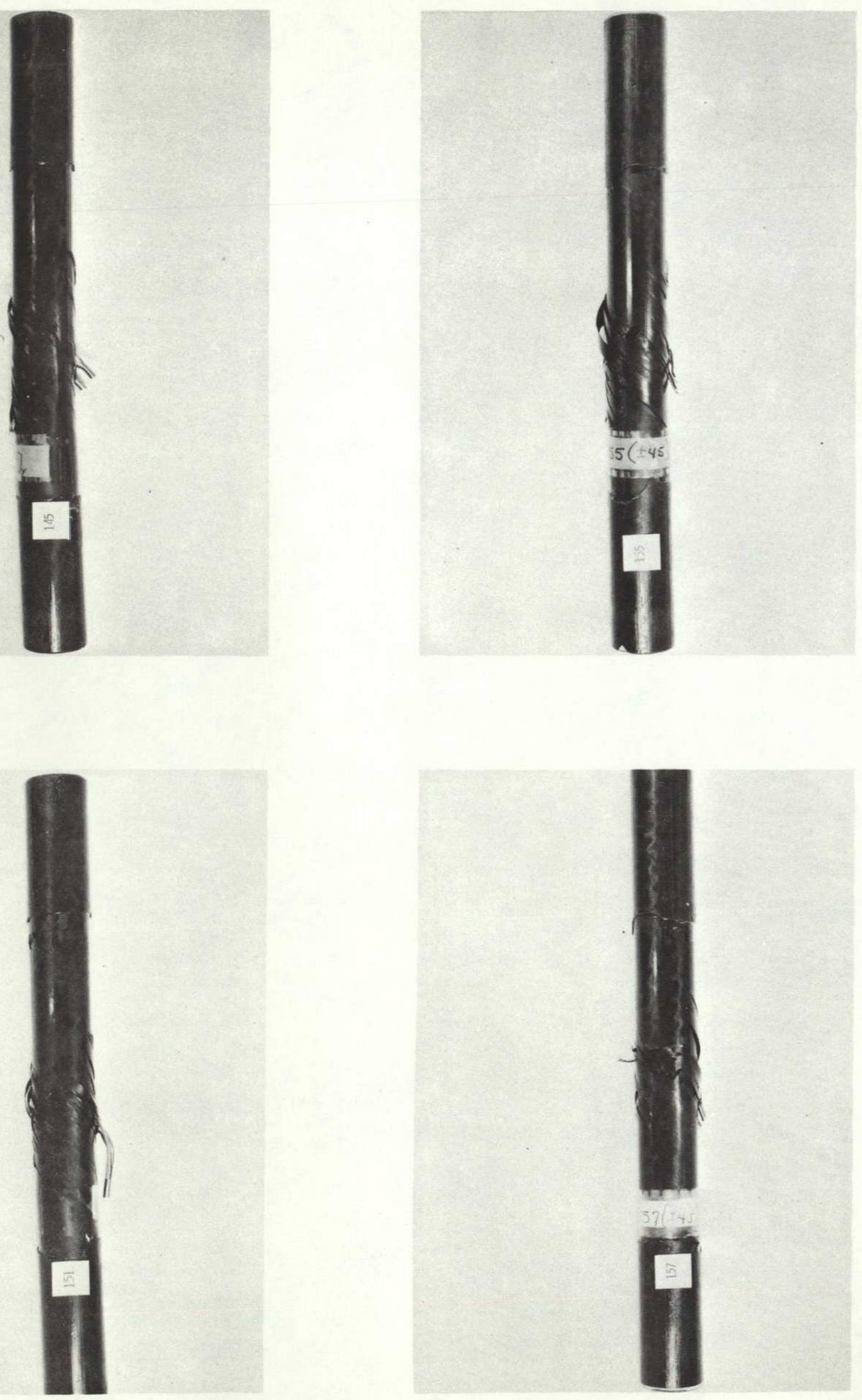

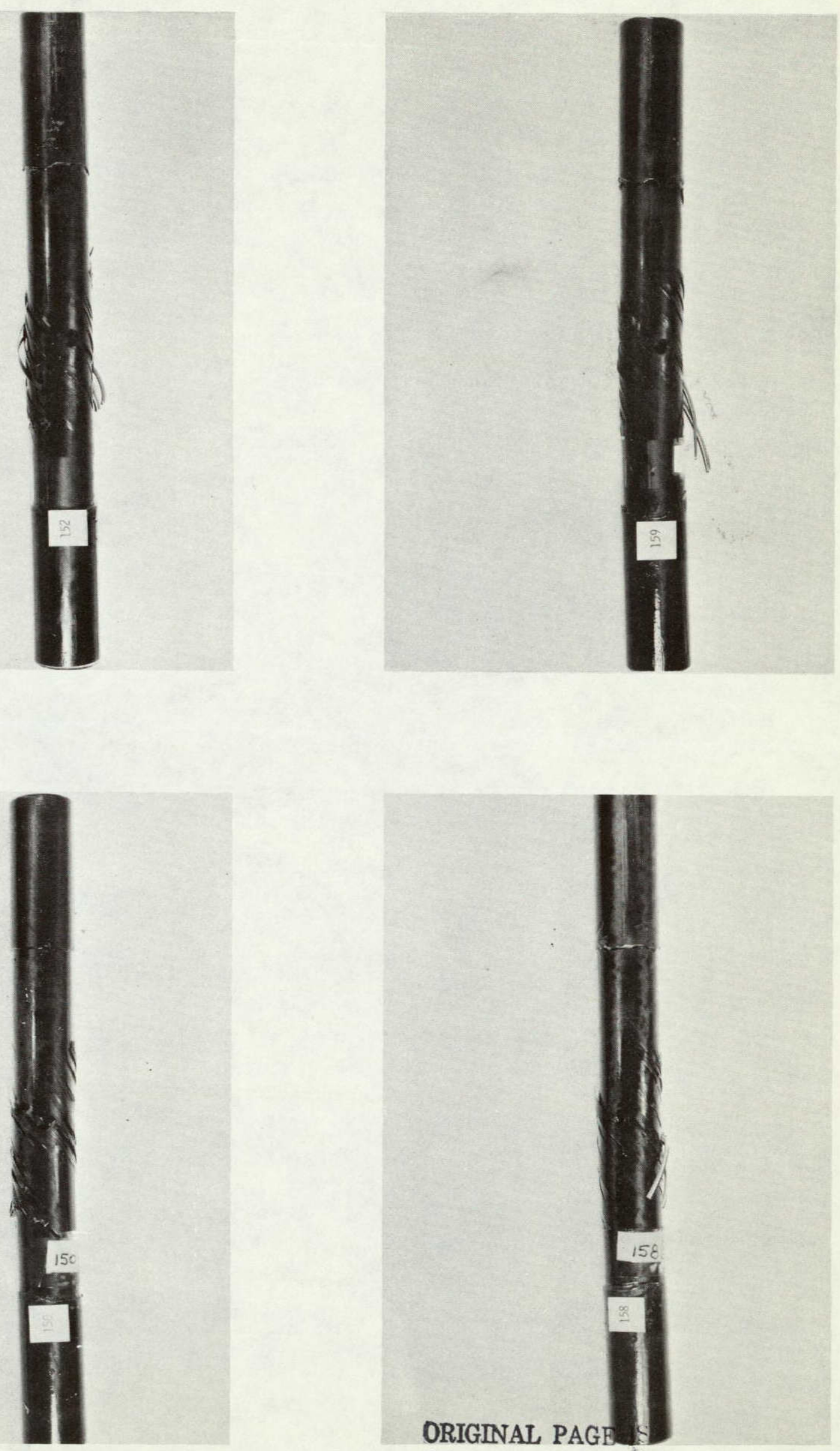

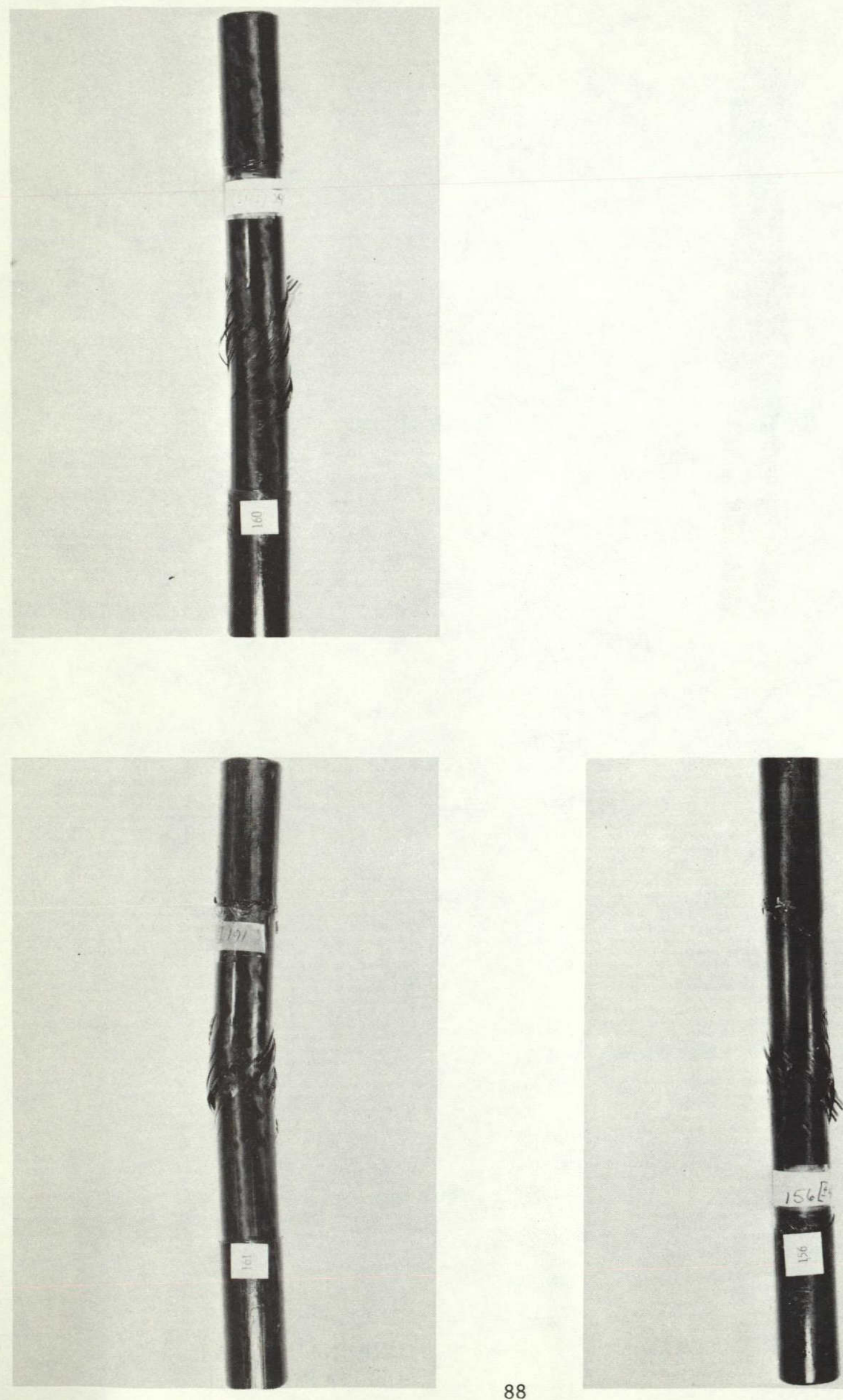
BROKEN SPECIMENS

$[0 / 90] S$

AXIAL FATIGUE 

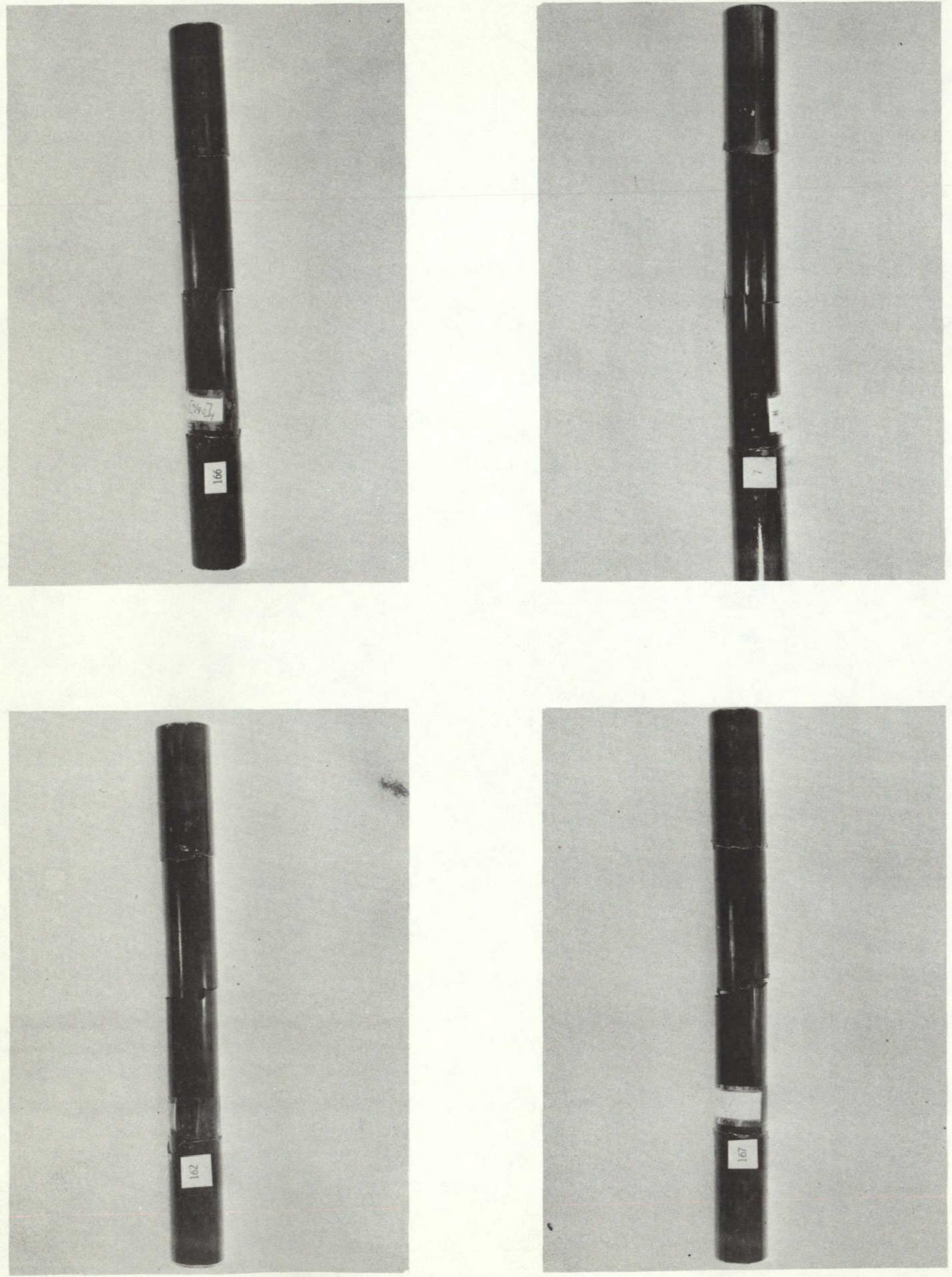


$$
11
$$




\section{BROKEN SPECTMENS$$
10 / 901 \mathrm{~s}
$$ \\ MORSTON EATIGUP}



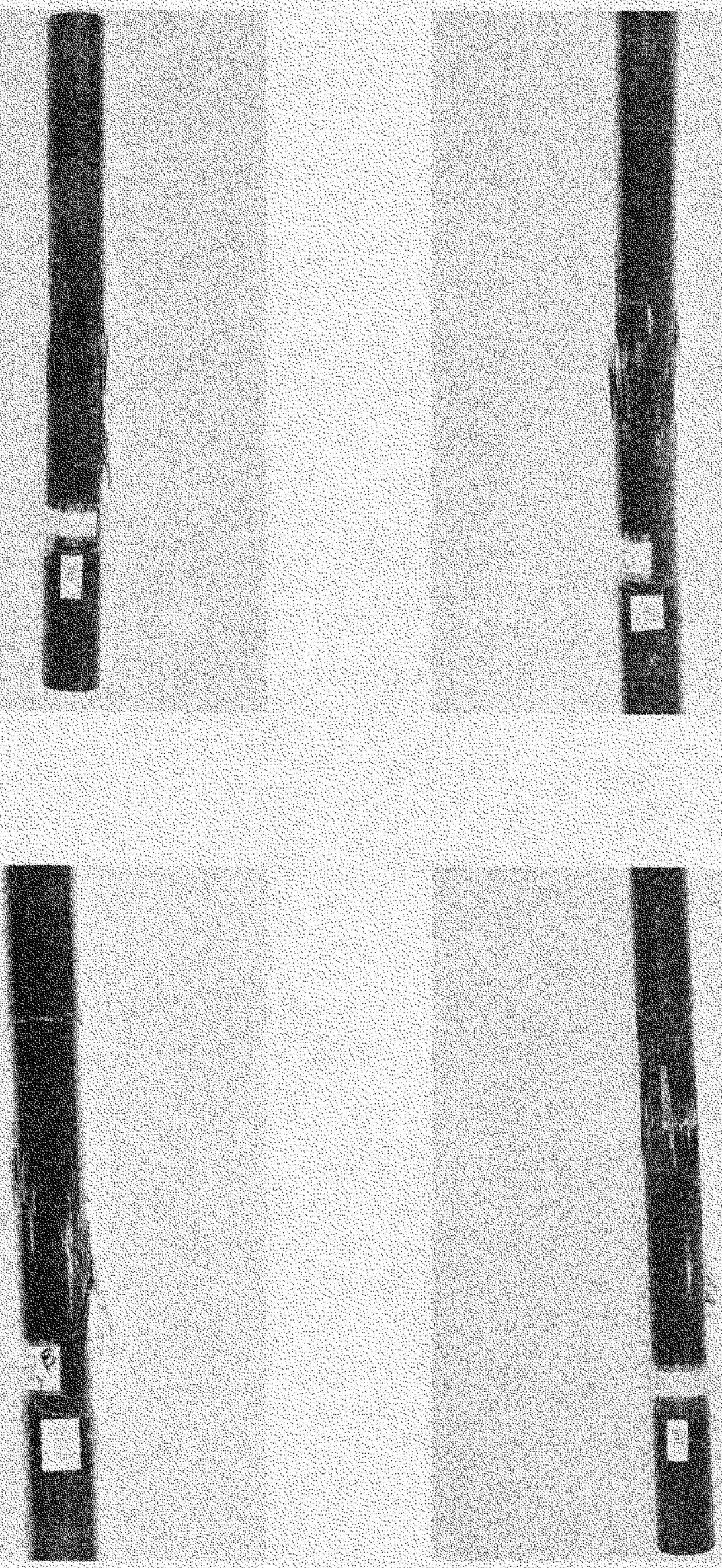



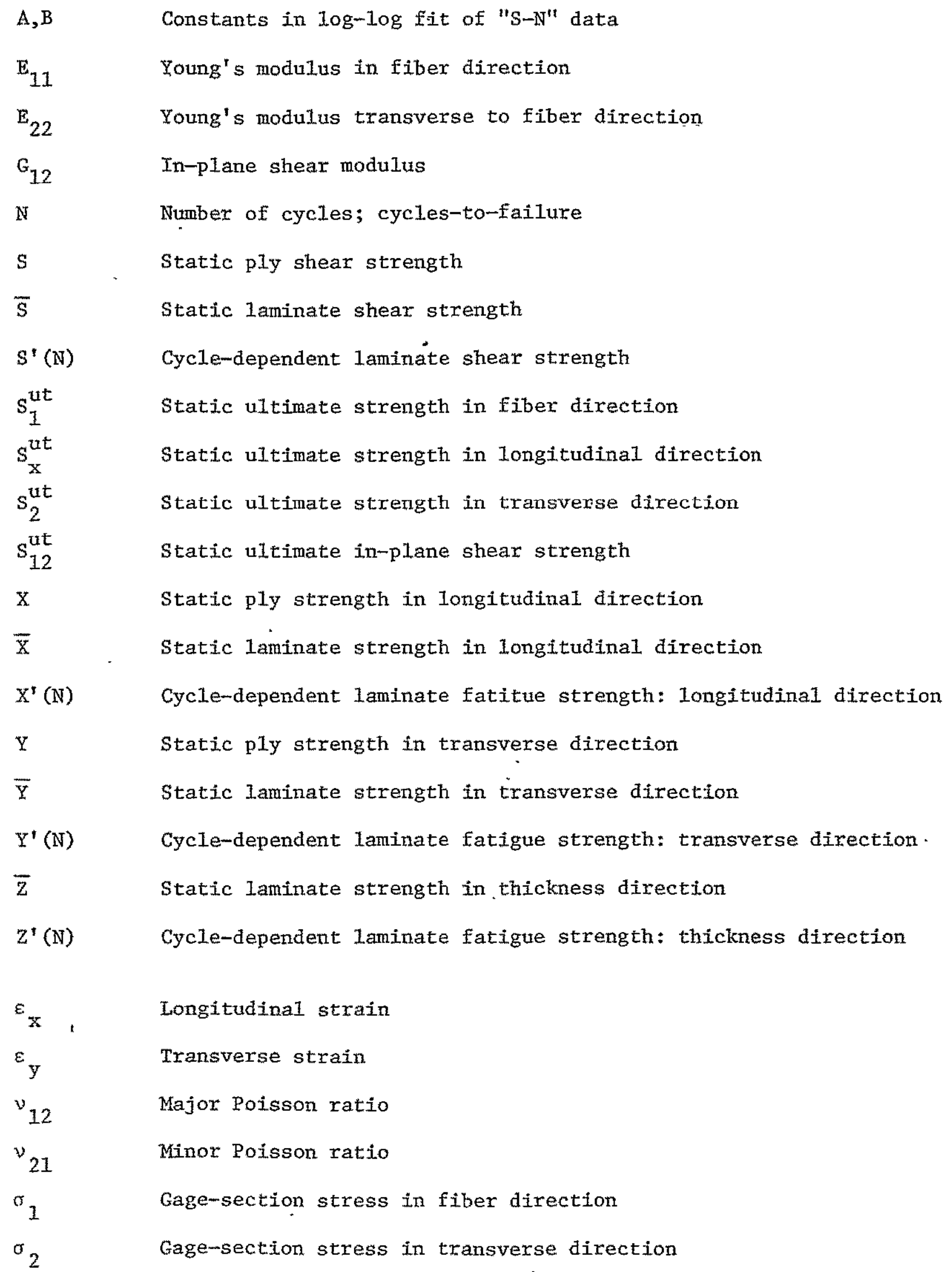


Maximum stress in cycle

12

Gage-section shear stress 